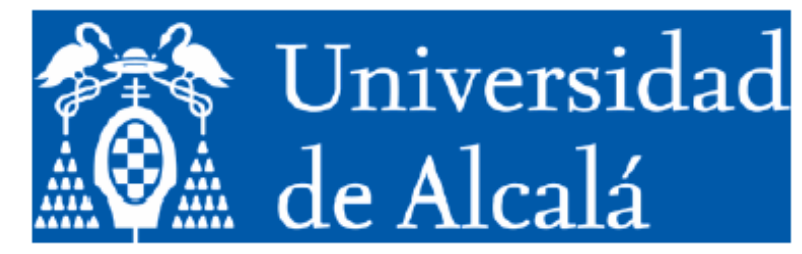

Programa de Doctorado en Análisis Económico

\title{
Innovation in Public Sector Services
}

\author{
PhD Dissertation \\ Héctor Javier Lagunes Marín
}

Under the supervision of

Prof. Dr. Luis Rubalcaba Bermejo

Alcalá de Henares, November 2014 
One generation departs and another generation comes, but the world forever stays.

The sun rises and the sun sets; then it presses on to the place where it rises.

Shifting south, then north, back and forth shifts the wind, constantly shifting its course.

All rivers flow to the sea, yet never does the sea become full.

To the place where they flow, the rivers continue to flow.

All things are wearisome, too wearisome for words.

The eye is not satisfied by seeing nor has the ear enough of hearing.

What has been, that will be; what has been done, that will be done. Nothing is new under the

Even the thing of which we say, "See, this is new!" has already existed in the ages that preceded us.

There is no remembrance of past generations; nor will future generations be remembered by those who come after them.

Book of Ecclesiastes 
To my blood: Hector, Carmen, Luis Daniel, Myriam and Joaquin. 


\section{Acknowledgements}

Although I am the only one who will take credit for the content in this thesis dissertation, I am aware that the merits that might be found in it are not the result of my only work and effort. Many people collaborated in some way to it and I want to take this place for publicly give recognition to them and share any merit. There are, however, some persons to whom I would like to explicitly give my gratitude.

I want to start by in first place making a recognition to my thesis supervisor, Luis Rubalcaba. His tutorship went far researching and the academic place. Thank you professor Luis for being patient, generous and careful to me.

I am especially thankful to all those persons who in some way provided me with comments, insights, research material and any kind of help for the purpose of developing my thesis dissertation. Nonetheless, I would like to make explicit my gratitude to some persons in particular. I want to say thank you to Hugo Hollanders for hosting me at the UNU-MERIT institute during a 3 months research visiting and also for taking the time to review my work and make many useful comments and suggestions. In the same way, thanks to Anthony Arundel, from the University of Tasmania, who was very kind to me during my visit at UNUMERIT and also took from his time for reviewing my work. Thanks also to Cristina Suárez, from the University of Alcala, for her directions on my econometric applications. Thanks to Marielle Linting, from the University of Leiden, for providing me with the programs for running categorical component analysis and bootstrap and thanks to Jose A. Sánchez, from CIDE, for providing me with the information used for analysis in chapter 4.

I would like to also make a recognition to people who gave me support, inspiration and good company during my days of work. Thanks to people from the Saint Angel parish for their friendship, thanks to Jorge and Gisela for being good spirited on me and thanks to my fellow Oscar for being a friend and a mentor.

Overall I must thank to my parents, Hector and Carmen. They were in first place who made possible my journey towards a PhD title. They have through my whole life given to me all kinds of support. Thanks mom and dad! I love you. 


\section{Abstract}

Studies already acknowledge some distinctive features of public innovation, such as factors having an influence in innovation generation, factors enabling the innovation process and also barriers counteracting the innovation process. Public sector innovation is an issue increasingly demanding for attention. The present dissertation is aiming on the issue through an empiricalquantitative approach. What has been stated in theory has only in a few cases been properly compared to corresponding empirical data. The present study is one more step ahead in that direction.

A main objective of this dissertation is to challenge conventional thinking about public sector being a barren ground for innovative activities. There is an emerging tradition of public innovation studies where it can be observed a tendency to contradict the view of a public sector where sustainable improvement processes are neglected. The conclusions that may be obtained after the applied empirical methods are meant to be part of it.

Three particular objectives lead the research questions and analysis presented along dissertation: 1) making some propositions and giving empirical evidence on the main factors driving and enabling public innovation to its successful implementation, 2) identifying some features of the innovation dynamics that can be seen as specific of the public sector and 3) making an assessment of results of innovation implementation.

Innovation in the public sector is the result of a complex process in which many factors play a role. Factors are of different kinds and they can be identified under different theoretical views on public innovation. Lack of the right incentives - market incentives in particular - has been thought for a while to be at the root of the public sector's innovation gap. However, despite lack of market incentives, it is possible to find a set of factors that are useful to innovation development in public organizations. Chapter 1 is addressed to identify some factors driving and enabling public sector innovation and to assess their effects on the innovation performance of public sector organizations. The analysis is based on data at EU level provided by the Innobarometer 2010 Survey. Results of empirical analysis suggest that factors related to some degree of use of external sources of information, active involvement of managers and implicating staff and users in the innovation process have a positive effect on implementation of service innovations; furthermore, they have a particularly significant effect on the implementation of services that are new to the whole public sector. In turn, political and legislative factors seem to be useful for implementing service innovations but their effect on new service implementation could not be properly assessed.

The use of external sources for innovation has an increasing role in organizations of all kinds; they can be essential for creating and developing innovation. With a particular theoretical approach, Chapter 2 provides with a framework to compare how significant it is for public service innovation the use of internal and external sources of information in innovation development. At the same time, statistical significance on innovation implementation from the use of both kinds of sources is assessed basing on evidence from the Innobarometer 2010 Survey. Results indicate a positive and significant relation between both the use of internal and external sources of information and the implementation of service innovations. They also give evidence to believe that using external sources of knowledge and information for innovation 
development is especially important for the implementation of services that are new to the whole public sector.

High risk aversion is argued to be one of the main causes for the innovation gap between public organizations and private firms. At the same time, risk aversion is a consequence of public policy leaded by public accountability instead of market profit. Then, one could reasonably ask what is worth for public organizations to take the risks of innovation. For approaching to the answer, the followed method consists in estimating probabilities of positive and negative effects experienced after implementation of service innovations by public organizations represented in the Innobarometer 2010 Survey. Chapter 3 presents empirical evidence for helping to support assumptions about the potential of public innovations for achieving positive effects after implementation, and also about the risk of suffering some negative effects. Analysis is based on statistical significance of the effect of being an organization that has implemented service innovations on the probability of experiencing certain positive and negative effects from innovation implementation, this compared to the effect of being an organization that has implemented services that are new to the whole public sector. Results suggest there is only a slight significant impact from new service implementation on the probability of having positive effects. In turn, the impact of new service implementation on the probability of having negative effects is significant and of an important magnitude.

Chapter 4 presents an alternative view for the analysis of public innovation implementation and its results. A big portion of public innovation studies are based in the observation of public organizations in developed countries. Therefore, are their findings equally valid in the context of developing countries' public sector? This chapter has as a purpose to approach to the answer. For doing so, methodology consists in the analysis of initiatives participating in the Local Governing and Management Award, following a cases-study approach. Results from observations support the idea that poorly developed institutions often fail in improving from innovation, since innovations requires an appropriate institutional set-up. Nonetheless, an important and useful conclusion from this analysis is that innovation may be especially helpful for developing institutions and, later on, implementing higher leveled innovations.

The central idea in this thesis dissertation suggests a view of public innovation under a multiagent framework, in such a way that public organizations keep a high degree of interaction with other organizations and individuals and also consider various ways for generating innovative processes, on top of those processes leaded under a rigid hierarchical structure. Results and conclusions obtained from empirical analysis in previous four chapters are helpful for supporting validity of the suggested view. The distinct ways for public innovation are reflected in the importance for new service implementation found in factors such as ideas and participation from staff, users and suppliers, and also in support from authorities and middlelevel managers. At the same time, results on the importance of using external sources of information towards implementing new services support an approach for public innovation which concedes a significant role to collaboration and participation from external agents, especially users and suppliers. 


\section{Table of Contents}

Towards an enhanced understanding of public innovation: An introduction $\quad$................................ 8

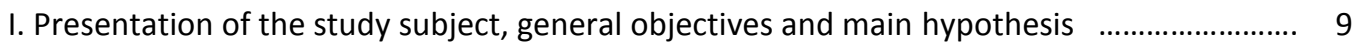

II. Defining a framework for understanding public innovation $\quad$................................................ 11

III. Content presentation .............................................................................................. 17

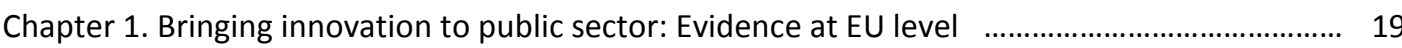

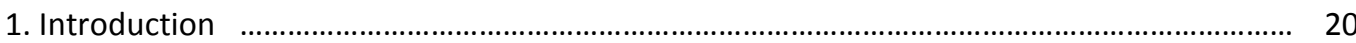

2. Literature review and theoretical framework f................................................................... 21

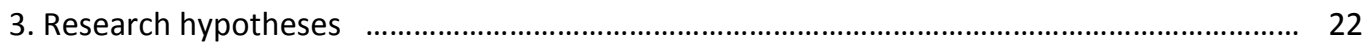

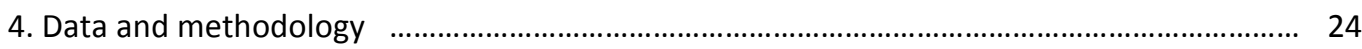

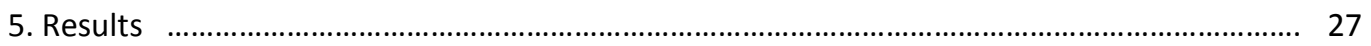

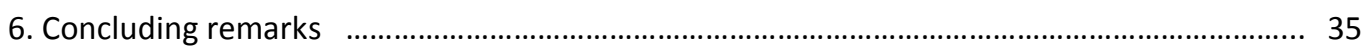

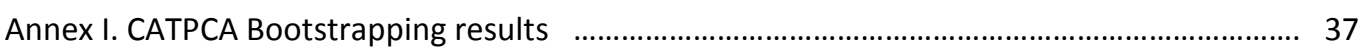

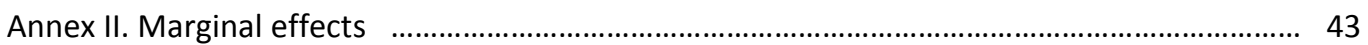

Chapter 2. The role of external information sources for service innovation in public

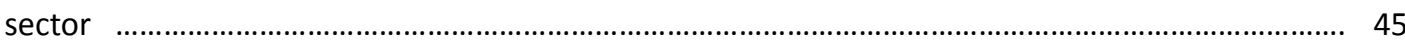

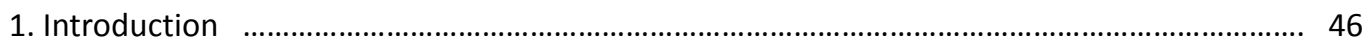

2. External sources for public innovation? A specific framework ............................................ 46

3. The empirical evidence for Europe: Research hypotheses .................................................... 53

4. Methodology and data description ................................................................................... 55

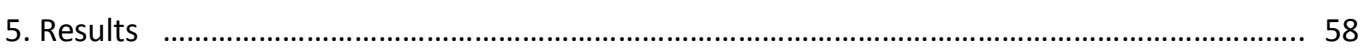

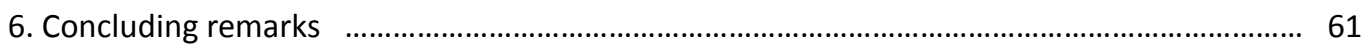

Chapter 3. Differences in effects from implementation of public innovations ............................. 63

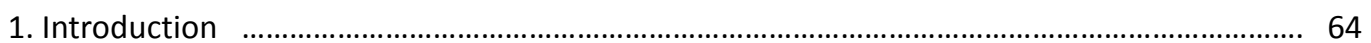

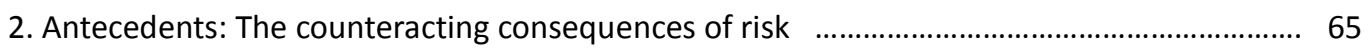

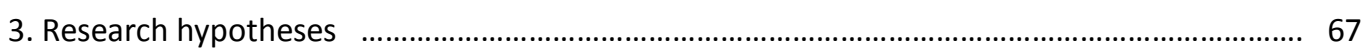

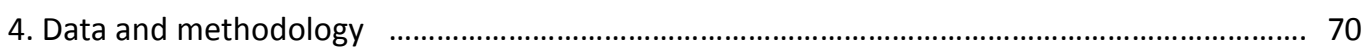

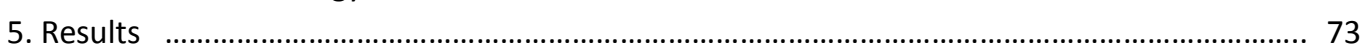

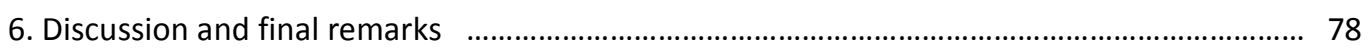

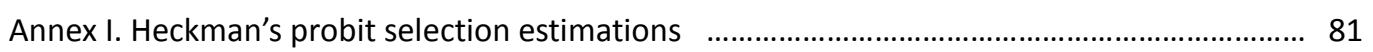

Chapter 4. The way of public innovation in developing countries: An approach for

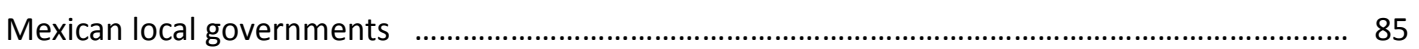

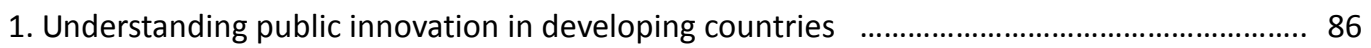

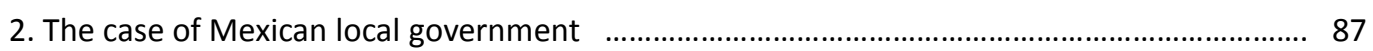

3. Mexican local governments in the way for successful innovation ......................................... 89

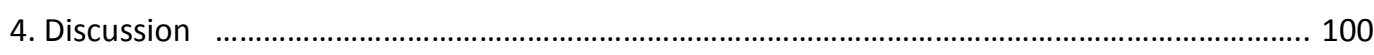

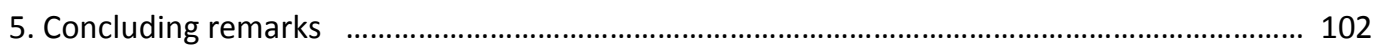

Concluding remarks

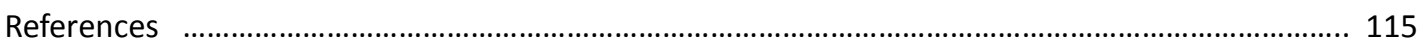


Towards an enhanced understanding of public innovation: An introduction 


\section{Presentation of the study subject, general objectives and main hypothesis}

Innovation in the public sector has been one of the most relevant innovation topics in last years. This is due to the importance of public services in modern economies both in terms of employment and growth and in terms of welfare generated from services to citizens and businesses. An innovative public sector is necessary in order to provide better and more efficient services, and also for helping to deal with societal challenges. This is particularly relevant in a context where budgetary constraints in many parts of the world, e.g. in Europe and in the US, are justifying actions to reduce the size of public sector and to increase its efficiency. Innovation can be the solution for promoting more efficient public services and increasing quality of performance at the same time.

Public services have often been considered among the low and sluggish productivity growth activities together to personal services and some professional services (Maroto, 2011; Maroto \& Rubalcaba, 2008), even though performance of public services shows variations among diverse public service activities such as health, education or public administration (di Meglio et al., 2013). A major reason behind the low productivity in services is related to the lack of innovation and the difficulties to integrate technological innovation in services (Baumol, 1966; 2004), public services in particular. However, recent large scale research projects have proved the importance of innovation affecting performance of public sector. Some good examples of these are in the projects PUBLIN and ServPPIN, founded by the European Commission; MEPIN, by the Danish Center for Studies in Research and other Nordic institutions; a pilot survey for measuring innovation in the public sector, by NESTA and a 'Better Practice Guide' on innovation in the public sector, by the Australian National Audit Office ${ }^{1}$.

Innovation is a key dimension of the new services economy, also in public sector (Rubalcaba, 2007). There is abundant literature about drivers of innovation in public organizations and about policy strategies necessary to promote and implement innovations (for a review of literature about public innovation, see Matthews et al., 2009). However, a more extended analysis is still needed in order to reach a better understanding of public sector innovation and its origin.

Unlike previous research on innovation in public services - largely analytical-conceptual or based on case studies - the present dissertation proposes an empirical-quantitative approach. Previous studies point to public sector innovation as an issue increasingly demanding for attention (Langergaard, 2009; Matthews et al., 2009; Windrum, 2008). Nowadays, we count on a consistent theoretical framework providing useful models to analyse the innovation process inside public organizations; however, what has been stated in theory has only in a few cases been properly compared to corresponding empirical data. The present study is one more step

\footnotetext{
${ }^{1}$ Extended information on these research projects and views of their final reports can be found at their institutional web pages: PUBLIN, http://survey.nifu.no/step/publin ; ServPPIN,

http://www.servppin.com ; MEPIN, http://www.nordicinnovation.org/Publications/measuring-publicinnovation-in-the-nordic-countries-mepin ; NESTA, http://www.nesta.org.uk/publications/reports/assets/features/innovation_in_public_sector_organisati ons ; ANAO guide, http://www.anao.gov.au/bpg-innovation/contents.html
} 
ahead in that direction. Research carried in this thesis dissertation is based on an analysis leaded by quantitative methods addressed to test theoretical propositions found in previous studies of public innovation. Furthermore, results of this empirical analysis are useful for making nuances on tested theoretical propositions, and also for making new propositions from findings in the applied methodologies.

Therefore, the empirical approach is in the core of the value added of the present thesis dissertation. Some of the tools for analysis in the followed methodology were implemented by first time - as far as it was corroborated - in researching the topic, in particular: a technique for principal component analysis specially addressed for categorical variables (chapters 1 and 2) and a bootstrapping method for testing data stability (chapter 1 ). Also, the empirical analysis was focused in such a way that a distinction is made between 'service innovations', as a broad group where any significant change can be identified as an innovation, and 'services new to the public sector', where only services that were by first time implemented within the public sector are taken into account; this as a way to highlight novelty, radical change and improvement for the public sector - instead of only the implementing organization (chapters 1,2 and 3).

A first objective of this dissertation is to challenge conventional thinking about public sector being a barren ground for innovative activities. This common idea comes from a bureaucratic view of public sector organizations, high risk aversion in public policy implementation and lack of incentives for introducing changes. There is an emerging tradition of public innovation studies where it can be observed a tendency to contradict the view of a public sector where sustainable improvement processes are neglected. The conclusions that may be obtained after the applied empirical methods are meant to be part of it.

A second objective is to make some propositions, and give empirical evidence, on the main factors driving and enabling public innovation to its successful implementation. Factors are of different kinds and they can be identified under different theoretical views on public innovation: political, organizational (systemic), managerial, environmental, industrial (inputoutput relations), etc. Lack of the right incentives - market incentives in particular - has been thought for a while to be at the root of the public sector's innovation gap. However, despite lack of market incentives, it is possible to find a set of factors that are useful to innovation development in public organizations. These might be as powerful for public innovation creations as powerful are market incentives for private business.

Another objective is in identifying some features of the innovation dynamics that can be seen as specific of the public sector. These are expected to be found around characteristics that correspond to the nature of the public sector, such as high risk aversion and interaction with citizens and enterprises when they both play the role of public organizations' suppliers and beneficiaries.

One more objective is in making an assessment of results of innovation implementation, given that it is a strategy addressed to obtain improvement. To this respect, a particular purpose is in making an analysis on how well policy recommendations following public innovation theory can be successfully applied in contexts where political and administrative set-up is more challenging than those from where public innovation theory was built in first place; that is, to 
compare pursued innovation in economically developing areas as a contrast of innovation pursued in economically developed areas.

The usual view of an innovation process as based on public organizations' hierarchical structure, decided by higher authorities, implemented by middle-level authorities and staff and with citizens playing only the role of beneficiaries, is useful and somewhat valid but still incomplete and generally wrong. Recent studies talk about a different public sector, where innovation can be also generated by user and employee initiatives and they can (and somewhat should) also take part in the development process. Plus, public sector organizations are in more recent time seen as operating in a networked form, with high levels of interaction and collaboration with other public and private organizations and with users and suppliers as well. The main idea proposed by this thesis dissertation (that is, the main thesis addressed by the whole dissertation work) is in stating that this last vision of innovation in public organizations is more appropriate than the former one. Therefore, dissertation is intended for concluding that public innovation is a complex process where many factors play a role and which does not follow one only way within implementing organizations; a process in which also agents external to implementing organizations have a fundamental participation (as explained by the multi-agent framework in the next section). This way to understand public innovation can be more helpful for a more innovative public sector and may also have relevant consequences for policy design and in how public innovation should be promoted.

In the next section of this introductory part will be described the concepts framing the understanding of public innovation. Innovation is a wide concept, difficult to define. An understanding of innovation will highly depend on its application. For example, it can be observed how studies based on private manufacturing business highlight technology and engineering improvements towards product development, while studies in industry sectors with less use of technology and product development less based on R\&D activities (like service business) they use an approach more focused on networked development and changes in form of organization, systems, methods, concepts, etc. Therefore, studying the innovation that takes place at the level of public organizations requires building an understanding that attends to the specifities and objectives behind the particular nature of the public sector. The next section describes the understanding of innovation that is going guide research carried along the whole dissertation.

\section{Defining a framework for understanding public innovation}

\section{Innovation in public sector organizations}

Why do public sector organizations innovate? This is a question often replied by comparing the differences and similarities between innovation in public sector and innovation in private sector. While profitability and competitiveness have been largely pointed to be at the aim for 
private sector innovation, these might not be suitable to explain the existence and importance ${ }^{2}$ of innovation in a public sector context.

Commercial applications of a technological/scientific improvement, efficiency brought by new methods or processes and gains in competitive advantage due to improvements or adaptations to the application of an existing product or service, these are good enough reasons for private firms to assume the inherent risk of the innovation process and its costs. In turn, public sector performance is not oriented to a pecuniary profit and - for that reason common market incentives (profitability, competitiveness and efficiency) are not what in first place move public organizations to take on the risky process of innovation. Even the possibility of being more efficient (i.e. having more available resources in an environment where budgetary constraints are a constant limitation) might not be enough to overcome the risk aversion prevalent in public sector, where it rules the sentence: "if it's not broken there's no need to fix it".

In spite of high risk aversion and lack of the typical pecuniary incentives, public sector innovation does exist.

In order to speak about innovation in public sector it is important to make a distinction between two different roles that the public sector takes towards innovation development. In one of them public sector performs as a provider and sponsor of innovation inside of what is known as National system of innovation ${ }^{3}$. Public sector funds and carries innovations by its own institutions (perhaps with some technical/scientific bias) with the purpose to give local industry better capabilities and greater competitiveness, and also with the purpose to help to improve citizens' quality of life, like in the case of medical solutions. In this case innovation turns out in new knowledge, useful to many sectors of economic activity. Hence, public sector performs as a sponsor for economic development, correcting market failures by absorbing risk and costs that private entities might not be willing to undertake because they are too high or because their profitability is uncertain. Within this view of public sector innovation it is quite evident the understanding of its benefits and willingness to assume its costs. However, this situation is limited to a reduced part of the public sector: that part accounted by budget addressed to specific development policies.

A second role of public sector with respect to innovation involves to all its organizations and institutions and has as a purpose not just to support the economy with research and development activities, but to improve public function in general. Here we understand public function as public sector delivering services to citizens. That is: public services. In this other view public innovation is seen as a process adopted by public organizations to improve services they provide. This second role of public sector towards innovation, the one involving all public organizations in public services improvement, is what we are trying to focus on.

\footnotetext{
${ }^{2}$ Innovation occurring in public sector out of pecuniary incentives, and its importance for the economy and social welfare, is well documented in studies such as Borins 2001, Halvorsen et al. 2005, Hartley 2005, Rubalcaba 2006, Windrum 2008, Langergaard and Scheuer 2009, etc.

3 For an extended overview of the 'national system of innovation' concept see Freeman (1995) and Nelson (1993)
} 


\section{Defining public sector innovation}

Innovation is commonly understood as the implementation of something new; a change addressed to obtain an improvement. From many theoretical perspectives it is also conventionally considered as a normative good; an ideal strategy to bring development and raise benefit (Borins, 2001; Mulgang and Albury, 2003; Vigoda-Gadot et al., 2005). Its economic potential has led to produce a considerable bulk of studies in different sectors of the economy, where efforts have been made to provide a formal definition of innovation in order to help its analysis. Despite efforts for providing a definition of innovation equally valid in all contexts, this has proven to be a highly complex and difficult task (Koch and Hauknes, 2005; Windrum, 2008). The understanding of innovation depends on the activity context under consideration, the analysis built around it and the questions raised on it (Koch and Hauknes, 2005). Therefore, the analysis of public sector innovation requires a definition that attends the nature and the objectives of public sector activities.

After reviewing definitions of innovation in previous studies (Koch and Hauknes, 2005; Hartley, 2005; Windrum, 2008; Langergaard and Scheuer, 2009; Matthews et al. 2009) the next elements have been found in common:

- Newness: Indeed, an adopted change for being considered as an innovation must show an essential element of novelty, which must be verified at least within the environment of the unit of adoption.

- Implementation: In order to be accounted, the innovation must be taken to its implementation.

- View of innovation as a process: Innovation ends with implementation but it has to go through a resource consuming process that includes idea generation and development.

- Improvement: Innovation is addressed to a specific objective whose purpose implies an improvement (even though improvement could be finally achieved or not after implementation).

- Significance: The magnitude of the improvement and the novelty of the introduced change must be of relevance for the unit of adoption.

- Variety of items to innovate (innovation typology): Changes in a variety of operational practices may be considered as innovations. Each of these can be seen as a type of innovation in its own.

For the purposes of providing at this point a definition that helps our understanding of public innovation it is next cited the work of Brown and Osborne (2013: 188), where they make an appropriate development of the concept:

The definition of innovation adopted for this paper is 'the intentional introduction and application within a role, group or organization of ideas, processes, products or procedures, new to the relevant unit of adoption, designed to significantly benefit the individual, the group organization or wider society' (West and Farr, 1990: 3)... As we have argued elsewhere, innovation is not simply a normative word to connote beneficial change in public policy or services, but is rather a distinctive category of discontinuous change that offers special 
challenges to policymakers and service manager alike (Osborne and Brown, 2011). This discontinuity can be in terms of a new public service product, a new policy program or service, a transformed process or a new configuration of an existing set of relationships to fulfil a task.

Innovation in public sector is not to be understood as in manufacturing industry sector, where the concept is frequently referred to product, technology and engineering improvements. Studies documenting public innovation suggest an innovation typology based on improvements in practices at various operational levels of an organization (Mulgang and Albury, 2003; Halvorsen et al., 2005; Windrum, 2008; Langergaard and Scheuer, 2009; Matthews et al. 2009; Bugee et al., 2011; European Commission, 2011). Typology can be summarized as follows:

- Service/product innovation: A new or significantly improved service or product.

- Process innovation: A new or significantly improved method for producing and delivering services or products.

- Organizational innovation: A new or significantly improved form for organizing and managing work.

- Communication innovation: A new or significantly improved method for promoting organizations' services and goods or for influencing the behaviour of individuals.

- System innovation: A new or significantly improved form to interact with other organizations and agents.

- Conceptual innovation: New concepts (world views, outlook of actors) underpinning the existence of products/services, processes and organizational forms.

\section{Public organizations dynamics}

Thinking of public organizations linking within the same field or sector (e.g. general administration, education, health, housing, environment...) is different from the case of private businesses linking in the same market. Business organizations compete among them and the ways they draw knowledge and information from each other are typically associated to some return that will let a firm to profit from collaboration with another firm (Veugelers, 1997; Chesbrough, 2003; Bonte et al., 2005). On the other hand, public sector organizations are not competitors: The special role and function of the public sector in society make public organizations subject to a democratic, political rule, which implies that the organizational context is normative and that democracy is the governing principle (Langergaard \& Scheuer, 2009: 3).

Langergaard and Scheuer (2009) refer to the work of Hartley (2005) and Hess and Adams (2007) for explaining different approaches to understand improvement and innovation in public sector, which have succeeded one another in the last decades as views on policy and public administration changed. These are called: Traditional Public Administration, New Public Management and Networked Governance. Traditional Public Administration sees public sector as embedded within a stable context and public organizations as a hierarchy (or bureaucracy) 
resting on legal rational authority and oriented towards procedures. New Public Management replaces bureaucracy with quasi-market conditions, challenging the hierarchical view of the public sector and separating organizations' producing units from political influence as far as possible. Networked Governance shows a shift to more networked forms of governance in the public sector, where public (beneficiaries of public services) also takes the role of co-producer of service and innovation. Referenced studies highlight a recent tendency to approach to improvement dynamics in public sector under a networked view. As pointed by Langergaard and Scheuer, a hierarchical understanding of the public sector, where organizations are seen as passive executors of political decisions - like in the Traditional Administration approach, is important for our political self-understanding; however, the tendency is today to see public organizations in terms both of markets, hierarchies and networks.

For progressing in the understanding of public innovation, drawing from studies based on private sector firms has proven to be useful for providing a frame of analysis. Following the tendency explained above and having as reference models that explain service innovation in the private sector, the multi-agent framework is a useful way for understanding public innovation. Basing on Saviotti and Metcalfe (1984), Gallouj and Weinstein (1997) proposed a simplified model where service characteristics are a consequence of a combination of two mechanisms: the utilization of (tangible or intangible) technical characteristics... and the direct mobilization of [firm's] competences. Competences may also be a combination of Firm's competences and competences of users or another entity, which is to be called co-production. Later on, Windrum and Garcia-Goñi (2008) took the Saviotti and Metcalfe and Gallouj and Weinstein approach for proposing an enhanced framework that accounts for multiple agents (specifically: consumers, policy makers and service providers) taking part in the process of coevolving service characteristics. At the same time, reviewed literature on public innovation frequently mentions about the importance of organizations' internal competences (e.g. staff participation and managers actively involved), decisions of political authorities and participation of users (beneficiaries of public services) and suppliers (procurers). This situation suggests an adapted multi-agent framework for understanding public innovation.

Figure I. Adapted multi-agent framework for public innovation

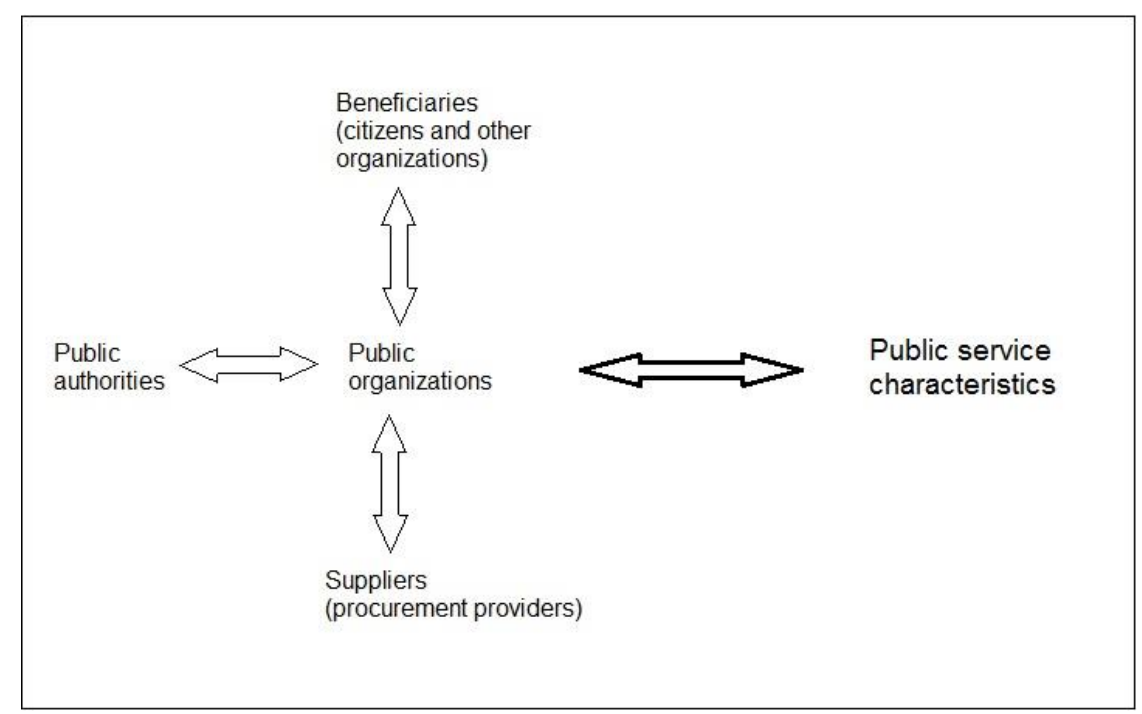


Figure I represents a multi-agent framework for public innovation, based on previous frameworks developed by Gallouj and Weinstein and Windrum and Garcia-Goñi. In this framework, public organizations' competences combines to competences of higher public authorities, beneficiaries and suppliers, within a process than can later combine to some technical characteristics for giving as a result public service provision (i.e. public service characteristics).

\section{Drivers and Barriers for public innovation}

So far, it does exist in the public sector a purpose to generate improvements by introducing changes (i.e. development and implementation of innovations). Such purpose is aimed not by traditional market incentives but by a set of elements typically referred to public functions (Borins 2002; 2006; Halvorsen et al., 2005; Hartley, 2005; Arundel \& Hollanders, 2011). Nevertheless, although improvement is at the aim of innovation, success in improving is not guaranteed by mere fact of implementation. Innovation brings with it some degree of uncertainty on resulting effects, and risk of not getting expected effects (thus, losing invested resources) and of getting some undesirable effects.

Studies already acknowledge some distinctive features of public innovation, such as factors having an influence in innovation generation, factors enabling the innovation process and also barriers counteracting and delaying implementation. Among the latter is frequently and remarkably mentioned a high risk aversion in decision making of public authorities, which causes the avoidance of practices that might bring with it failure and waste (Vigoda-Gadot et al., 2005; Potts, 2009; Brown and Osborne, 2013).

A growing interest in benefits expected from innovation has led to emphasize the power of innovation for improvement, suggesting the strategy to follow for a more innovative public sector and pointing to the gap that still divides the innovation levels observable in public organization and private firms, respectively. Private firms will advocate resources for development of new products and new methods and technology as long as they can expect a net economic benefit from their innovations. On the other hand, public administration decisions are not oriented to pecuniary objectives but to public accountability objectives. That is at the root of public sector's high risk aversion and the innovation gap between public organizations and private firms.

\section{Understanding public innovation in developing countries}

Public innovation studies highlight the need for more flexible public organizations that allow for experimentation, waste and failure (Borins, 2006; Potts 2009; Brown and Osborne, 2013), in such a way that the innovation process is enabled. At the same time, there is a claim for reforming public administration, so institutional bureaucratization might not be a barrier for implementing technical instruments and managerial strategies that help for increased efficiency, quality and effectiveness in public administration. This kind of observations recall highly regulated organizations with strong hierarchic patterns of authority and whose views on policy and accountability makes them to avoid implementations that represent a chance of failure. However, what could be expected about promotion and implementation of innovation in organizations that do not resemble the latter? 
Expectations for development and improvement make implementation of innovations something desirable at all levels of all kinds of organizations. This is also true for regions where society, economy and public institutions remain at a developing state. Therefore, it arise a question on whether the understanding of processes enabling public innovation - acquired in developed contexts - is the same valid for organizations in developing regions. A complete understanding of public innovation should account for innovation in contexts of developing economies, where weakness of public institutions might be more challenging for successful implementation.

\section{Content presentation}

The content in this thesis dissertation obeys to the objectives mentioned in first section. Objectives are all tackled to some degree along the next four chapters. Chapters 1 and 2 are to a higher extent addressed to the observation of the innovation dynamics in public innovation, with a particular focus on innovation drivers and enablers, while chapters 3 and 4 they are addressed to analyse the benefits of implemented innovations, including a particular analysis on some required conditions for letting public innovation to be a source of improvement, as it is meant to be. Figure II below synthesizes how the study carried in this thesis dissertation is followed.

\section{Figure II. Content Diagram}

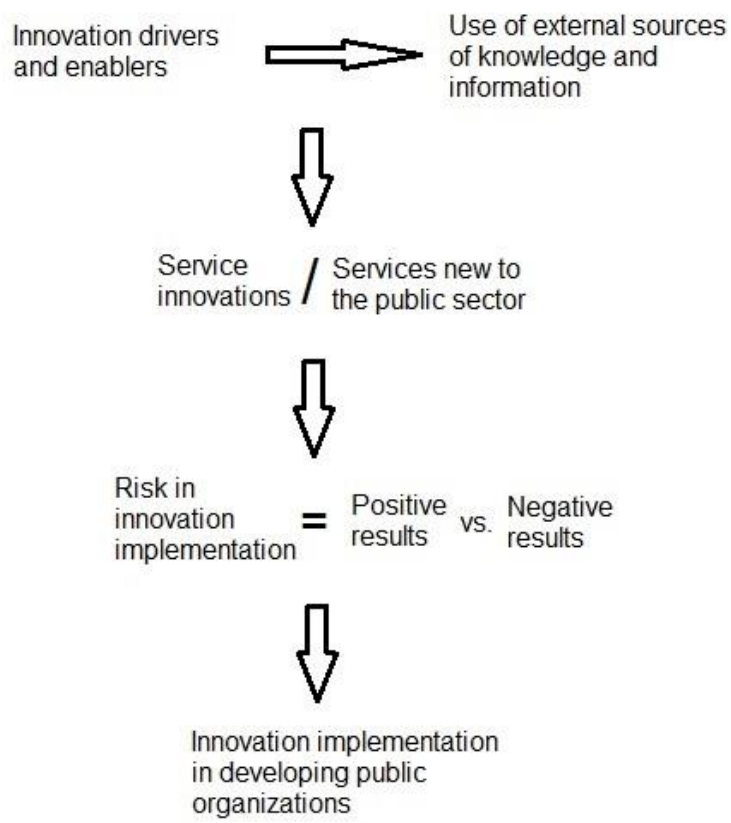

Innovation in the public sector is the result of a complex process in which many factors play a role. Chapter 1 is addressed to identify some factors driving and enabling public sector innovation and to assess their effects on the innovation performance of public sector organizations. The analysis is based on data at EU level provided by the Innobarometer 2010 
Survey. Categorical Principal Component Analysis is used for finding components that are expected to explain performance of public organizations and a bootstrapping method is applied to test the stability of extracted components. Results show that components related to using external sources of information, active involvement of managers and implicating staff and users in the innovation process have a positive effect on implementation of service innovations, while the effect of political and legislative factors turns to be somewhat contradictory.

The use of external sources for innovation has an increasing role in organizations of all kinds; they can be essential for creating and developing innovation. With a particular theoretical approach, Chapter 2 provides with a framework to compare how significant it is for public service innovation the use of internal and external sources of information in innovation development. At the same time, effects on innovation implementation from the use of both kinds of sources are assessed basing on evidence from the Innobarometer 2010 Survey. Results indicate a positive and significant relation between both the use of internal and external sources of information and the implementation of service innovations. They also give evidence to believe that using external sources of knowledge and information for innovation development is especially important for the implementation of services that are new to the whole public sector.

The aim in Chapter 3 is to present empirical evidence for helping to support assumptions about the potential of public innovations for achieving positive effects after implementation, and also about the risk of suffering some negative effects. High risk aversion is argued to be one of the main causes for the innovation gap between public organizations and private firms. At the same time, risk aversion is a consequence of public policy leaded by public accountability instead of market profit. Then, one could reasonably ask what is worth for public organizations to take the risks of innovation. For approaching to the answer, the followed method consists in estimating probabilities of positive and negative effects experienced after implementation of service innovations by public organizations represented in the Innobarometer 2010 Survey. It is expected that results will help to address a relation between willingness of an organization to engage in innovations with higher degree of novelty and the effects obtained from innovation implementation.

In addition, Chapter 4 presents an alternative view for the analysis of public innovation implementation and its results. A big portion of public innovation studies are based in the observation of public organizations in developed countries. Therefore, are their findings equally valid in the context of developing countries' public sector? This chapter has as a purpose to approach to the answer. For doing so, methodology consists in the analysis of initiatives participating in the Local Governing and Management Award, following a casesstudy approach. This contest awards initiatives of Mexican local governments with original design and remarkable positive impact after implementation. Results from observations support the idea that poorly developed institutions often fail in improving from innovation, since innovations requires an appropriate institutional set-up.

At the end of the main four chapters described above a conclusive chapter will gather the findings that synthesize the efforts in the study presented through this thesis dissertation. 
Chapter 1. Bringing innovation to public sector:

Evidence at EU level 


\section{Introduction}

Despite public sector was thought for a long time to be opposed to innovation, there is wide evidence in the literature about how innovation exists in public services provision and about the processes behind innovation (e.g. Windrum and Koch, 2008). Nonetheless, a more extended analysis is needed in order to reach a better understanding on the relation between factors driving public innovation and innovation performance, fields that have traditionally been more researched in the area of private services (Gallouj and Djellal, 2011). Particularly, there is a gap with respect to empirical studies at international level that may support or revise theoretical frameworks. This chapter contributes to filling this research gap by analysing which of the mentioned drivers and enabling factors lead to a better innovation performance of organizations in public administration.

Unlike previous research on innovation in public services - largely analytical-conceptual or based on case studies - this research proposes an empirical-quantitative approach. The lack of empirical research results from a lack in available data about public sector innovation. However, in 2010 the European Commission released the largest data source on public innovation till now: The Innobarometer Survey on Public Innovation, which contains responses from public agencies from the $\mathbf{2 7}$ member states of the European Union and also Norway and Switzerland. The 2010 Innobarometer Survey is therefore the data source used for this study.

The 2010 Innobarometer Survey includes questions about drivers and strategies of innovations implemented since January 2008. The objective of our analysis is to assess their effects on the innovation performance of public sector organizations. Innobarometer data will be subject to Categorical Principal Component Analysis (CATPCA) in order to build variables containing information about drivers and enablers of public innovation. A bootstrapping method will be applied to CATPCA results to check for stability of results and to provide robustness to our analysis.

Previous studies point to public sector innovation as an issue increasingly demanding for attention (Langergaard, 2009; Matthews et al., 2009; Windrum, 2008). Nowadays, we count on a consistent theoretical framework providing useful models to analyse the innovation process inside public organizations; however, what has been stated in theory has only in a few cases been properly compared to corresponding empirical data. Analysis presented in this chapter is one more step ahead in that direction.

The chapter is organized as follows. After this introductory part, Section 2 contains a literature review building the theoretical framework. Section 3 presents the research hypothesis addressing the study. Section 4 widely describes the methodology that will be applied for testing proposed hypotheses and also the data base in use. In Section 5 results are presented and interpreted. The concluding statements correspond to Section 6. 


\section{Literature review and theoretical framework}

\section{Drivers and enablers of public innovation}

In reviewing previous literature several factors have been identified explaining public sector innovation. Some of them are found creating pressure for improvements and reforms. These are related to citizens' evaluation of government performance, measured by popular opinion and - in democratic countries - votes; also emerging and changing laws and regulations force organizations to adapt processes and delivery of services (Halvorsen et al.; 2005, Borins, 2002). A developing society is another cause that demands the introduction of 'newness' to the public sector (Recascino, 2002), while the use of technological tools makes technological and scientific developments pushing for public innovation (Arduini et al., 2010; Earl, 2002). Borins (2001) lists five groups of conditions influencing public organizations to innovate: initiatives coming from the political system; new leadership; publicly visible failures or problems; internal problems or difficulties; and new opportunities created by technology or other factors.

There are some other factors stimulating innovation by means of a feeling of dissatisfaction. Dissatisfaction might be perceived by employees in day-to-day interaction with citizens whose needs and preferences are not being properly fulfilled by service delivery. Also, dissatisfaction might be placed in employees, who are willing to provoke a change due to a set of personal (either selfish or altruistic) motivations (Halvorsen et al., 2005; Borins, 2002). Likewise, motivation may be really necessary both at front-lines and managerial level in order the get high performance innovation as shown by Garcia-Goñi et al. (2008) for the health sector.

Along with innovation drivers explained above, there are also factors enabling the innovation process, whose quality and intensity in application will help to achieve innovation development and implementation. Public innovation enablers frequently mentioned include: participation of staff in designing and developing innovations; active involvement of organizations' managers for promoting generation of ideas and giving support to their implementation; rewarding innovative behaviour; allocating resources for innovation; taking advantage of experiences and information sources outside the organization; making alliances and networks with other organizations and allowing experimentation and evaluation (Borins, 2006; Vigoda et al., 2005; Koch and Hauknes, 2005; Mulgang and Albury, 2003).

At the same time, organization's willingness to innovate depends significantly on those responsible of decision making being aware about potential benefits of innovation as a strategy of improvement (Borins, 2001; 2006; Mulgang and Albury, 2003; Potts, 2009). Here we have a positive association between innovation outputs, support and engagement of managers and authorities to innovation and resources set to innovation activities, with an emphasis on human resources (employee qualification and participation). It is then believed that Managers' involvement in the innovation process as well as use of resources and employee participation will help to better innovation performance (Vigoda-Gadot et al., 2005; Klein et al., 2009; Potts, 2009; Arundel and Hollanders, 2011). 


\section{'New innovations' and 'innovations done before'}

Innovation and imitation is a common path for introducing technology shifts in industry business. Imitators try to catch up profitability and market share from innovators. At the same time, exclusive use of an innovation gives innovators the opportunity to make it more profitable. However, from another point of view, imitations can also be called innovations, given that one of the primary conditions for changes and reforms to be considered as innovations is that they introduce a significant element of novelty to the organization that implements them (OECD, 2005). That is why public organizations implementing innovations previously implemented by another organization can also be considered innovators.

It is expected that the search for competitive advantage will bring private sector firms to design and implement more and better innovations than other firms, looking for greater differentiation through completely new products, applications, ways to deliver, ways to communicate, etc. Due to a lack of competitive incentives ${ }^{4}$, public sector organizations might not be similarly motivated as private firms to enter in an intense process of generation of innovations that are implemented by first time. Studying public organizations as they approach to introduce innovation not only to their own operational practices but to the whole public sector might help to identify to which extent specific drivers and enablers of innovation (as those mentioned before) contribute to better innovation performance in public sector.

\section{Research hypotheses}

Some factors will influence public organizations to undertake innovation. Averse popular opinion creating pressure, new policies, laws and regulations (sometimes derived from political goals), improvements in technology and changes in society drive organizations to introduce changes and reforms. The innovation process can be brought to an organization through employee entrepreneurship and managers' support and involvement. In addition, enablers of the innovation process facilitate successful innovations. Enablers can be found in the form of strategies such as participation of employees and final users in the developing process, giving rewards to innovators, taking advantage of external sources of information, etc.

It is expected that the kinds of factors mentioned above will make a relevant and effective contribution to public sector innovation. Thus, analysis is addressed to measure the effects of some identified innovation drivers and enablers on the innovation performance of public organizations. The data base that will help the analysis provides information on political and legislative factors making pressure for innovation, factors reflecting support and participation of organizations' authorities (managers) and also strategies enabling the innovation process.

\footnotetext{
${ }^{4}$ There are some incentives among public organizations for competing to innovate and they are based on the idea that public organizations with better performance will be rewarded with a bigger budget. Competition among public organizations would be occurring to enhance budget (Hartley 2005, Roste 2005). However, this view of public management as replicating private firms' incentives oriented to market goals is out of the framework of analysis of this study as it has been shown that public sector organizations do not share with private firms the same incentives towards their final objectives (see Recascino 2002).
} 
Since this is the data we rely on for building our analysis, the focus of research will be on these kinds of drivers and enablers.

Review of literature points to factors useful to generate and develop innovation. Hypotheses highlight an assumed link between some of these factors found in the 2010 Innobarometer Survey and the effective implementation of innovations by public organizations. Hence, empirical analysis is intended to confirm and asses the existence of that link. Nonetheless, research questions and subsequent analysis are addressed to service innovations in particular, leaving aside results that could be obtained from including method and process/organizational innovations. This is due to the fact that all organizations under analysis have to some extent implemented innovations of any kind and the only type of innovation identifiable in every case is service innovation.

Innovation might be taken to public organizations by mandated changes in policy and law (Langergaard and Scheuer, 2009; Koch and Hauknes, 2005; Borins, 2002). Reference texts (e.g. Borins, 2002; Potts, 2009; Brown and Osbore, 2013) highlight the role of policy authorities in addressing the innovation process. Also, it has been remarked how reforms in policy and law are conditioning the introduction of changes in public organizations' operations. First research hypothesis is thus formulated as follows:

H1: Political and legislative factors are a significant driver for implementing public service innovations.

Factors helping public innovation through managers' involvement can lead to a successful innovation process. A key feature in here is how they support innovation (Borins, 2002; 2006; Klein et al., 2009; Vigoda-Gadot et al., 2005). Managers supporting employees' entrepreneurship and getting involved in start and development of innovations suggest a greater understanding of the risks, costs and benefits of innovation. Therefore, managers' involvement reflects a clearer vision of the objectives of innovation and the process that must be carried to achieve those (Vigoda-Gadot et al., 2005). Organizations that innovate leaded by managers' support and involvement are expected to widen their efforts in order to achieve an adequate solution, within a process which is closer to what we commonly understand by 'innovation': the development of something significantly new. Thus, second hypothesis is stated as:

H2: Drivers and enablers that imply active involvement of mangers are significant for implementing public service innovations.

A third group of factors refers to strategies enabling successful innovation processes. Literature tells about the boundaries of these factors to enhance innovation performance. It seems obvious to expect that strategies implemented to succeed in innovation will have a significant effect on the innovation performance of an organization. Nonetheless - now that extensive data on public innovation has been made available - this is a good opportunity for empirically testing (and exploring) what was previously set out only at the analyticalconceptual level. It is expected that, in general, these enablers will show great effects on the development of innovations, assuming that strategies are implemented for helping a process 
directed to specific needs for improvement (Borins, 2001; Potts, 2009). Thus, third research hypothesis is stated:

H3: Application of enabling strategies has a significant effect in the implementation of public service innovations.

For the case of the analysis carried in this chapter, the definition of innovation understood in the applied analysis method is the one indicated by the 2010 Innobarometer Survey (European Comission, 2011), given that the information that is going to help our empirical analysis was built by the survey application. The survey report explains that innovation has been taken to mean any novel or significantly improved service, communication or organizational method. It also remarks that the emphasis is on applicability: any significant improvement in operational practices (either in the product/service range or in support structures) can be classified as an innovation. It is easy to see that the Innobarometer definition share essential features with the definition of public innovation provided in the introductory chapter, particularly by understanding innovation as a significant change and also by identifying the many ways in which innovation can be implemented: either at the service (product) level or as a method for organizing and/or communicating.

\section{Data and methodology}

The method of analysis will be carried out in two steps. First, a set of variables about drivers and enablers for public innovation will be subject to component analysis, in order to obtain a reduced number of variables that could be interpreted in the sense expressed by our research hypotheses. To provide robustness to analysis, data stability in extracted components will be tested with a bootstrapping technique. Next, components will be used for probability estimation as explicative variables in a bivariate probit regression with sample selection. The dependent variable in the selection equation identifies public organizations implementing service innovations and the dependent variable in the objective equation (for conditioned probability estimation) identifies organizations that have introduced a service which is new within the whole public sector. Additionally, variables will be added to check for the effects of organizations' and area of responsibility (local, regional or national). Results from regression will be helpful in addressing how important are identified drivers and enablers for developing public sector innovations.

\section{Data source and CATPCA}

The component analysis that will be applied is known as Categorical Principal Component Analysis (CATPCA). More commonly used, Principal Component Analysis (PCA) requires making some assumptions about data that would not be appropriate for variables not measured in a numeric scale ${ }^{5}$ (interval or ratio scale). Frequently, social science researchers are confronted with data reflecting behaviour whose analysis would not be justified at the numeric level but only at the categorical level. Thinking of any set of suggested answers in a questionnaire as

\footnotetext{
${ }^{5}$ See Linting et al. (2007).
} 
categories (measured in a nominal or ordinal scale), CATPCA gives a solution for carrying out the PCA while overcoming the restrictions imposed on data in the variable reduction problem ${ }^{6}$. CATPCA is based on a technique known as optimal quantification which quantifies categories by assigning to each one a new value, so the new values are expressed in an interval scale while preserving the relations observed in the original values.

Although PCA has been applied to ordinal variables with acceptable results ${ }^{7}$, CATPCA shows better adequacy to ordinal data. Given that selected data for the current analysis offers variables measured in an ordinal scale, CATPCA is a more suitable method for the intended analysis.

There is, however, one objection to the validity of component analysis for making concluding statements. Results of component extraction depend on sample data, which might cause the use of different samples to lead to significantly different results. To overcome this objection and to provide robustness to our analysis the CATPCA process will be complemented with a bootstrapping exercise as a way to test stability of results.

The bootstrapping method - proposed by Linting et al. (2007b) - consists in a nonparametric procedure for establishing confidence regions for CATPCA results. Confidence regions will be calculated for eigenvalues and loadings of extracted components. An important characteristic of the method is that it is a balanced bootstrap: it guarantees every case to appear a number of times equal to the number of samples generated.

The data used for this analysis comes from the Innobarometer Survey on Innovation in Public Administration, which was developed by the European Commission and released in October 2010. For the Innobarometer Survey 4.063 organizations were surveyed from the 27 Member States of the European Union and also Norway and Switzerland. Eligible respondents of the questionnaire were senior managers responsible for strategic decision-making: typically, general managers or strategic directors of the institutions. To carry out the application of CATPCA those organizations which failed to report any innovation since January 2008 will be removed.

The Innobarometer Survey questionnaire includes questions about drivers and strategies for innovations made since January 2008. Some questions ask about the level of importance of various information sources for the development of innovations. Some other questions ask about the level of importance of various political or legislative factors in driving innovations. Another group of questions ask about how well are applied some actions supporting the innovation process. Each question includes a set of eligible answers ranking from 1 to 3 whose correspondent labels are Not important, Somewhat important and Very important (Not at all, Partly and Fully for questions about actions supporting innovation); the usual Don't know/Not applicable (DK/NA) option applies to all questions. These are the ordinal variables that are going to be subject to CATPCA.

\footnotetext{
${ }^{6}$ For a detailed and technical overview of CATPCA (also known as nonlinear PCA) see Meulman et al. (2004).

7 See Arundel and Hollanders (2011).
} 
$D K / N A$ is a difficult category to manage in an ordinal scale. However, deleting all cases reporting an answer like that will lead to lose nearly a third of the available cases. To avoid that loss of information and following the Arundel \& Hollanders (2011) criteria - where the same data was used for component analysis - all DK/NA answers have been turned into Not important, assuming that an important information source, policy or strategy is likely to be remembered. Parallel to the Arundel and Hollanders work, those cases simultaneously displaying $D K / N A$ responses in all questions were deleted from the sample database. Thus, our final data set accounts for 3.553 available cases.

\section{Probability estimation: bivariate probit with sample selection}

Once the extracted components have proven to be stable their scores will be saved and used for probability estimation. A bivariate probit regression with sample selection (also known as Heckman's probit) was chosen as estimation model in order to fit the database structure and also for giving a nuance to hypotheses conclusions. The dependent variable in the selection equation identifies public organizations implementing service innovations and the dependent variable in the objective equation identify organizations that have introduced a service which is new within the whole public sector. Results from estimation will be helpful in addressing how important are drivers and enablers represented in extracted components for developing public service innovations. Additionally, variables will be included in the selection equation to check for the effects of organizations' size and area of responsibility (local, regional or national), since level of authority and resource availability (reflected in size) is something that can certainly affect innovation behaviour. The estimation model is then represented as follows:

$$
\begin{aligned}
& P(Z=1 \mid Y=1)=\beta_{0}+\beta_{i} \text { Component }_{i} \\
& P(Y=1)=\beta_{0}+\beta_{1} \text { Size }+\beta_{2}{\text { Governance_level }+\beta_{i} \text { Component }_{i}}
\end{aligned}
$$

Survey questionnaire asks public organizations whether or not they have implemented new or significantly improved services. Those that gave an affirmative response are then asked if any of the new services they have implemented were - as far as they know - implemented before any other public organization within their own country. It can then be verified that the survey addresses a strong relation of dependence between organizations being identified as introducing services that are new to the whole sector and the fact that they are previously identified as implementing new or improved services (no matter if they were implemented within the sector by another organization before). Therefore, a bivariate probit estimation with sample selection will let know the probability of being an organization that introduces services new to the whole sector, conditioned to be and organization that implements service improvements $\{P(Z=1 \mid Y=1)\}$. That seems more accurate than just estimate probabilities with conventional logit or probit estimations.

Variables about organizations' size and area of responsibility are also drawn from the Innobarometer dataset. Area of responsibility identifies whether public organizations belong to a local, regional or national area, according to their own survey responses, and it is measured in an ordinal scale. The variable about organizations' size indicates the number of employees working in each organization and it is also measured in an ordinal scale. Size categories represent intervals among which respondents must choose the one that correspond 
to the right number of employees of their organization (less than 10, between 10 and 49, between 50 and 99, between 100 and 249, between 250 and 499, between 500 and 999, 1000 or more $)^{8}$.

\section{Results}

The main feature of our CATPCA application for component extraction is in quantification of variables. If quantified ordinal variables (now transformed in a numerical scale) were taken to a conventional PCA the extracted components in the final solution would be exactly the same of those that would be obtained through CATPCA, even though CATPCA process differs from that of conventional PCA. Thus, similar treatments usually made on PCA components for interpretation can also be made on CATPCA components, like rotation and measurement of variable correlation.

The application of CATPCA on the selected variables gives a solution accounting for $47,7 \%$ of the observed variance. Kept extracted components are those with eigenvalues greater than 1. They were subject to Varimax rotation for making them easier to interpret. Table 1 shows the component loadings. Highest correlations are highlighted in bold.

Table 1. CATPCA loadings of variables and extracted components.

\begin{tabular}{|c|c|c|c|c|}
\hline & $\begin{array}{c}\text { External } \\
\text { information } \\
\text { sources } \\
\end{array}$ & $\begin{array}{l}\text { Political and } \\
\text { legislative } \\
\text { factors } \\
\end{array}$ & $\begin{array}{c}\text { Active } \\
\text { involvement of } \\
\text { managers }\end{array}$ & $\begin{array}{c}\text { User and } \\
\text { staff } \\
\text { participation }\end{array}$ \\
\hline Ideas from management. ${ }^{i}$ & .303 & .122 & .552 & .076 \\
\hline Ideas from staff. ${ }^{i}$ & .361 & .073 & .307 & .363 \\
\hline $\begin{array}{l}\text { Examples of best practice by another government } \\
\text { organisation. }{ }^{i}\end{array}$ & .454 & .135 & .358 & .038 \\
\hline Professional organisations. ${ }^{i}$ & .582 & .075 & .245 & .063 \\
\hline Visits to conferences. ${ }^{i}$ & .615 & .072 & .084 & -.023 \\
\hline Enterprises as suppliers. ${ }^{i}$ & .706 & .054 & .031 & -.008 \\
\hline Enterprises as clients or users. ${ }^{i}$ & .738 & .070 & .036 & .159 \\
\hline Citizens as clients or users. ${ }^{i}$ & .624 & .155 & -.001 & .240 \\
\hline Mandated decrease in your organisation's budget. ${ }^{p}$ & .027 & .659 & .032 & .098 \\
\hline Mandated increase in your organisation's budget. ${ }^{p}$ & .057 & .612 & -.091 & .096 \\
\hline Importance of new laws or regulations. ${ }^{p}$ & .053 & .727 & .117 & .018 \\
\hline Importance of new policy priorities. ${ }^{p}$ & .113 & .636 & .147 & .094 \\
\hline $\begin{array}{l}\text { Mandated introduction of new e-government or } \\
\text { online services. }{ }^{p}\end{array}$ & .222 & .553 & .133 & -.112 \\
\hline
\end{tabular}

${ }^{8}$ Question about organizations' size include a Don't know/Refusal option. Frequency of this answer is very low. It was found that most of these cases (13 out of 15) correspond to local organizations. Given that more than a half of local organizations responded to have between 10 and 49 employees, the 15 cases with $D K$ responses were recoded into this size interval. 


\begin{tabular}{|c|c|c|c|c|}
\hline $\begin{array}{l}\text { Managers support trial-and-error testing of new } \\
\text { ideas. }{ }^{s}\end{array}$ & .054 & .031 & .770 & .098 \\
\hline $\begin{array}{l}\text { Managers take an active role in developing and } \\
\text { implementing innovations. } s\end{array}$ & .042 & .087 & .786 & .209 \\
\hline $\begin{array}{l}\text { Staff has incentives to think of new ideas and take } \\
\text { part in their development. }{ }^{s}\end{array}$ & -.024 & .014 & .073 & .783 \\
\hline $\begin{array}{l}\text { Users are involved in the design or planning of new } \\
\text { or improved services. }{ }^{s}\end{array}$ & .133 & .059 & .059 & .761 \\
\hline $\begin{array}{l}\text { New or improved services are evaluated after } \\
\text { completion. s }\end{array}$ & .150 & .114 & .249 & .533 \\
\hline
\end{tabular}

First component shows higher correlations to variables indicating the importance of the use of information sources that are external to the organization. Second component is mostly correlated to variables indicating the importance of political and legislative factors driving innovations. Third component is correlated to variables reflecting the level of implication of managers in developing innovations. Finally, highest loadings in the fourth component correspond to variables indicating involvement of staff and users in the innovation process.

To test the stability of components a bootstrapping exercise was carried out setting 1000 samples to generate confidence regions expected to contain true values of component eigenvalues and loadings at a confidence level of $95 \%$. Confidence regions are displayed in two-dimension graphics, following the method of Linting et al. (2007b). CATPCA bootstrapping method turns conventional confidence regions into ellipse areas on a two-dimensional space by plotting pairs of components. Ellipse areas draw a space containing $95 \%$ of eigenvalues and loadings obtained from CATPCA on bootstrap samples. The closer values generated in the original CATPCA process are placed to the center of the ellipse the closer they will be to the mean of values from bootstrap samples. Ellipse width indicates how disperse bootstrap values are. Stability on CATPCA values becomes evident when ellipse areas are small and original CATPCA values are close to the center of the ellipse ${ }^{9}$.

Displaying graphics for confidence ellipses demands a large space. For that reason, full results of CATPCA bootstrapping are presented in an annex part. Observed bootstrap results suggest stability on extracted components and, therefore, validity of results in the next step of our empirical analysis.

Once components have been extracted and interpreted, and stability has been proven, their scores are saved and used as explicative variables in a bivariate probit regression with sample selection. The selection equation identifies organizations that implement new or significantly improved services (i.e. service innovations) no matter they are services or improvements that were implemented before by another organization. The objective equation explains the probability of being an organization that introduces services that are new within the whole

\footnotetext{
${ }^{9}$ Thus, accepting stability depends on observer appreciation. A practical application of CATPA bootstrapping in Linting et al. (2007b) might be useful as a reference to interpret results.
} 
public sector. Variables accounting for organizations' size and level of governance have been introduced to the selection equation. Table 2 shows estimation results.

Table 2. Results of Heckman's probit with sample selection

\begin{tabular}{|c|c|c|}
\hline & $\begin{array}{c}\text { Innovate services } \\
\text { (selection) }\end{array}$ & $\begin{array}{c}\text { Introduce new } \\
\text { services }\end{array}$ \\
\hline \multicolumn{3}{|l|}{ Size (number of employees) } \\
\hline $10-49$ & (base) & -- \\
\hline $50-99$ & $0,1726^{* *}$ & -- \\
\hline $100-249$ & $0,1111^{*}$ & -- \\
\hline $250-499$ & $0,4003^{* * *}$ & -- \\
\hline $500-999$ & $0,4944^{* * *}$ & -- \\
\hline 1000 or more & $0,64^{* * *}$ & -- \\
\hline \multicolumn{3}{|l|}{ Area of responsibility } \\
\hline Local & (base) & -- \\
\hline Regional & $0,1541^{* * *}$ & -- \\
\hline National & $0,1502^{*}$ & -- \\
\hline External information sources & $0,1035^{* * *}$ & $0,0953^{* * *}$ \\
\hline Political and legislative factors & $0,0392^{*}$ & $-0,032$ \\
\hline Managers actively involved & $0,1141^{* * *}$ & 0,0202 \\
\hline User and employee participation & $0,0672^{* * *}$ & $0,0738^{* * *}$ \\
\hline Constant & $0,5252^{* * *}$ & $-0,2277^{* * *}$ \\
\hline
\end{tabular}

The estimated coefficients of variables that define the probability of being observed (i.e. being identified as an organization that has recently introduced service innovations) are all statistically significant to some degree. Coefficients suggest that organizations' size has an important effect on the probability, this especially true for larger organizations. To be in a bigger area of responsibility (regional or national, as opposed to local) also has a significant effect, as well as components representing drivers and enablers. Components' coefficients seem to indicate that active involvement of managers and the use of external sources of information have a more relevant effect than political factors and participation of users and employees.

In turn, components explaining the probability of being an organization that introduces services new to the whole sector -conditioned to be previously known as an organization that introduces service innovations - they show small and not always significant coefficients. Political and legislative factors (which show a negative effect) and active involvement of managers does not reach individual significance. In turn, use of external information sources and user and employee participation does reach individual significance, but their small coefficients suggest their effect on the conditioned probability is modest.

Constants in both probability estimations might tell something about the resilience of public organizations to carry implementations with higher degree of novelty. The constant term in the estimated probability of being observed is positive and large. In turn, that in the estimated conditioned probability is negative and also of considerable magnitude. A plausible 
interpretation is that there is a certain inclination among public organizations towards implementing service innovations, while organizations are also inclined in the opposite sense towards introducing services that are new within the whole public sector. It might here be found some evidence on the high public sector aversion to the risk implied in innovation (as something essentially new) and how it can be to some extent overcome by the drivers and enablers that are here analyzed.

Coefficients are, however, only a partial reading of the estimation results. A more revealing way to analyze relevance of variables explaining probabilities is in calculating their predictive marginal effects.

Predictive marginal effects were calculated for all organization's size intervals. Marginal effects were calculated giving specific values for each of the components while holding the rest of variables at their average value. Results predict the exact magnitude that the probability takes at specific values of the correspondent component, from changes in the size variable. Specific values of components were chosen having as reference consecutive increases of 0,5 starting from their lowest value. Results were plotted and are next displayed for their analysis. All marginal effects have proven to be statistically significant at a $99 \%$ confidence level. Although the changing variable in marginal effects is not the observed component, but the size variable, this exercise still works as a way to address differences in the overall probability due to different values of the one component under analysis. The purpose, though, is in observing magnitudes of probability at different values of each component.

With respect to marginal effects for the three levels of area of responsibility, it should be enough to say that they offer a picture very similar to that of the size effects. But this is something one could have expected since there is an important relation between organizations' size and the responsibility area they belong to.

In addition, there were also calculated marginal effects for changes in the value of extracted components. These represent the magnitude of a change in the predicted probability from a "one unit" change in the average value of the component under analysis. Effects were calculated at representative values of organizations' size and area of responsibility. Results on these marginal effects are shown in tables in Annex II. They show similar tendencies as those that will next be reviewed. An important difference, however, is that most of marginal effects in the predicted conditioned probability from the second component (Political and legislative factors) does not reach any level of statistical significance. The reason is that significance is here tested on changes in the average value of the component. When the value of the component changes the effect on the predicted probability is not found statistically significant. On the other hand, statistical significance in the following effects was tested on changes in organizations' size, from which the overall value of predicted probabilities was calculated. 
Figure 1: Predictive marginal effects for organizations' size at representative values of 'External information sources'.
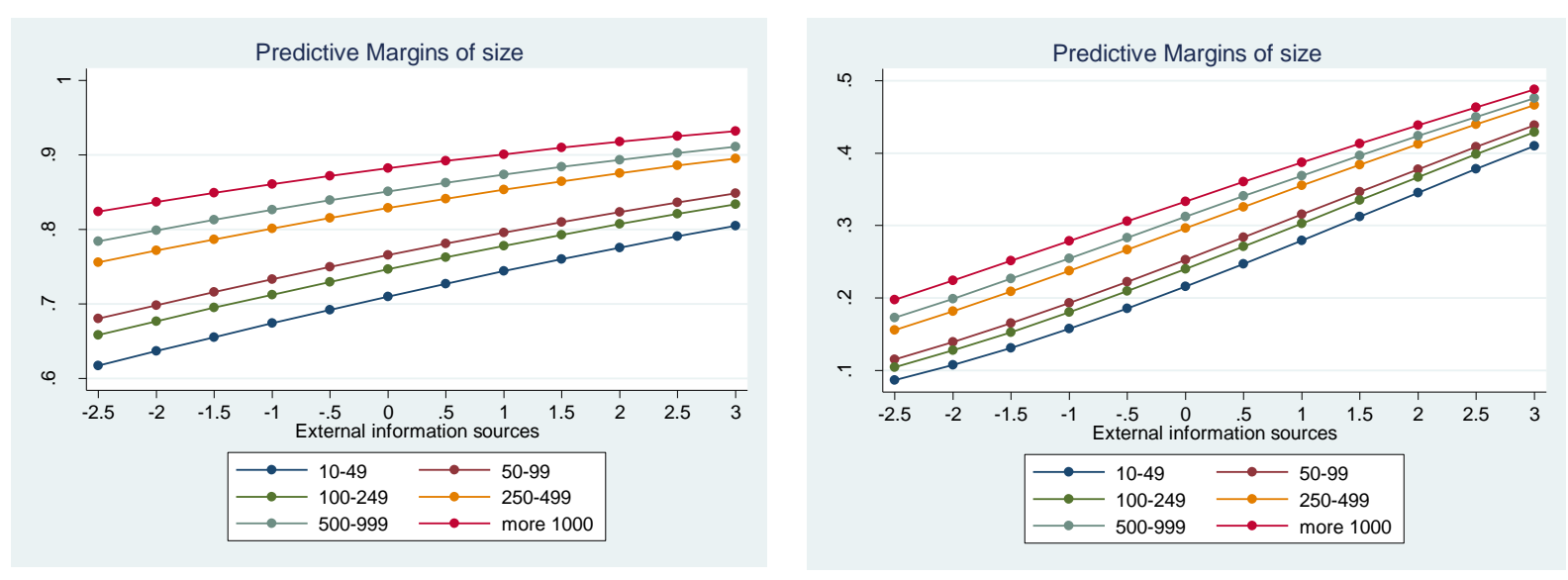

As seen in Figure 1, marginal effects at representative values of the 'External information sources' component show a positive relation between discrete values of the component and the predictive probability of being an organization that introduces new or significantly improved services (i.e. service innovations). It also shows a positive relation for the probability of being an organization that introduces services that are new to the whole public sector conditioned to be previously known as an organization that introduces service innovations. There is a small but noticeable gap between the lines representing probabilities of bigger organizations in the upper part and the lines of smaller organizations at the bottom. This can be observed in both kinds of probabilities, although differences are more compact among conditioned probabilities. This might indicate organizations' size (and other capability characteristics related to it) loses some relevance when introducing services that are new for the whole sector.

It is also interesting to observe differences of probabilities when they are predicted in the lowest and highest values of the external sources component. Differences are slightly larger for smaller organizations, which is easier to observe in the probability of introducing service innovations. This probability increases around 17 to 19 percent points for smaller organizations and around 11 to 13 points for bigger ones, from the lowest to the highest value of the component. On the other hand, the conditioned probability of organizations introducing services new for the whole sector increases around 30 percent points for all organizations' sizes. 
Figure 2: Predictive marginal effects for organizations' size at representative values of 'Political and legislative factors'.
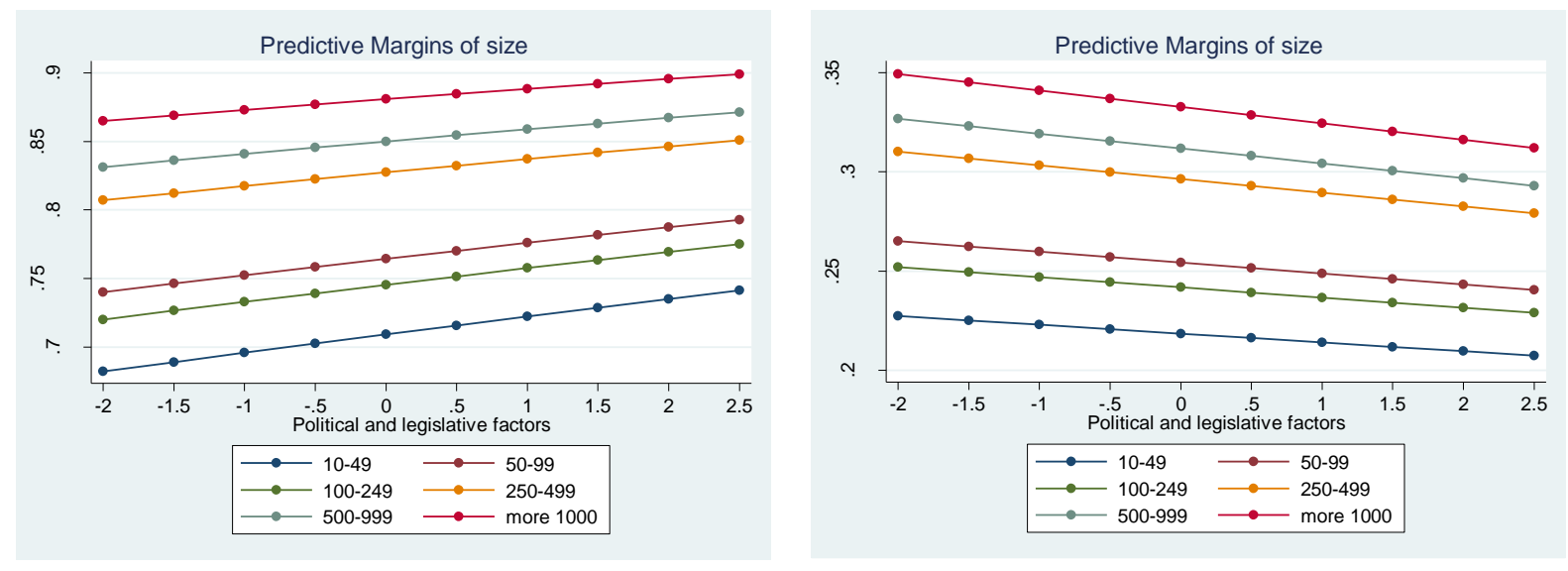

Figure 2 shows a positive relation between discrete values of the 'Political and legislative factors' component and the predictive probability of being an organization that implements service innovations. This relation turns to be negative for the probability of being an organization that introduces services new to the whole public sector. However it is not possible to determine the effect that different values of the importance of Political and legislative factors will have on the overall conditioned probability, given that statistical significance couldn't be proved on this component's effects (see Table 2 and Anex II).

Differences between predictive probabilities for the lowest and highest values of the Political factors component are small (compared to those calculated at 'External information sources' values). Differences for organizations introducing service innovations account for about 3 to 6 percent points, while differences in the conditioned probabilities of organizations introducing services new to the whole sector accounts for about -3 points. 
Figure 3: Predictive marginal effects for organizations' at representative values of 'Managers actively involved'.
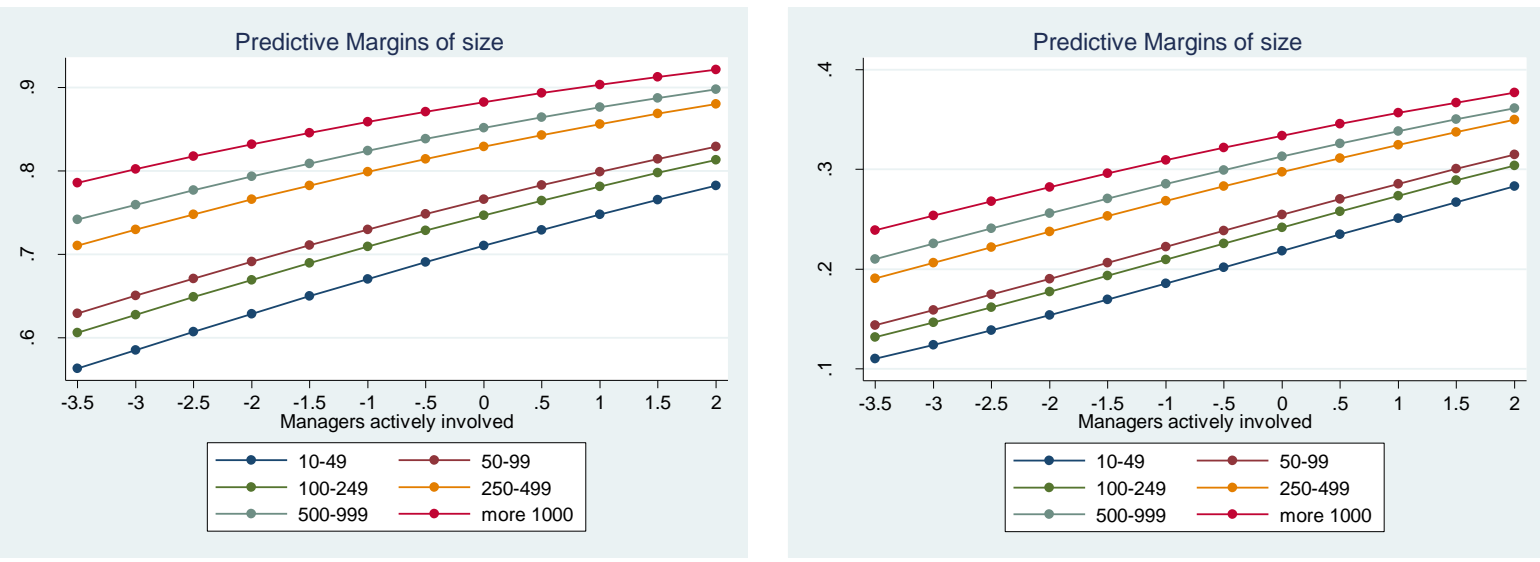

In Figure 3 it can be seen that marginal effects at representative values of the 'Managers actively involved' component behave similar to those calculated at values of the 'External information sources' component. They show a positive relation between increments in predictive probabilities and discrete values of the component.

The gap of the lines of bigger and smaller organizations can also here be observed. Probabilities for introducing service innovations increase about 20 to 22 percent points for smaller organizations and about 13 to 17 points for bigger ones. On the other hand, the conditioned probability of organizations introducing services new for the whole sector increase around 14 to 17 percent points for all organizations' sizes.

Figure 4: Predictive marginal effects for organizations' size at representative values of 'Users and employee participation'.
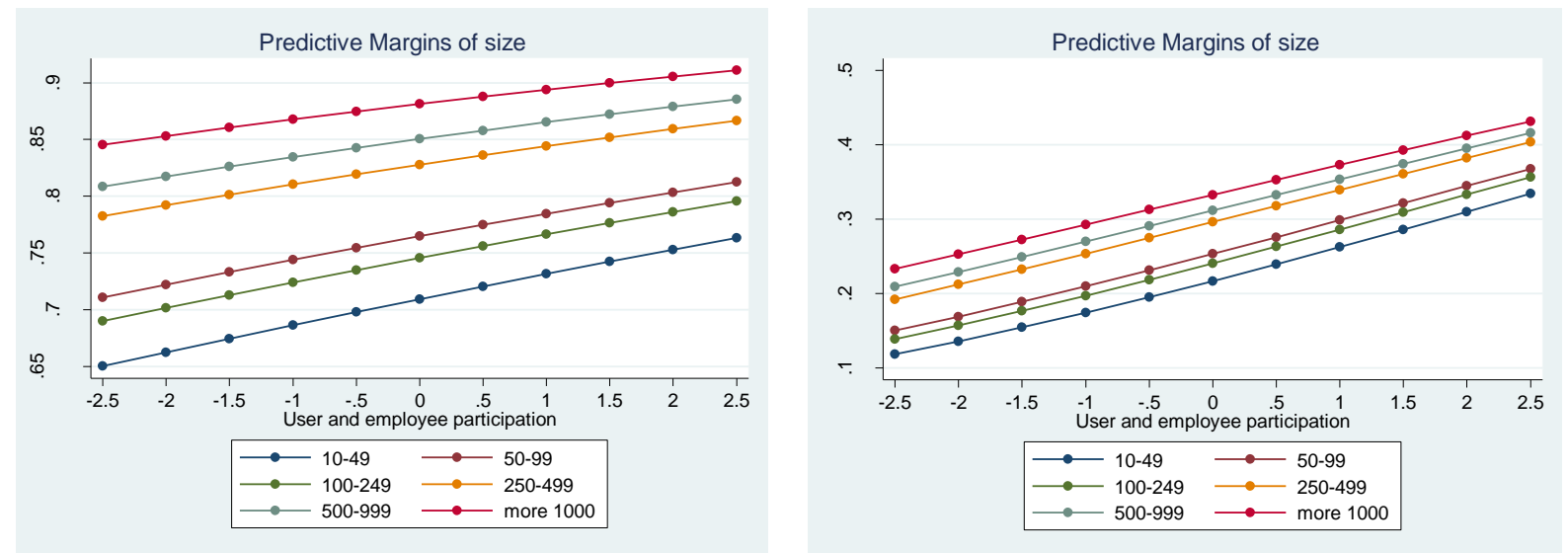

Marginal effects at representative values of the 'User and employee participation' component are also similar than previous ones. Probabilities of organizations introducing service innovations increase around 11 percent points for smaller organizations and around 6 to 9 points for bigger ones. On the other hand, the conditioned probability of organizations introducing services new for the whole sector increase around 20 percent points for all organizations' sizes. 
Thus, after reviewing probability estimation results and marginal effects, the next overall conclusions can be stated.

The probability of being identified as an organization introducing service innovations is already high at a starting point, especially for larger organizations and those at higher levels of governance. It can be verified that a more intensive use (reflected in the 'how important' survey questions on innovation drivers and strategy) of innovation drivers and enablers will help to increase this probability and the increase will be proportionally bigger for the smallest organizations. Active involvement of managers in first place and the use of external sources of information in second place they both appear to have the more powerful effects on the probability.

The probability of being identified as an organization introducing services that are new within the whole public sector is low at a starting point, especially for smaller organizations and those at the local level of governance. Nevertheless, it can be verified that a more intensive use of innovation drivers and enablers will help to largely increase this probability, except for political and legislative factors, whose effects couldn't be determined from estimations and marginal effects. Proportion of increases looks similar among all organizations' sizes; however, it can be verified that increases are still slightly bigger for smaller organizations. Differences in predicted conditioned probability at representative components' values are noticeably larger than those of probability of being observed. Regarding this, the effect of the 'External information sources' component is remarkable.

Results from the empirical analysis are helpful to support to a higher or a lesser extent propositions stated in research hypotheses. First hypothesis suggests that political and legislative factors are significant for implementing public service innovation. In Heckman's probit estimations, the effect of the political and legislative factors component is barely found statistically significant, and something similar can be said from results on marginal effects. On the other hand, when we point only to implementation of services that are new within the whole public sector, the effect of political and legislative factors is not found statistically significant and, therefore, cannot be determined from this empirical analysis. Meanwhile, the second hypothesis suggests that active involvement of managers is also significant for implementing public service innovations. In this case, empirical results are better conclusive. Magnitude and statistical significance of component coefficient in Heckman's estimation is high for the probability of being observed (i.e. being and organization implementing service innovations). At the same time, marginal effects are highly significant and of considerable value (compared to the effects of the rest of components) for the predicted probability of being an organization introducing services that are new to the whole sector. Finally, third hypothesis suggests that the application of some enabling strategies has a significant effect in implementation of public service innovation. To this respect we have analyzed two strategies in particular: the use of external sources of information and user and staff participation. Both of them show - as can be seen in results from Heckman's estimation and marginal effects high and significant effects on both the probability of being an organization implementing service innovations and the probability of being an organization introducing services that are new to the whole sector. 


\section{Concluding remarks}

Previous research on public sector tells about drives and enablers helping public innovation. Some of them create pressure for improvements and reforms: e.g. citizens' evaluation of government performance, emerging and changing laws and regulations, societal changes and technological and scientific developments. Employee motivation and user dissatisfaction also work as forces aiming public innovation. In addition, we have factors enabling the innovation process, whose quality and intensity in application will lead to a successful innovation process, such as active involvement and support of managers, rewarding innovative behaviour, taking advantage of experiences and information sources outside the organisation and allowing experimentation and evaluation.

CATPCA application on the 2010 Innobarometer Survey data has provided with variables that can be interpreted as some of the public innovation drivers and enablers previously reviewed. Our research hypotheses and empirical analysis are addressed to identify and asses a link between variables of drivers and enablers and the implementation of service innovations by public organizations.

Results of the empirical analysis give evidence in favor of hypotheses propositions. Political and legislative factors, active involvement of managers in the innovation process and strategies enabling innovation (found in the use of external sources of information and user and employee participation) they all prove to be relevant at some level in implementation of public service innovations.

Nonetheless, some contradictions are found when evaluating the role of political and legislative factors in innovation development. Even though literature highlights the role of policy authorities and law and regulation reform as drivers for public innovation, their effect on service innovation was found modest. Moreover, their effect on introducing services new to the whole sector couldn't be determined.

A more intensive use of innovation drivers and enablers will help to increase the probability of being an organization that implements service innovations. Likewise, a more intensive use of innovation drivers and enablers will help to largely increase the probability of being an organization that introduces services that are new for the whole public sector (except for political and legislative factors). On both matters, the effect of use of external sources of information is remarkable. Use of external sources of information, active involvement of managers and user and employee participation as well, all have an important effect on public service innovation implementation; however, the use of external sources of information holds higher potential for an organization to enhance its innovation performance. This finding deserves particular consideration.

Estimation results and marginal effects points to some resistance found in public organizations to the implementation of services that are new to the whole sector. The intensive use of drivers and enablers that are here analyzed seem to be helpful to overcome it. 
Finally, organisations' size and area of responsibility also appear as important features explaining differences between organizations' innovation performance. Results suggest there is greater chance that service innovation (in the form of services new for the whole sector) is being introduced to the public sector by big national/regional organisations than by small local ones. 


\section{Graphic 1a. Component 1 vs. Component 2. Eigenvalues.}

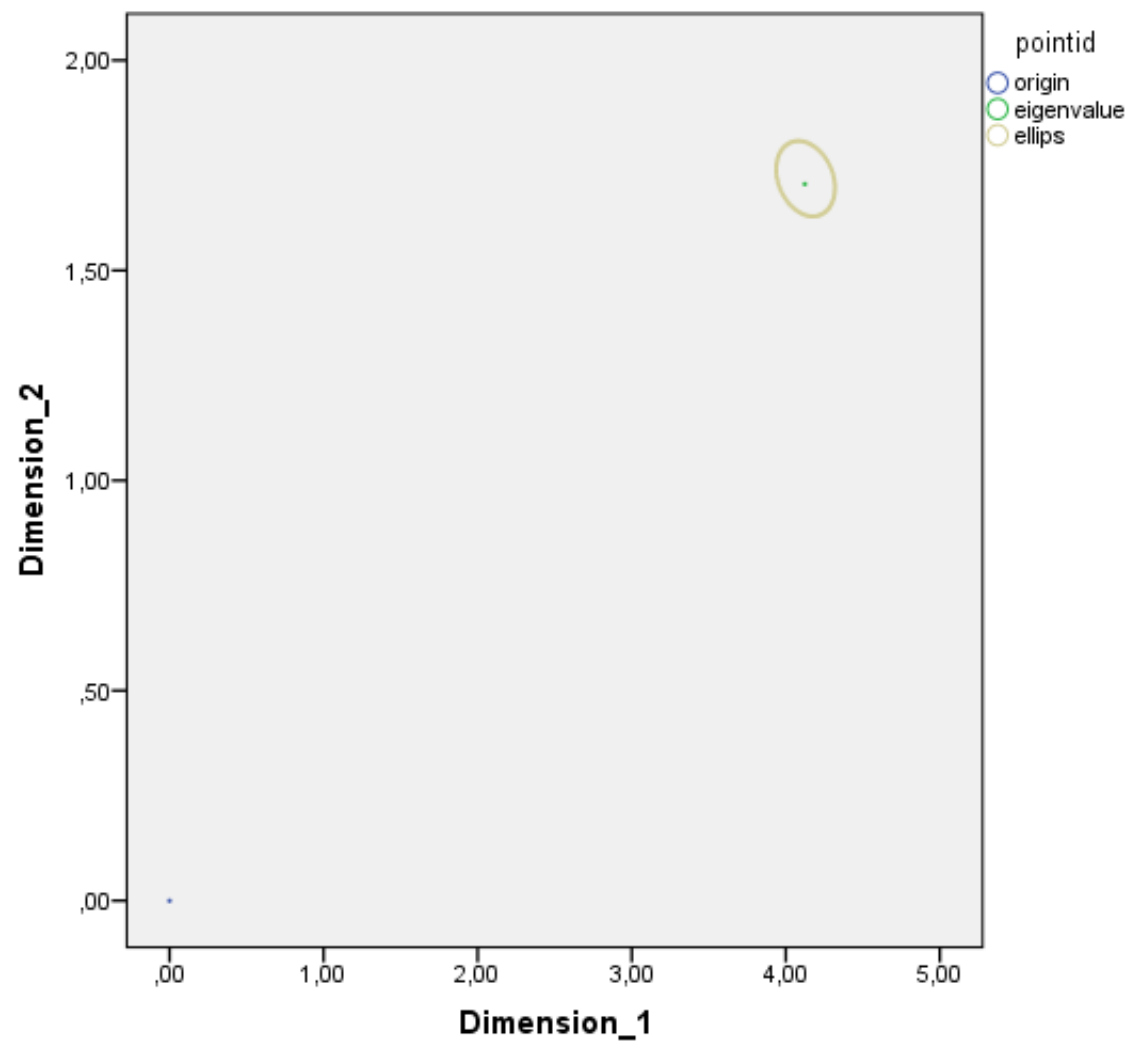

Graphic 1b. Component 1 vs. Component 2. Loadings.

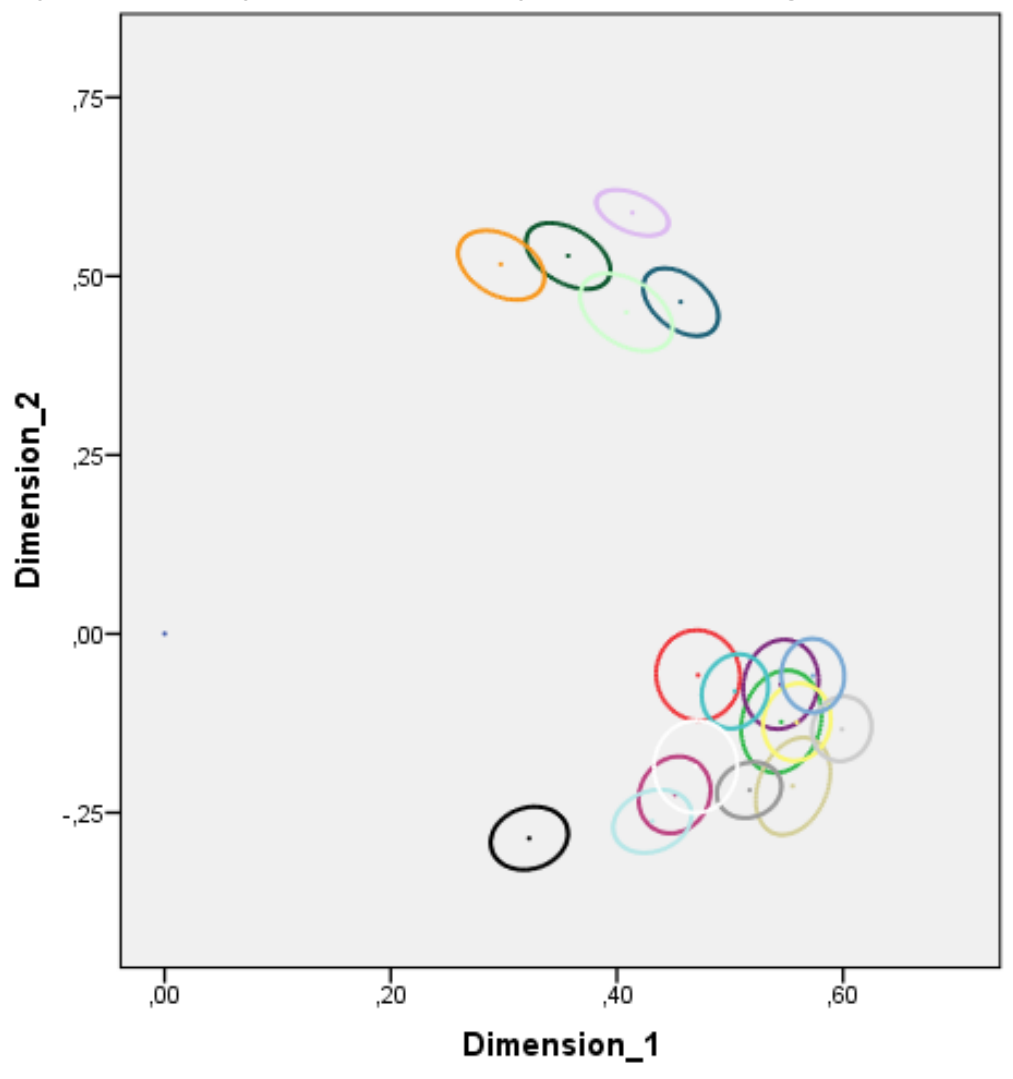

q14_a: Ideas from management. q14_b: Ideas from staff. q14_c: Examples of best practice by another government organization. q14_d: Professional organizations. q14_e: Visits to conferences. q14_f: Enterprises as suppliers. q14_g: Enterprises as clients or users. q14_h: Citizens as clients or users. q16_a: Mandated decrease in your organization's budget. q16_b: Mandated increase in your organization's budget.

q16_c: New laws or regulations. q16_d: New policy priorities. q16_e: Mandated introduction of new e-government or online services. q17_a: Managers support trial-anderror testing of new ideas. q17_b: Managers take active role in developing and implementing innov. q17_c: Staff has incentives to think of new ideas and take part in develop. q17_d: Users are involved in the design or planning of new or improved services.

q17_e: New or improved services are evaluated after completion. 
Graphic 2a. Component 1 vs. Component 3. Eigenvalues.

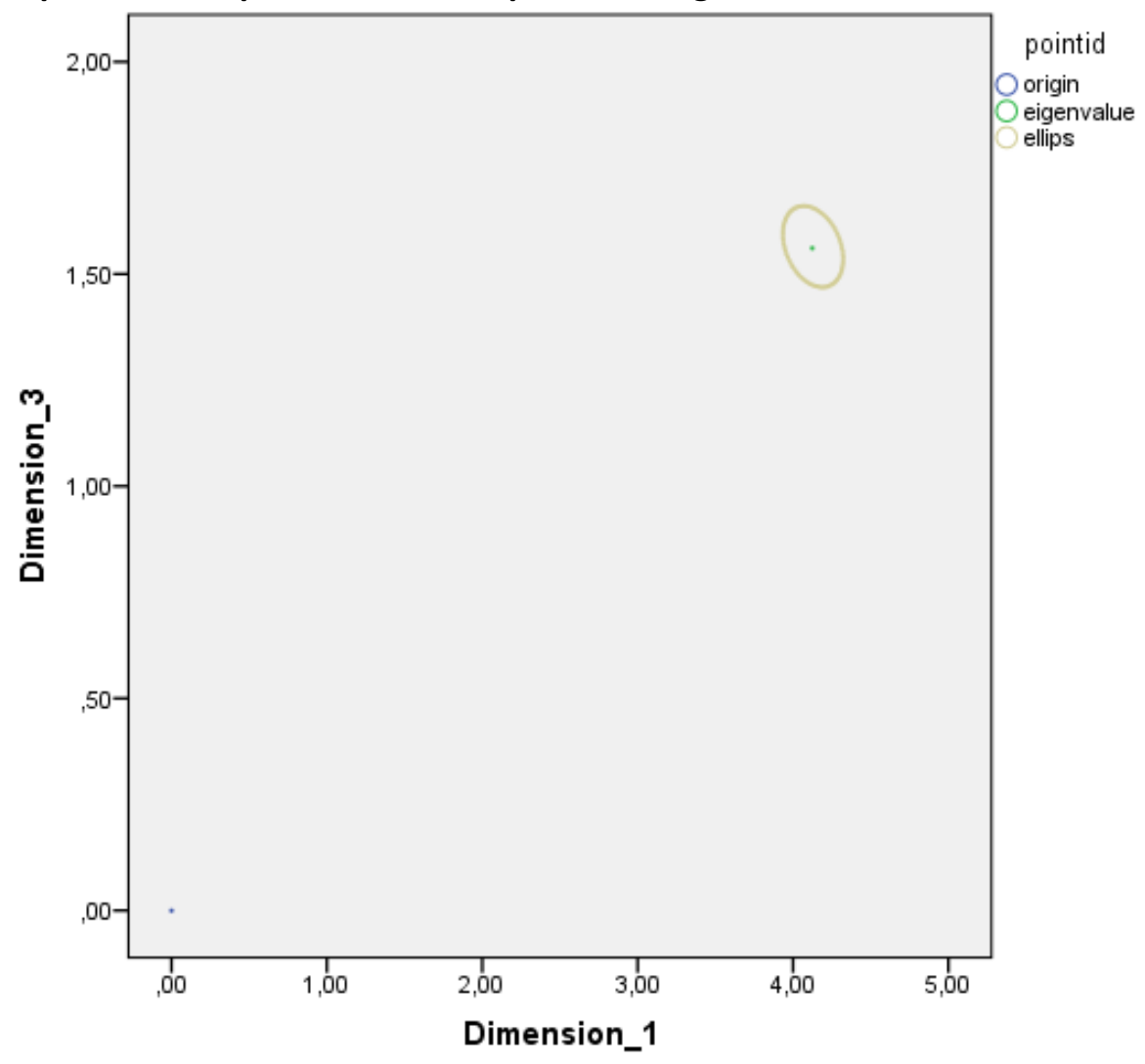

Graphic 2b. Component 1 vs. Component 3. Loadings.

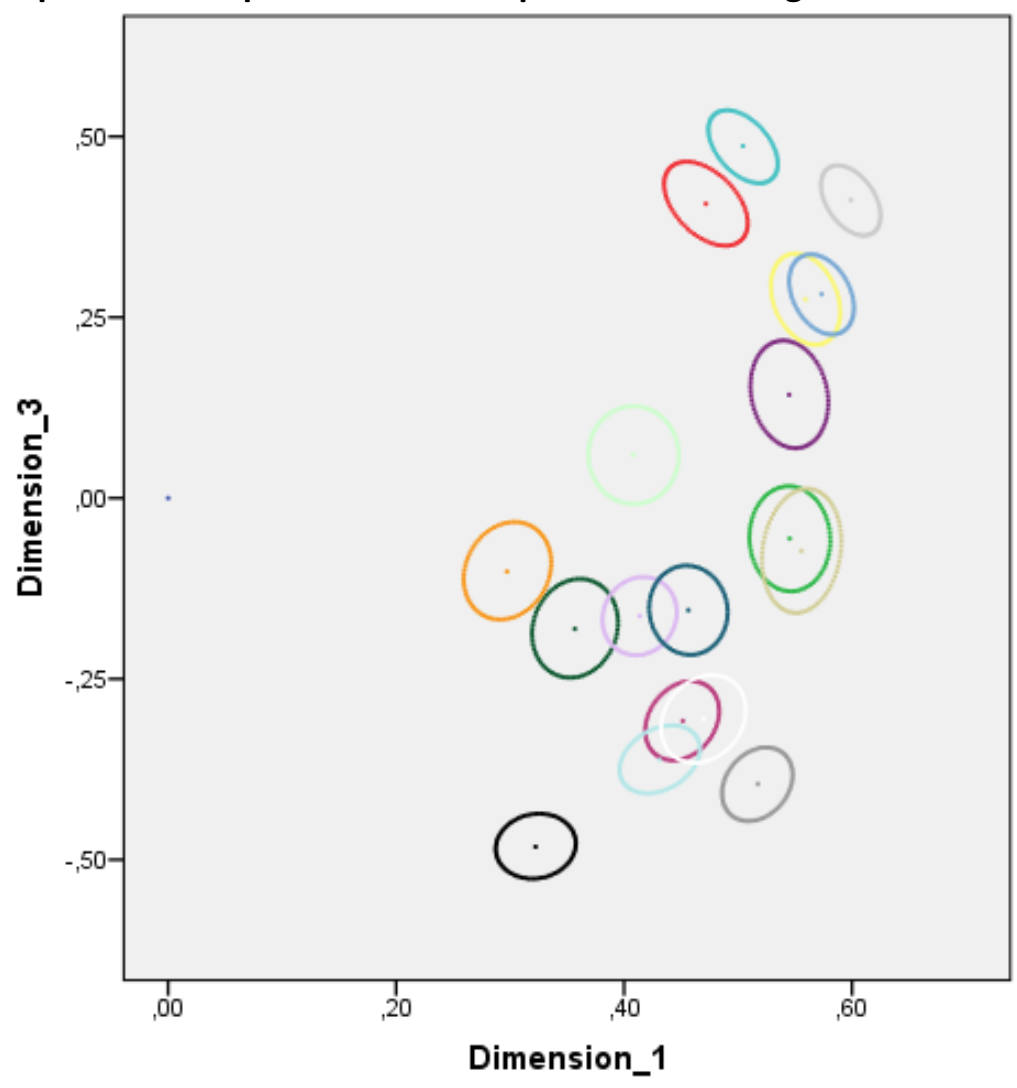

varname

origin

q14_a

q14_b

q14-c

q14_e

q14-f

q14_g

q14_h

Oq16_a

q16_b

q16_c

O16_d

q16_e

q17_a

q17_b

Oq17c

q17_d

q17_e q14_a: Ideas from management. q14_b: Ideas from staff.

q14_c: Examples of best practice by another government organization. q14_d: Professional organizations. q14_e: Visits to conferences. q14_f: Enterprises as suppliers. q14_g: Enterprises as clients or users. q14_h: Citizens as clients or users. q16_a: Mandated decrease in your organization's budget.

q16_b: Mandated increase in your organization's budget.

q16 c: New laws or regulations. q16_d: New policy priorities. q16_e: Mandated introduction of new e-government or online services. q17_a: Managers support trial-anderror testing of new ideas.

q17 b: Managers take active role in developing and implementing innov. q17_c: Staff has incentives to think of new ideas and take part in develop. q17_d: Users are involved in the design or planning of new or improved services.

q17_e: New or improved services are evaluated after completion. 
Graphic 3a. Component 1 vs. Component 4. Eigenvalues.

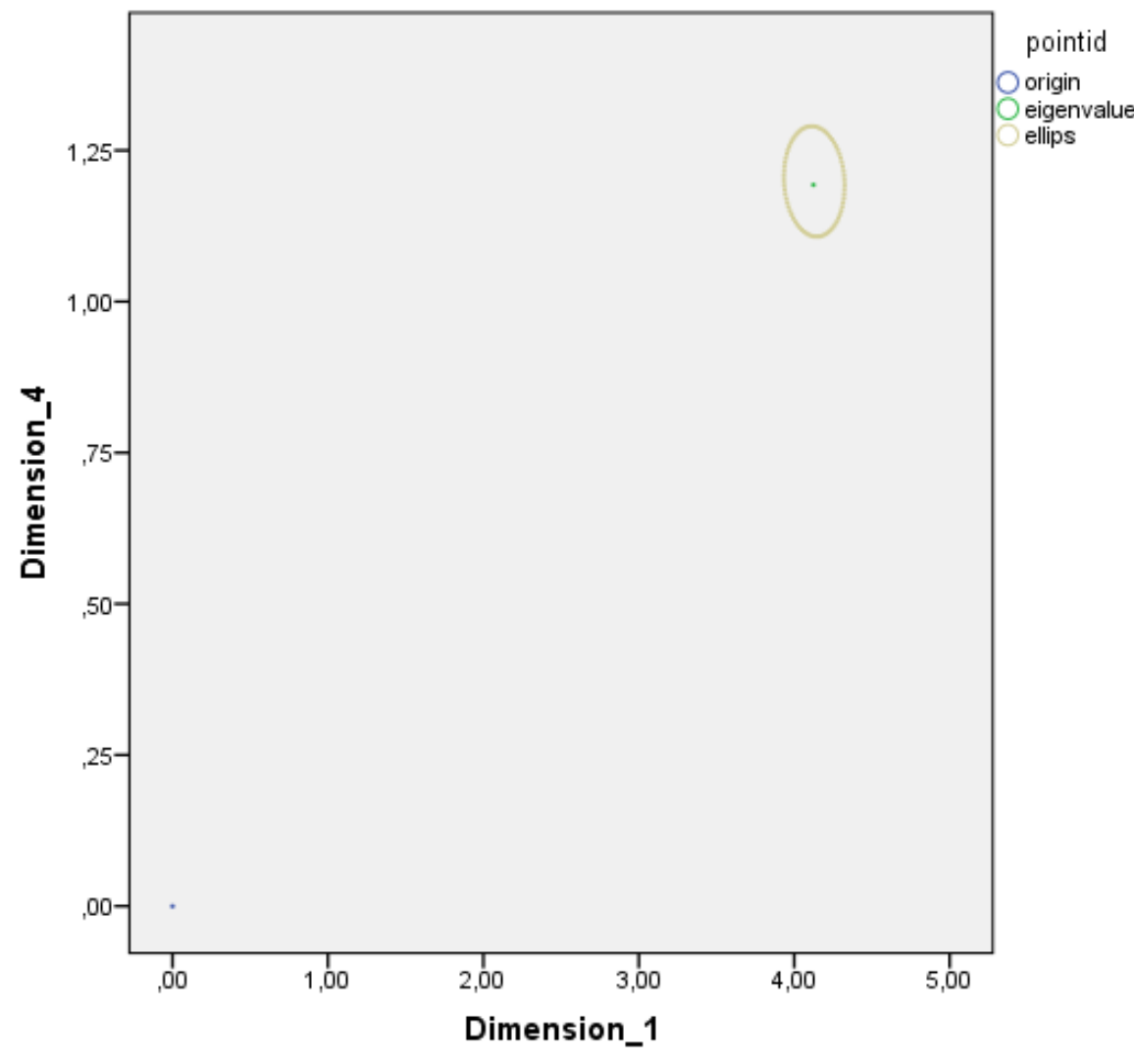

Graphic 3b. Component 1 vs. Component 4. Loadings.

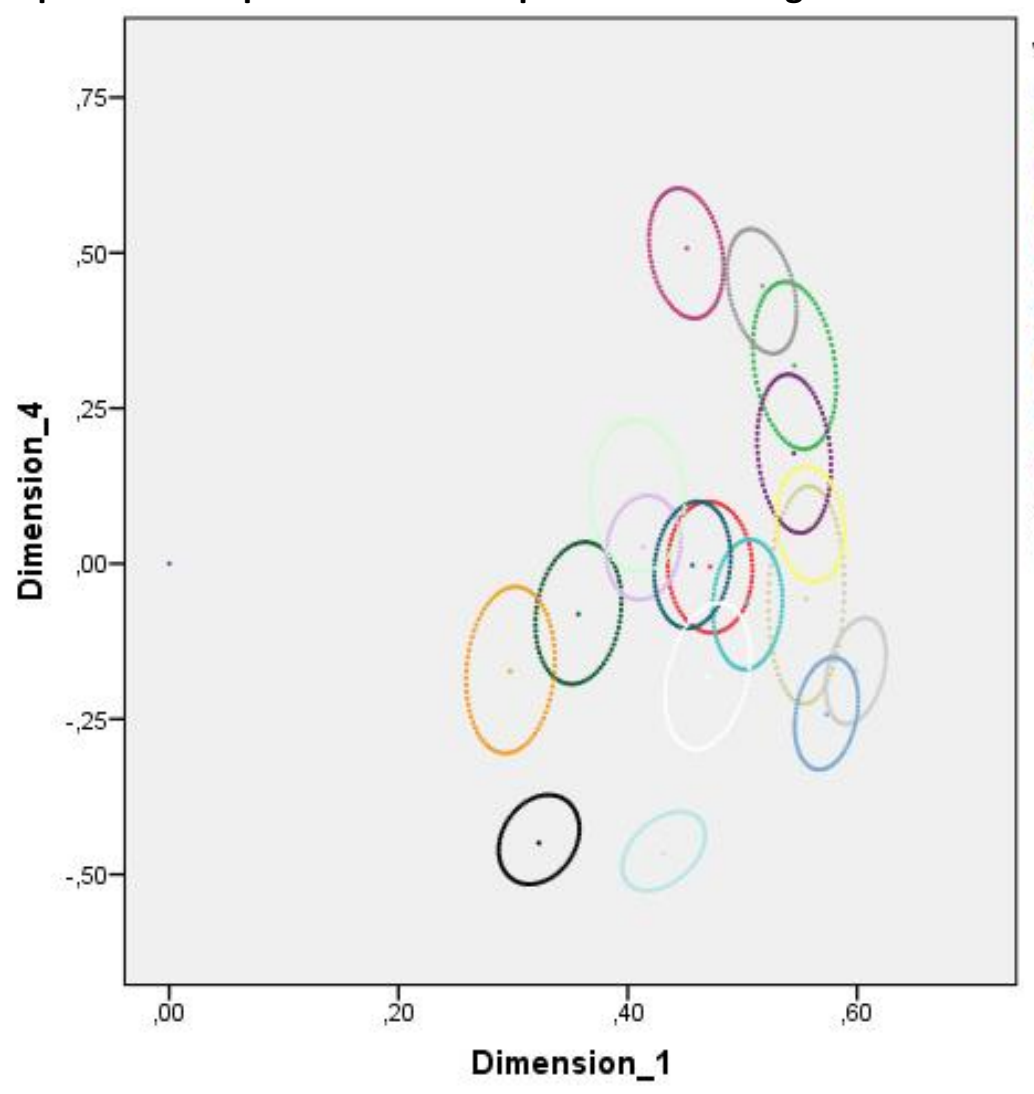

q14_a: Ideas from management. q14_b: Ideas from staff.

q14_c: Examples of best practice by another government organization. q14_d: Professional organizations. q14_e: Visits to conferences. q14_f: Enterprises as suppliers. q14_g: Enterprises as clients or users. q14_h: Citizens as clients or users. q16_a: Mandated decrease in your organization's budget.

q16_b: Mandated increase in your organization's budget.

q16_c: New laws or regulations. q16_d: New policy priorities. q16_e: Mandated introduction of new e-government or online services. q17_a: Managers support trial-anderror testing of new ideas.

q17_b: Managers take active role in developing and implementing innov. q17_c: Staff has incentives to think of new ideas and take part in develop. q17_d: Users are involved in the design or planning of new or improved services.

q17_e: New or improved services are evaluated after completion. 
Graphic 4a. Component 2 vs. Component 3. Eigenvalues.

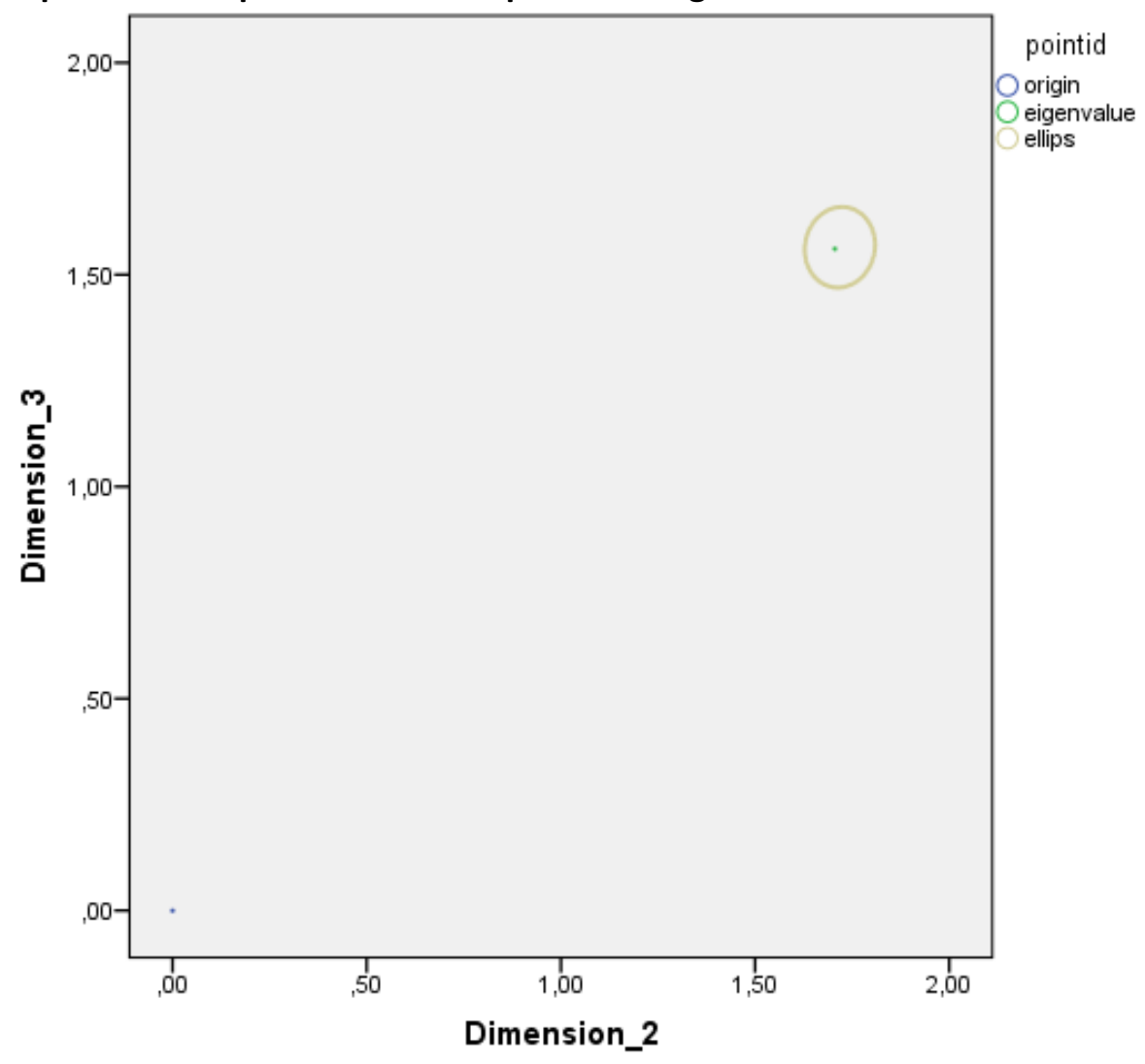

Graphic 4b. Component 2 vs. Component 3. Loadings.

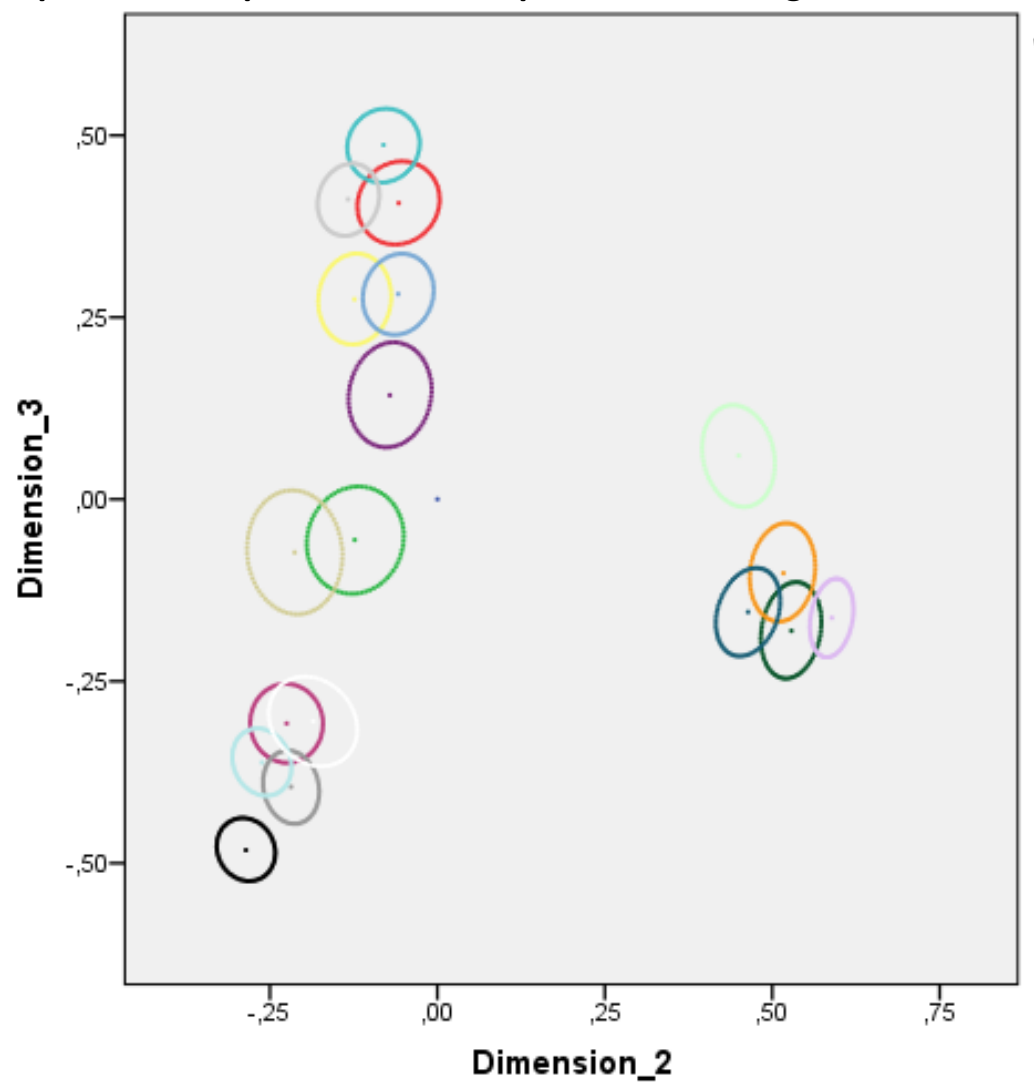

q14_a: Ideas from management. q14_b: Ideas from staff. q14_c: Examples of best practice by another government organization. q14_d: Professional organizations. q14_e: Visits to conferences. q14_f: Enterprises as suppliers. q14_g: Enterprises as clients or users. q14_h: Citizens as clients or users. q16_a: Mandated decrease in your organization's budget. q16_b: Mandated increase in your organization's budget. q16_c: New laws or regulations. q16_d: New policy priorities. q16_e: Mandated introduction of new e-government or online services. q17_a: Managers support trial-anderror testing of new ideas. q17_b: Managers take active role in developing and implementing innov. q17_c: Staff has incentives to think of new ideas and take part in develop. q17_d: Users are involved in the design or planning of new or improved services.

q17_e: New or improved services are evaluated after completion. 
Graphic 5a. Component 2 vs. Component 4. Eigenvalues.

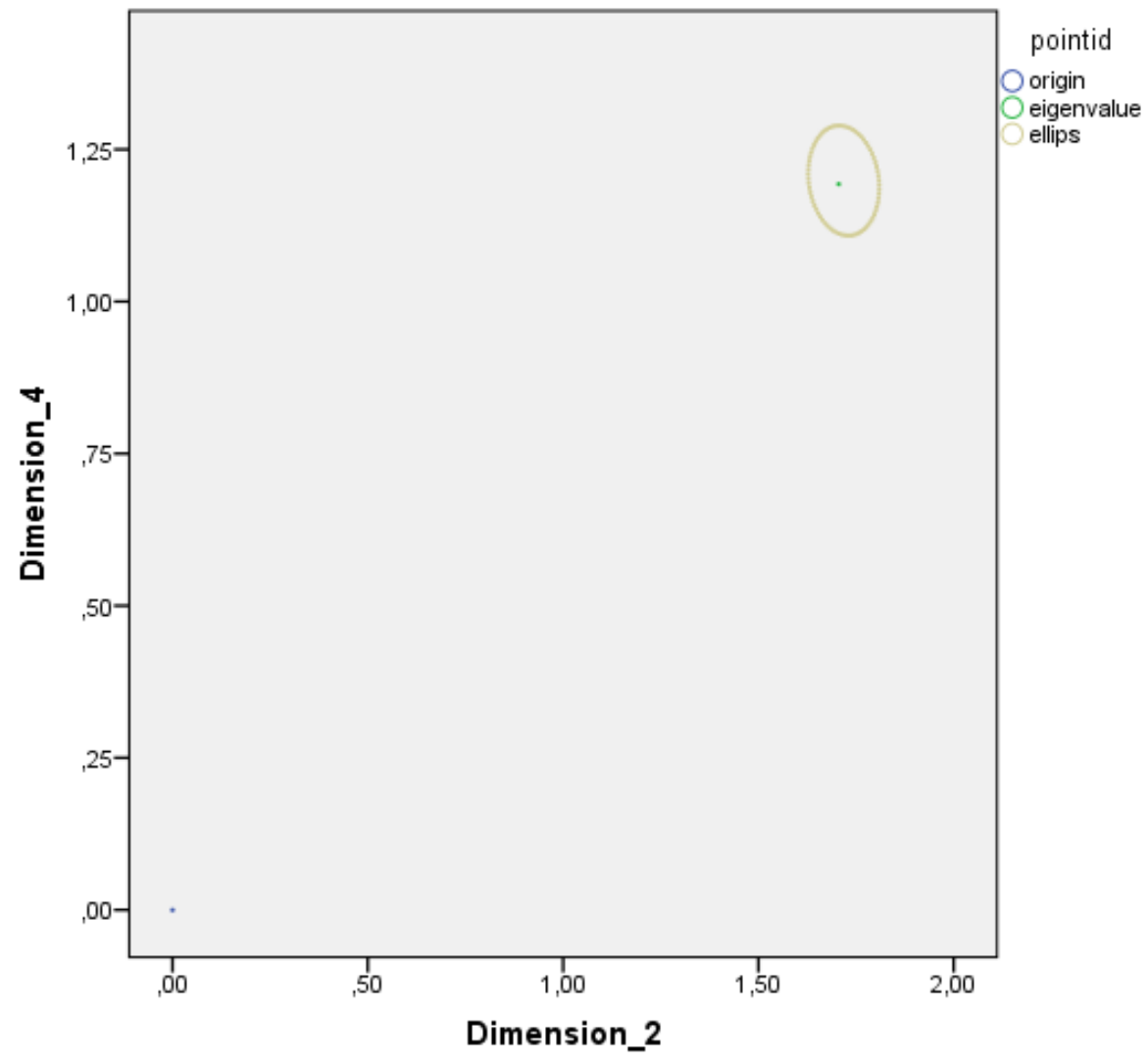

Graphic 5b. Component 2 vs. Component 4. Loadings.

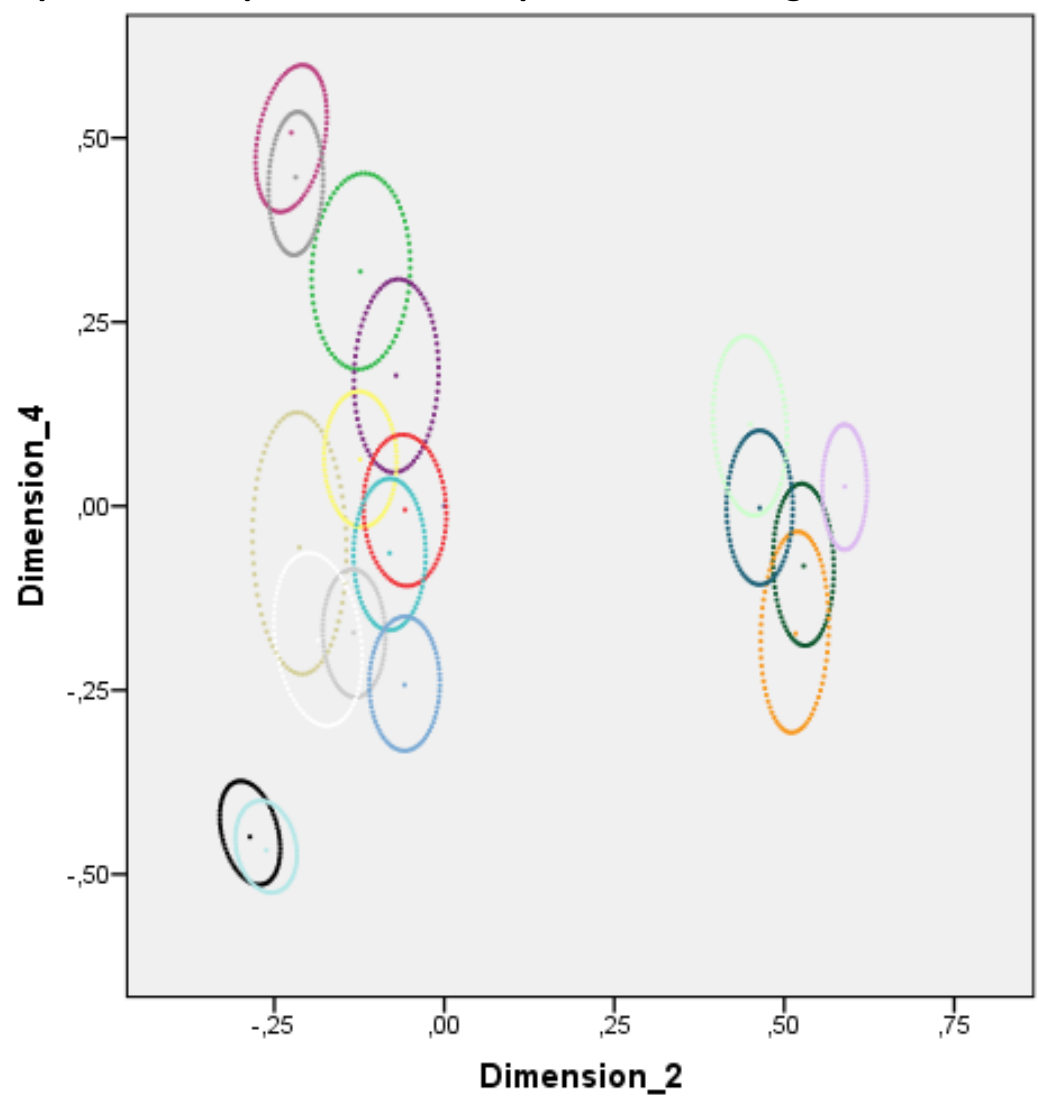

q14_a: Ideas from management. q14_b: Ideas from staff.

q14_c: Examples of best practice by another government organization. q14_d: Professional organizations. q14_e: Visits to conferences. q14_f: Enterprises as suppliers. q14_g: Enterprises as clients or users. q14_h: Citizens as clients or users. q16_a: Mandated decrease in your organization's budget.

q16_b: Mandated increase in your organization's budget.

q16_c: New laws or regulations. q16_d: New policy priorities. q16_e: Mandated introduction of new e-government or online services. q17_a: Managers support trial-anderror testing of new ideas. q17 b: Managers take active role in developing and implementing innov. q17_c: Staff has incentives to think of new ideas and take part in develop. q17_d: Users are involved in the design or planning of new or improved services.

q17_e: New or improved services are evaluated after completion.

Graphic 6a. Component 3 vs. Component 4. Eigenvalues. 


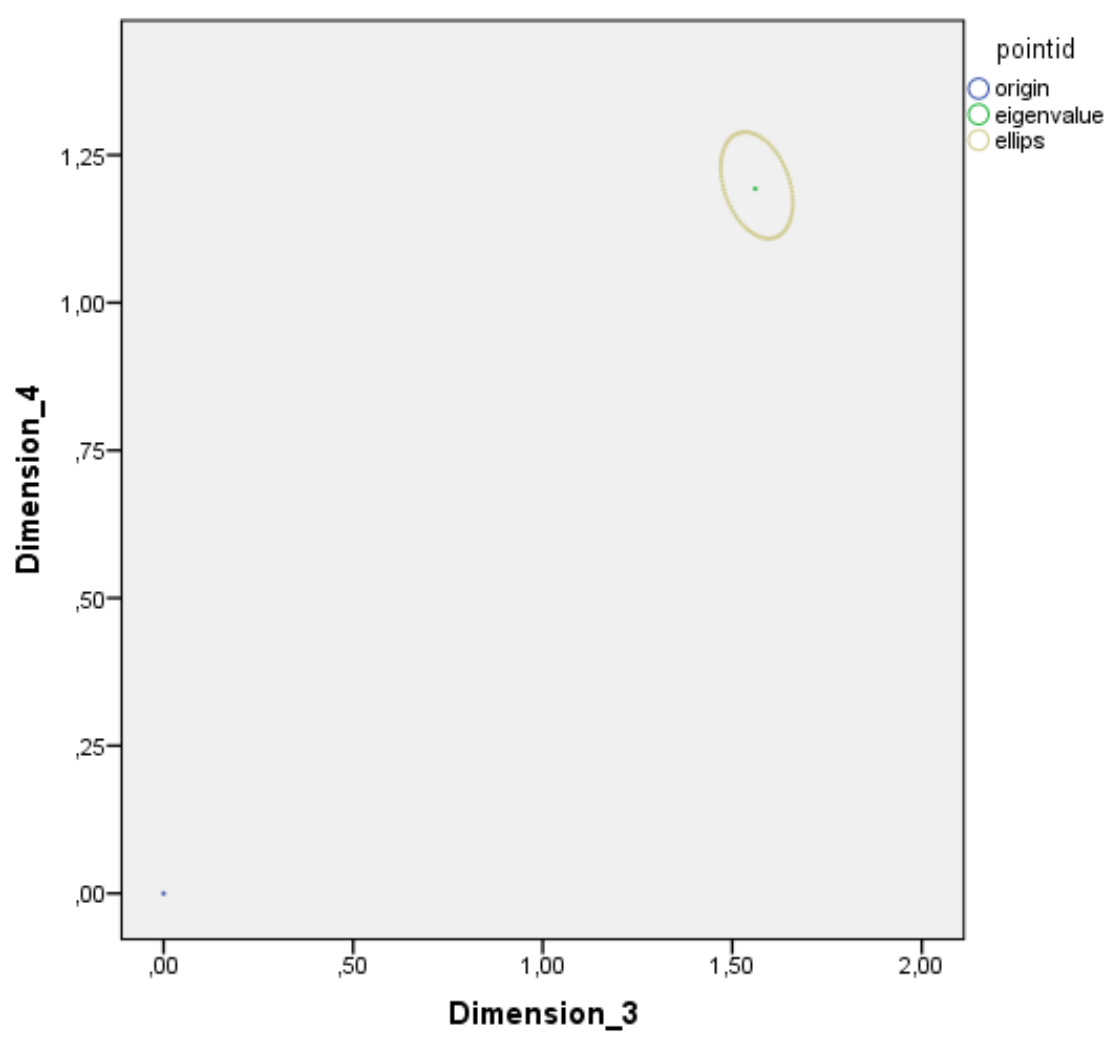

Graphic 6b. Component 3 vs. Component 4. Loadings.

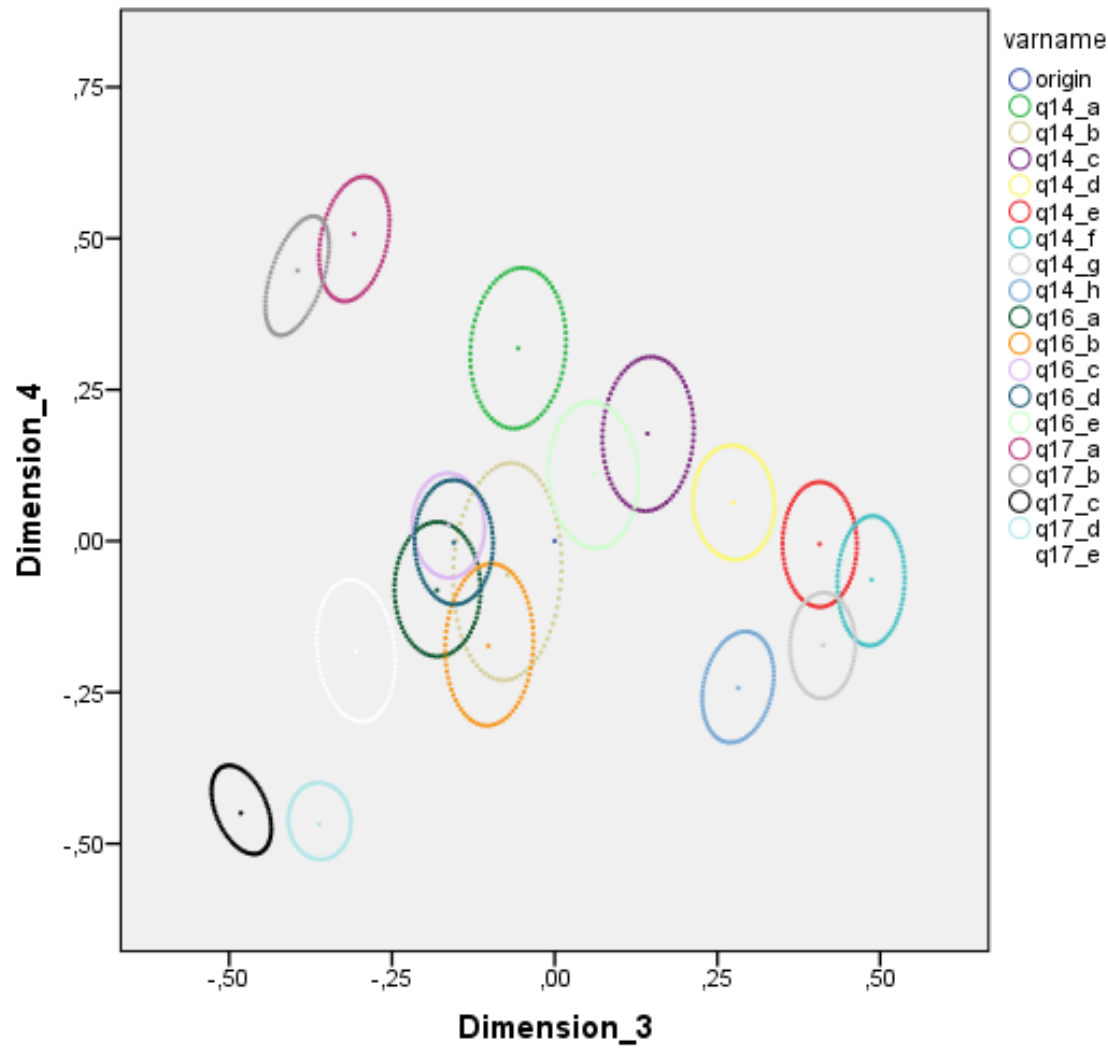

q14_a: Ideas from management. q14_b: Ideas from staff.

q14_c: Examples of best practice by another government organization. q14_d: Professional organizations. q14_e: Visits to conferences. q14_f: Enterprises as suppliers. q14_g: Enterprises as clients or users. q14_h: Citizens as clients or users. q16_a: Mandated decrease in your organization's budget.

q16_b: Mandated increase in your organization's budget.

q16_c: New laws or regulations. q16_d: New policy priorities. q16_e: Mandated introduction of new e-government or online services. q17_a: Managers support trial-anderror testing of new ideas.

q17_b: Managers take active role in developing and implementing innov. q17_c: Staff has incentives to think of new ideas and take part in develop. q17_d: Users are involved in the design or planning of new or improved services.

q17_e: New or improved services are evaluated after completion. 
Table. Marginal effects at representative values of size and area of responsibility ${ }^{\text {a) }}$

\begin{tabular}{|c|c|c|c|c|c|c|}
\hline $\begin{array}{l}\text { External sources of information } \\
\text { (conditioned probability) }\end{array}$ & $10-49$ & $50-99$ & $100-249$ & $250-499$ & $500-999$ & $\begin{array}{c}1000 \text { or } \\
\text { more }\end{array}$ \\
\hline Local & $\mathbf{0 , 0 6 0 0}$ & $\mathbf{0 , 0 6 0 6}$ & $\mathbf{0 , 0 6 0 6}$ & $\mathbf{0 , 0 5 8 6}$ & $\mathbf{0 , 0 5 7 1}$ & $\mathbf{0 , 0 5 4 5}$ \\
\hline Regional & $\mathbf{0 , 0 6 0 6}$ & $\mathbf{0 , 0 5 9 5}$ & $\mathbf{0 , 0 6 0 1}$ & $\mathbf{0 , 0 5 6 1}$ & $\mathbf{0 , 0 5 4 3}$ & $\mathbf{0 , 0 5 1 5}$ \\
\hline National & $\mathbf{0 , 0 6 0 6}$ & $\mathbf{0 , 0 5 9 6}$ & $\mathbf{0 , 0 6 0 1}$ & $\mathbf{0 , 0 5 6 2}$ & $\mathbf{0 , 0 5 4 4}$ & $\mathbf{0 , 5 1 6}$ \\
\hline $\begin{array}{l}\text { External sources of information } \\
\text { (selection probability) }\end{array}$ & $10-49$ & $50-99$ & $100-249$ & $250-499$ & $500-999$ & $\begin{array}{c}1000 \text { or } \\
\text { more }\end{array}$ \\
\hline Local & $\mathbf{0 , 0 3 5 5}$ & $\mathbf{0 , 0 3 2 1}$ & $\mathbf{0 , 0 3 3 4}$ & $\mathbf{0 , 0 2 6 8}$ & $\mathbf{0 , 0 2 4 5}$ & $\mathbf{0 , 0 2 1 0}$ \\
\hline Regional & $\mathbf{0 , 0 3 2 5}$ & $\mathbf{0 , 0 2 8 6}$ & $\mathbf{0 , 0 3 0 0}$ & $\mathbf{0 , 0 2 3 1}$ & $\mathbf{0 , 0 2 0 8}$ & $\mathbf{0 , 0 1 7 5}$ \\
\hline National & $\mathbf{0 , 0 3 2 6}$ & $\mathbf{0 , 0 2 8 7}$ & $\mathbf{0 , 0 3 0 1}$ & $\mathbf{0 , 0 2 3 2}$ & $\mathbf{0 , 0 2 0 9}$ & $\mathbf{0 , 0 1 7 5}$ \\
\hline
\end{tabular}

a) $d y / d x$ are for a one unit increase, predicted for conditional probability in Heckman's probit estimation.

b) Effects highlighted in bold are statistically significant at a minimum of $99 \%$ confidence level.

Table. Marginal effects at representative values of size and area of responsibility ${ }^{\text {a) }}$

\begin{tabular}{|c|c|c|c|c|c|c|}
\hline $\begin{array}{l}\text { Political and legislative factors } \\
\text { (conditioned probability) }\end{array}$ & $10-49$ & $50-99$ & $100-249$ & $250-499$ & $500-999$ & $\begin{array}{c}1000 \text { or } \\
\text { more }\end{array}$ \\
\hline Local & $-0,0042$ & $-0,0053$ & $-0,0049$ & $-0,0067$ & $-0,0073$ & $-0,0081$ \\
\hline Regional & $-0,0052$ & $-0,0063$ & $-0,0059$ & $-0,0076$ & $-0,0082$ & $-0,0089$ \\
\hline National & $-0,0051$ & $-0,0062$ & $-0,0059$ & $-0,0076$ & $-0,0081$ & $-0,0089$ \\
\hline $\begin{array}{l}\text { Political and legislative factors } \\
\text { (selection probability) }\end{array}$ & $10-49$ & $50-99$ & $100-249$ & $250-499$ & $500-999$ & $\begin{array}{c}1000 \text { or } \\
\text { more }\end{array}$ \\
\hline Local & $\mathbf{0 , 0 1 3 5}$ & $\mathbf{0 , 0 1 2 1}$ & $\mathbf{0 , 0 1 2 6}$ & $\mathbf{0 , 0 1 0 1}$ & $\mathbf{0 , 0 0 9 3}$ & $\mathbf{0 , 0 0 8 0}$ \\
\hline Regional & $\mathbf{0 , 0 1 2 3}$ & $\mathbf{0 , 0 1 0 8}$ & $\mathbf{0 , 0 1 1 4}$ & $\mathbf{0 , 0 0 8 7}$ & 0,0079 & 0,0066 \\
\hline National & $\mathbf{0 , 0 1 2 3}$ & $\mathbf{0 , 0 1 0 8}$ & $\mathbf{0 , 0 1 1 4}$ & $\mathbf{0 , 0 0 8 8}$ & 0,0079 & 0,0066 \\
\hline
\end{tabular}

a) $d y / d x$ are for a one unit increase, predicted for conditional probability in Heckman's probit estimation.

b) Effects highlighted in bold are statistically significant at a minimum of $90 \%$ confidence level.

Table. Marginal effects at representative values of size and area of responsibility ${ }^{\text {a) }}$

\begin{tabular}{|c|c|c|c|c|c|c|}
\hline $\begin{array}{l}\text { Active involvement of managers } \\
\text { (conditioned probability) }\end{array}$ & $10-49$ & $50-99$ & $100-249$ & $250-499$ & $500-999$ & $\begin{array}{c}1000 \text { or } \\
\text { more }\end{array}$ \\
\hline Local & $\mathbf{0 , 0 3 2 7}$ & $\mathbf{0 , 0 3 1 7}$ & $\mathbf{0 , 0 3 2 2}$ & $\mathbf{0 , 0 2 8 6}$ & $\mathbf{0 , 0 2 7 0}$ & $\mathbf{0 , 0 2 4 3}$ \\
\hline Regional & $\mathbf{0 , 0 3 1 8}$ & $\mathbf{0 , 0 2 9 8}$ & $\mathbf{0 , 0 3 0 6}$ & $\mathbf{0 , 0 2 5 9}$ & $\mathbf{0 , 0 2 4 1}$ & $\mathbf{0 , 0 2 1 4}$ \\
\hline National & $\mathbf{0 , 0 3 1 9}$ & $\mathbf{0 , 0 2 9 8}$ & $\mathbf{0 , 0 3 0 7}$ & $\mathbf{0 , 0 2 6 0}$ & $\mathbf{0 , 0 2 4 2}$ & $\mathbf{0 , 0 2 1 5}$ \\
\hline $\begin{array}{l}\text { Active involvement of managers } \\
\text { (selection probability) }\end{array}$ & $10-49$ & $50-99$ & $100-249$ & $250-499$ & $500-999$ & $\begin{array}{c}1000 \text { or } \\
\text { more }\end{array}$ \\
\hline Local & $\mathbf{0 , 0 3 9 2}$ & $\mathbf{0 , 0 3 5 4}$ & $\mathbf{0 , 0 3 6 8}$ & $\mathbf{0 , 0 2 9 6}$ & $\mathbf{0 , 0 2 7 1}$ & $\mathbf{0 , 0 2 3 2}$ \\
\hline Regional & $\mathbf{0 , 0 3 5 8}$ & $\mathbf{0 , 0 3 1 5}$ & $\mathbf{0 , 0 3 3 1}$ & $\mathbf{0 , 0 2 5 4}$ & $\mathbf{0 , 0 2 3 0}$ & $\mathbf{0 , 0 1 9 3}$ \\
\hline National & $\mathbf{0 , 0 3 5 9}$ & $\mathbf{0 , 0 3 1 6}$ & $\mathbf{0 , 0 3 3 2}$ & $\mathbf{0 , 0 2 5 5}$ & $\mathbf{0 , 0 2 3 1}$ & $\mathbf{0 , 0 1 9 4}$ \\
\hline
\end{tabular}

a) $d y / d x$ are for a one unit increase, predicted for conditional probability in Heckman's probit estimation.

b) Effects highlighted in bold are statistically significant at a minimum of $95 \%$ confidence level. 
Table. Marginal effects at representative values of size and area of responsibility ${ }^{\text {a) }}$

\begin{tabular}{|c|c|c|c|c|c|c|}
\hline $\begin{array}{l}\text { User and staff participation } \\
\text { (conditioned probability) }\end{array}$ & $10-49$ & $50-99$ & $100-249$ & $250-499$ & $500-999$ & $\begin{array}{c}1000 \text { or } \\
\text { more }\end{array}$ \\
\hline Local & $\mathbf{0 , 0 4 3 7}$ & $\mathbf{0 , 0 4 4 3}$ & $\mathbf{0 , 0 4 4 3}$ & $\mathbf{0 , 0 4 3 1}$ & $\mathbf{0 , 0 4 2 2}$ & $\mathbf{0 , 0 4 0 4}$ \\
\hline Regional & $\mathbf{0 , 0 4 4 3}$ & $\mathbf{0 , 0 4 3 7}$ & $\mathbf{0 , 0 4 4 1}$ & $\mathbf{0 , 0 4 1 5}$ & $\mathbf{0 , 0 4 0 3}$ & $\mathbf{0 , 0 3 8 4}$ \\
\hline National & $\mathbf{0 , 0 4 4 3}$ & $\mathbf{0 , 0 4 3 7}$ & $\mathbf{0 , 0 4 4 1}$ & $\mathbf{0 , 0 4 1 5}$ & $\mathbf{0 , 0 4 0 4}$ & $\mathbf{0 , 0 3 8 5}$ \\
\hline $\begin{array}{l}\text { User and staff participation } \\
\text { (selection probability) }\end{array}$ & $10-49$ & $50-99$ & $100-249$ & $250-499$ & $500-999$ & $\begin{array}{c}1000 \text { or } \\
\text { more }\end{array}$ \\
\hline Local & $\mathbf{0 , 0 2 3 1}$ & $\mathbf{0 , 0 2 0 9}$ & $\mathbf{0 , 0 2 1 7}$ & $\mathbf{0 , 0 1 7 4}$ & $\mathbf{0 , 0 1 6 0}$ & $\mathbf{0 , 0 1 3 7}$ \\
\hline Regional & $\mathbf{0 , 0 2 1 1}$ & $\mathbf{0 , 0 1 8 6}$ & $\mathbf{0 , 0 1 9 5}$ & $\mathbf{0 , 0 1 5 0}$ & $\mathbf{0 , 0 1 3 5}$ & $\mathbf{0 , 0 1 1 4}$ \\
\hline National & $\mathbf{0 , 0 2 1 2}$ & $\mathbf{0 , 0 1 8 6}$ & $\mathbf{0 , 0 1 9 6}$ & $\mathbf{0 , 0 1 5 1}$ & $\mathbf{0 , 0 1 3 6}$ & $\mathbf{0 , 0 1 1 4}$ \\
\hline
\end{tabular}

a) $d y / d x$ are for a one unit increase, predicted for conditional probability in Heckman's probit estimation.

b) Effects highlighted in bold are statistically significant at a minimum of $99 \%$ confidence level. 
Chapter 2. The role of external information sources for service innovation in public sector 


\section{Introduction}

One of the objectives of the present study is to contribute to fill in the gap of empirical work by using a quantitative approach to analyse a key aspect in factors driving public services innovation: the use of external sources of information in innovation development.

The discussion about using externals sources for better innovation performance has a basic reference in studies on manufacturing industry firms (e.g. Cassiman \& Veugelers, 2006; Laursen \& Salter, 2006; Sofka \& Grimpe 2010) where it was observed a shift in their innovation production process, from a closed model, mostly reliant on internal activities of $R \& D$, to an open model, which allows and support integration of knowledge from sources external to the organisation, as a way to enhance the limited internal capabilities to innovate. Recently and following the development of the open model approach in the manufacturing sector, the use of external sources as a factor explaining differences in innovation performance has been taken to the services sector study field. As a natural step in this conceptual development, our article tests the role of external sources in public services innovation by measuring the effect of the use of external sources on public organisations' innovation performance.

A different framework is needed for public services, since drivers of public innovation are found to be out of market incentives - usually aiming innovation in private sector - and the strategies towards its development and implementation are not typically relying on internal $R \& D$ activities, like in the case of product innovation among manufacturing industry firms. Learning from the outside means relationships with other organizations (public, private third sector) and citizens than can bring the idea and knowledge for innovation on top of the internal generation of ideas and knowledge from managers or front-line staff.

The chapter is organized as follows. After this introductory part, section 2 contains a summary of literature review where the concept of open innovation and use of external sources is explained. After that it is there proposed a theoretical framework based on the specificities of public sector innovation. Section 3 presents the research hypothesis addressing the empirical part of our study. Section 4 widely describes the methodology that will be applied for testing our hypothesis and also the data base in use. In section 5 results are presented, interpreted and discussed, and the concluding statements correspond to section 6 .

\section{External sources for public innovation? A specific framework}

Many academics agree to say that studies about public sector innovation are still on an early stage (e.g. Vigoda-Gadot et al., 2008; Alves, 2013; Osborne \& Brown, 2013). To advance on the development of the subject, drawing from private sector studies on innovation has proven to be useful for providing a frame of analysis. However, this approach demands a revised conceptual frame in order to adequate to the particular specifities of the public sector. In attention to that, we start to establish a conceptual frame by reviewing some studies based on evidence from private sector firms. Then we focus on public sector innovation specifities acknowledged in public sector innovation studies. Thus, our frame of analysis will be focused 
on public sector specifities, but having as reference and starting point the innovation dynamics already observed in private business sector.

\subsection{The open model: using external sources for innovation}

The idea of incorporating external sources to the innovation process (rather than only relying on internal R\&D) has been repeatedly issued in the literature about innovation. From different approaches, studies have pointed to the importance of taking advantage from external sources to shift innovation benefits (e.g. von Hippel, 1988; Cohen \& Levinthal, 1990). However, competing markets, integration, globalization and development of ICTs have made the use of external sources almost imperative (Porter \& Stern, 2001; Rigby \& Zook, 2002; Chesbrough, 2003). On that matter, the conceptual construct known as 'open innovation' has emerged as a new trend in academic studies to explain the dynamics of the innovation process nowadays (Gassman, 2006).

There is a widening tendency about focusing firm behavior studies on openness and interaction, strongly suggesting that the link between the firm and its external environment can play an important role in shaping innovation performance. For that reason, firms should shift their R\&D efforts to the outside by making cooperation agreements, looking for publicly available information, taking part in networks, going to universities and research institutes, etc. in order to reach a bigger pool of market opportunities (Nelson \& Winter, 1982; Metcalfe, 1994; Sakkab, 2002).

On the other hand, the multiple concepts and approaches brought together in open innovation makes it a blurry concept that complicates the task of defining a consistent analytical frame (Dahlander \& Gann, 2010). Nonetheless, among the many identified dimensions, modes and levels of openness (Gassman \& Enkel, 2004; Dahlander \& Gann, 2010), the use of knowledge and information gathered from external sources is a primary feature of an open process. Thus, the use of external sources of knowledge and information is frequently used in studies to make reference to openness in firms' innovation processes (e.g. Laursen \& Salter, 2006; Santamaria et al., 2009; Sofka \& Grimpe, 2010).

Studies on manufacturing industry suggest that strategies of innovation based on making use of knowledge and information from external sources lead to better results in innovation performance and - therefore - to a greater value production. Widely cited, the work of Laursen and Salter (2006) finds that searching outside the organization does improve innovation performance and Cassiman and Veugelers (2006) get to similar conclusions. Another important finding in them is that depending on the specific context of the firm, external search activities not only complement internal development efforts but they could also work as a substitute of internal R\&D. This is not to mean that firms should abandon inputs to innovation provided by internal sources - which are still fundamental to the innovation process - but to put an emphasis on the potential of an adequate strategy of external search (Pisano, 1990; Veugelers, 1997; Rigby \& Zook, 2002; Cassiman \& Veugelers, 2006; Grimpe \& Kaiser, 2010). Moreover, Windrum et al. (2013) stress the importance of external sources for incremental innovation in Europe, what has also been tested in the case of European services (Battisti et al., 2014). 
Efforts have been made to translate ideas on the use of external sources and the open model to a field that counts on the characteristics of services business and products. For many years the study of innovation has been biased to technology development in a manufacturing industry context, which has led to concepts and ideas rigidly defined fitting industrial activities (Miles, 2007). However, innovation in service activities demands a wider conceptualization of service products and delivery, activities of R\&D and how they are organized inside the firm and also the ways in which service firms can link and engage to external agents for gathering knowledge and information (Gallouj, 2002; Hipp \& Grupp, 2005; Rubalcaba, 2006; Miles, 2007). In fact, there are important difficulties in the applicability of conventional definitions of R\&D to much of the innovation activities in services (Djellal et al., 2003); these activities involve knowledge and processes different than those involved in manufacturing firms (Djellal et al., 2003; Miles, 2007).

While studies on manufacturing firms give importance to $R \& D$ as the main source where the innovation process rely, service firms studies does not give the same relevance to conventional $R \& D$ as driving service sector innovation. This is not to mean that service sector firms are not conducting R\&D; they are, in fact ${ }^{10}$. But, the proportion of activities in service R\&D is still fairly low compared to the weight of the service sector economic value (Evangelista, 2000; Rubalcaba, 2006; Miles, 2007). Innovation in services mostly relies on sources that are not directly related to R\&D (Barras, 1990; Gallouj, 1998; Howells, 2000; Miles \& Tether, 2003; Miles, 2007; Tether, 2005; Rubalcaba et al., 2012)

There is a general pressure above business organizations to become more innovative and that is also true for service sector organizations. A competing market is taking service firms - just as manufacturing firms - to look for competitiveness and differentiation, and innovation is certainly a powerful tool to get it. Furthermore, the trend to greater liberalization in services trade adds pressure to service firms to engage in innovation activities (Miozzo \& Soete, 2001; Miles, 2007). The open innovation model and the use of external sources of knowledge is therefore a promising way to enhance innovation performance for service firms (Gallego et al., 2013).

It is a new interest in service innovation studies to observe if external sources of knowledge and information might be as important as internal development sources, like studies on manufacturing industry suggest (Chesbrough, 2011). Battisti et al. (2014) prove the role of external sources for incremental innovation in private European firms, but not for radical innovation, and the importance of public-private innovation networks in services (Gallouj et al., 2013) proves the role of networking and collaboration between different agents: a dimension of the service innovation concept (Rubalcaba et al., 2012).

10 For instance, the National Science Foundation reported in 2005 those service sectors to which substantial R\&D is attributed in the United States. These are sectors carrying professional, scientific and technical services such as computer systems design, scientific R\&D, architecture, engineering and related services (see Miles, 2007) 


\subsection{The role of external sources in public sector services innovation}

We have until now reviewed the use of external sources of knowledge and information as a way to enhance innovation occurring at the business level. Profitability of innovation and declining results from internal efforts for innovation development appear to be the force pushing for an open model towards innovation. However, while competitiveness and profitability have been largely pointed to be at the aim for private sector innovation, these might not be the right ones to explain innovation within public sector organizations. There is a consistent bulk of studies that document drivers and enablers of public innovation attending to the particular nature of the public sector (e.g. Borins 2002; 2006; Halvorsen et al., 2005; Hartley, 2005; Vigoda-Gadot et al., 2005; Potts, 2009; Arundel \& Hollanders, 2011).

\section{Public organizations' boundaries: internal and external information sources.}

As the innovation dynamics evolved in private firms studies so did the way organizations boundaries are defined. Boundaries are dependent on the approach to how organizations relate and build networks with other organizations and agents (Dahlander\& Gann, 2010). However, thinking of public organizations linking within the same field or sector (e.g. general administration, education, health, housing, environment...) is different from the case of business organizations linking in the same market. Business organizations compete among them and the ways they draw knowledge and information from each other are typically associated to some return that will let a firm to profit from collaboration with another firm (Veugelers, 1997; Chesbrough, 2003; Bonte et al., 2005). On the other hand, public sector organizations are not competitors: The special role and function of the public sector in society make public organizations subject to a democratic, political rule, which implies that the organizational context is normative and that democracy is the governing principle (Langergaard \& Scheuer, 2009: 3).

Langergaard and Scheuer (2009) refer to the work of Hartley (2005) and Hess and Adams (2007) for explaining different approaches to understand improvement and innovation in public sector, which have succeeded one another in the last decades as views on policy and public administration changed. These are called: Traditional Public Administration, New Public Management and Networked Governance. Traditional Public Administration sees public sector as embedded within a stable context and public organizations as a hierarchy (or bureaucracy) resting on legal rational authority and oriented towards procedures. New Public Management replaces bureaucracy with quasi-market conditions, challenging the hierarchical view of the public sector and separating organizations' producing units from political influence as far as possible. Networked Governance shows a shift to more networked forms of governance in the public sector, where public (beneficiaries of public services) also takes the role of co-producer of service and innovation. Referenced studies highlight a recent tendency to approach to improvement dynamics in public sector under a networked view. As pointed by Langergaard and Scheuer, a hierarchical understanding of the public sector, where organizations are seen as passive executors of political decisions - like in the Traditional Administration approach, is important for our political self-understanding; however, the tendency is today to see public organizations in terms both of markets, hierarchies and networks. 


\section{On the specificities of external sources in public sector}

To test for patterns of open innovation among public sector organizations has not the same implications than it does for the manufacturing sector or even for the private services sector. However, it is a useful model for advancing in understanding public sector innovation. Table 1 depicts conceptual differences framing each reviewed sector.

Table 1. Conceptual framework for innovation in public sector: a comparative view

\begin{tabular}{|c|c|c|c|}
\hline & Manufacturing Business & Service Business & Public Organizations \\
\hline $\begin{array}{l}\text { Incentive } \\
\text { system }\end{array}$ & Market & Market & $\begin{array}{l}\text { Non-market } \\
\text { Political cycle }\end{array}$ \\
\hline $\begin{array}{l}\text { Internal } \\
\text { sources }\end{array}$ & $\begin{array}{l}\text { - Internal activities of } \\
\text { R\&D. }\end{array}$ & $\begin{array}{l}\text { - Internal activities of R\&D } \\
\text { (mostly in ICT services and } \\
\text { median and large firms). }\end{array}$ & $\begin{array}{l}\text { - Ideas from authorities } \\
\text { (head managers), middle- } \\
\text { level managers and staff. }\end{array}$ \\
\hline $\begin{array}{l}\text { External } \\
\text { sources }\end{array}$ & $\begin{array}{l}\text { - Publicly available } \\
\text { information and } \\
\text { research conducted } \\
\text { outside the organisation. } \\
\text { - User /customer driven } \\
\text { innovation. }\end{array}$ & $\begin{array}{l}\text { - Knowledge intensive } \\
\text { services and innovation } \\
\text { networks. } \\
\text { - User/customer driven } \\
\text { innovation. }\end{array}$ & $\begin{array}{l}\text { - Information from } \\
\text { enterprises and citizens in } \\
\text { the role of service users. } \\
\text { - Information and } \\
\text { knowledge provided by } \\
\text { professional organisations, } \\
\text { knowledge-intensive } \\
\text { services and civil society. }\end{array}$ \\
\hline $\begin{array}{l}\text { Internal \& } \\
\text { external } \\
\text { combinations }\end{array}$ & $\begin{array}{l}\text { - Collaboration } \\
\text { agreements on R\&D with } \\
\text { other public/private } \\
\text { organisations }\end{array}$ & $\begin{array}{l}\text { - Internally and externally } \\
\text { generated information } \\
\text { and knowledge (more } \\
\text { 'concept' focused). } \\
\text { - Multi-agent frameworks }\end{array}$ & $\begin{array}{l}\text { - Public procurement } \\
\text { - Multi-agent frameworks }\end{array}$ \\
\hline $\begin{array}{l}\text { Innovation } \\
\text { modes }\end{array}$ & $\begin{array}{l}\text { - New or substantially } \\
\text { improved products. } \\
\text { - New or substantially } \\
\text { improved production } \\
\text { processes. } \\
\text { - Organisational and } \\
\text { marketing innovations }\end{array}$ & $\begin{array}{l}\text { - New or substantially } \\
\text { improved services. } \\
\text { - New or substantially } \\
\text { improved ways for service } \\
\text { delivering. } \\
\text { - New ways to promote a } \\
\text { service, influence user } \\
\text { behaviour and new } \\
\text { interfaces. } \\
\text { - Non-technological } \\
\text { innovations play an } \\
\text { important role. }\end{array}$ & $\begin{array}{l}\text { - New or substantially } \\
\text { improved services. } \\
\text { - New or substantially } \\
\text { improved ways for service } \\
\text { delivering. } \\
\text { - Changes in processes } \\
\text { and/or work organisation. } \\
\text { - New ways to interact } \\
\text { (communicate) with } \\
\text { service users and citizens } \\
\text { (emphasis on ICT } \\
\text { applications and } e \text { - } \\
\text { government) }\end{array}$ \\
\hline $\begin{array}{l}\text { Quality/ } \\
\text { intensity of } \\
\text { innovations }\end{array}$ & $\begin{array}{l}\text { - Radical/High impact: } \\
\text { Causes dramatic changes } \\
\text { in market and industry. } \\
\text { - Incremental/Low } \\
\text { impact: Provides new } \\
\text { functions and } \\
\text { improvements. }\end{array}$ & $\begin{array}{l}\text { - Radical/limited number: } \\
\text { New service applications } \\
\text { for new and better ways } \\
\text { of satisfying needs. } \\
\text { - Incremental/higher } \\
\text { number: Improvements on } \\
\text { existing applications; } \\
\text { adaptations. }\end{array}$ & $\begin{array}{l}\text { - New-to-the-whole- } \\
\text { sector/limited number: } \\
\text { Developed and } \\
\text { implemented by first time } \\
\text { among the whole public } \\
\text { sector. } \\
\text { - Previously developed } \\
\text { somewhere else/higher } \\
\text { number: Implemented by }\end{array}$ \\
\hline
\end{tabular}




\begin{tabular}{|l|l|l|l|}
\hline & & $\begin{array}{l}\text { first time within an } \\
\text { organisation, but } \\
\text { implemented by another } \\
\text { one before. }\end{array}$ \\
\hline $\begin{array}{l}\text { Main } \\
\text { Protection } \\
\text { mechanism }\end{array}$ & IPR, patents mainly & $\begin{array}{l}\text { IPR, soft IPR mainly like } \\
\text { copyright, secrecy or } \\
\text { reputation }\end{array}$ & $\begin{array}{l}\text { Reputation, } \\
\text { institutionalisation }\end{array}$ \\
\hline
\end{tabular}

Compared concepts in Table 1 show that while innovation in manufacturing and service business are typically driven by market incentives, public innovation is driven by incentives that do not follow profit and efficiency objectives (named not-market). At the same time, public innovation process is timed by the political cycle. Identified sources for innovation (internal, external or a combination of these two) are shaped by the particular understanding of innovation that dominates in each reviewed sector. Hence, internal activities of R\&D (oriented to product development) are the main source for knowledge among manufacturing business and service business (specially median and large firms and those based on ICT application), while public organizations rely on ideas generated by their management and staff personnel. External sources used by manufacturing firms are found in publicly available knowledge contents and information provided by clients and users (customer driven innovation). Service business typically takes advantage of external sources in the form of knowledge intensive services and innovation networks and also by interaction with clients and users. In turn, external information sources benefit public organizations' innovation in the form of enterprises and organizations providing knowledge services and transferring information, and also by interaction with enterprises, third sector organizations and citizens while these take the role of public service users. Combined (internal-external) sources of information take place, in the case of manufacturing business, under R\&D collaborations with other (public or private) organizations. Service business' combined sources for innovation are identifiable in information developed within a framework where development effort is shared by multiple stake holders (multi-agent), while public innovation is also benefited by combined sources under multi-agent frameworks, and also by procurement contracts where information is generated by interaction of public and private stakeholders.

The dominant understanding of innovation also shape in an important manner the innovations modes recognized in each sector, as this is illustrated in Table 1. On the other hand quality and intensity of innovations is generally approached in the three reviewed sectors attending to their degree of novelty and their potential for creating more market opportunities (reach more users and/or improve service quality, in the case of public innovation).

Under this framework, the existing of external sources in public sector is different to that in private sector as far the incentive systems are different (e.g. mainly non market) and the external sources are heavily connected to citizens and final users, instead of customers or market users. However, the use of external sources in public sector has also some similarities with service innovation in private firms, sharing both the strong role of service delivery and interfaces and interactions, among the different services innovation modes, and the role of networking in service innovation multi-agent frameworks (Gallouj \& Weinstein, 1997; Windrum \& García-Goñi, 2008). 


\section{Three types of knowledge flows}

In Table 2 it is proposed a framework for understanding external sources in public sector innovation. There, sources of knowledge and information for innovation can be seen as internal, external or a combination of these two and they are identified by different kinds of organizations, human resources (agents, individuals), flows of knowledge and contracts that shape the latter.

Table 2. Internal and external sourcing of knowledge for public innovation

\begin{tabular}{|c|c|c|c|}
\hline & Internal-driven & External-driven & $\begin{array}{c}\text { Combined } \\
\text { (internal-external) }\end{array}$ \\
\hline Organizations & Public organizations & $\begin{array}{l}\text { Private firms and third } \\
\text { sector }\end{array}$ & Multi-agent networks \\
\hline Human resources & Managers and staff & Citizens, users, providers & $\begin{array}{l}\text { Groups of civil servants, } \\
\text { and business or civil } \\
\text { actors }\end{array}$ \\
\hline Knowledge flows & $\begin{array}{l}\text { Information extant } \\
\text { outside organizations is } \\
\text { accessed from the inside } \\
\text { of the public sector (e.g., } \\
\text { accessing pools like } \\
\text { libraries or internet } \\
\text { contents, seeking for } \\
\text { examples from other } \\
\text { organizations) }\end{array}$ & $\begin{array}{l}\text { External knowledge is } \\
\text { brought to public } \\
\text { organizations from } \\
\text { external agents (e.g., } \\
\text { professional orgs. } \\
\text { providing to public orgs., } \\
\text { delegated production of } \\
\text { public services) }\end{array}$ & $\begin{array}{l}\text { Joint sourcing: } \\
\text { knowledge developed in } \\
\text { collaboration (e.g. needs } \\
\text { assessment session, } \\
\text { seminars jointly } \\
\text { organized, public-private } \\
\text { innovation networks) }\end{array}$ \\
\hline $\begin{array}{l}\text { Contractual } \\
\text { agreements }\end{array}$ & $\begin{array}{l}\text { Political mandates. } \\
\text { Public administration } \\
\text { and civil servants } \\
\text { contracts. } \\
\text { Intra- and inter } \\
\text { organisational } \\
\text { arrangement. }\end{array}$ & $\begin{array}{l}\text { Supplier contracts. } \\
\text { Public contests and } \\
\text { awards. } \\
\text { Public procurement } \\
\text { traditional simple } \\
\text { contracts (passive role of } \\
\text { public administration in } \\
\text { the conceptualization } \\
\text { creation of the } \\
\text { innovation). }\end{array}$ & $\begin{array}{l}\text { Public services provided } \\
\text { by private or third sector } \\
\text { companies under bi- or } \\
\text { multi-parties contracts. } \\
\text { Public procurement co- } \\
\text { innovation contracts. } \\
\text { Multi-agent networks } \\
\text { with no formal } \\
\text { contracts. }\end{array}$ \\
\hline
\end{tabular}

The interesting value added of this framework can be found in the identification of three different ways of sources creating knowledge flows for public administrations: internal driven, external driven and mixed (combined) innovations. What establish the differences between them is not so much the type of actors participating in the knowledge and information flows, but the directions these flows are formed. In internal driven category public sector staff seeks for information flows inside and outside the public sector but basically as a result of an internal effort. External drive means that the knowledge is generated and transmitted from external sources, whether private firms, citizens or third sector organizations. Combined means that there are some established formal or non-formal cooperation agreements between different actors that co-produce the knowledge in an interactive way. In "internal driven" and "external driven" categories interactions take place in a particular moment (generally at the beginning of the information seeking by public sectors in the first case, or at the end of the transmission of the information and knowledge from external agents in the second case). The combined form 
means some degree of co-innovation, co-creation or even some co-development like in the case of public-private-third sector innovation networks that become professional innovation networks more than social networks (Gallouj et al., 2013). Obviously, the boundaries of the three categories are not rigid and similar innovation activities may combine several of the forms or move from one to another.

The contractual arrangement for these information flows, when exist, can vary depending of the type of agreement. Internal driven arrangements can be formal or informal within the public organizations (intra or inter-), under the legal contracts regulations staff work and political mandates representing the contract between societies and the State. External driven contracts focus on the transmission of knowledge generated in private sector, third sectors or citizens through supply contracts, contest or awards or traditional public procurement involving some innovation. Combined form requires innovation networks or platforms or public procurement with some degrees of co-innovations.

From our framework can be inferred, for example, that information from elected representatives can be considered internal-driven. Representatives might often be outside the organization that develops an innovation; however their information form part of an internaldriven flow, where source-organization interaction takes place at the beginning of the seeking moment and information transference obeys to political mandate. In turn, an external-driven source can be identified when the innovation development process is entirely contracted to a private enterprise or when a professional or third sector organization transfers information while in the role of public organizations' suppliers. On the other hand, public organizations and external stake-holders might join development efforts and form combined sources of knowledge and information, like in the case of public service users acting as service co-creators (e.g. established public-private networks, citizens participating in a needs assessment session).

\section{The empirical evidence for Europe: Research hypotheses}

What we already know about public sector innovation gives us some hints to believe that the use of external sources is an important driver of innovation development among public organizations. Our research hypotheses are addressed to test for such idea.

Previous discussion on external sources has proven they can be a key element shifting internally generated knowledge in private manufacturing firms' innovation; furthermore, the fact of service innovation being less reliant on internal R\&D efforts suggest that service firms can benefit from an strategy of innovation development based on the use of external sources (Djellal et al., 2003; Rubalcaba, 2006; Miles, 2007). Wide differences exist between public and private sectors with respect to incentives and formal organization; however, more recent views on the public sector under a networked approach take us to believe that innovation in public sector is not particularly reliant on organizations' internal search activities and that the process of coming up with new ideas and contents towards innovation development can be enhanced by an adequate strategy of use of external information sources. That is why first hypothesis is stated as follows: 
H1: Use of external sources of information in innovation development has a significant effect in the implementation of services that are new to the whole public sector.

The reference studies by Laursen and Salter (2006) and Cassiman and Veugelers (2006), using private manufacturing sector data, respectively found effects of substitution and complementarity between the use of internal and external sources of information as a strategy for innovation management. These results suggest that using external sources re-enforces the innovation development process; thus, differences in innovation results among firms might be explained by the use of external sources. In this case, it is believed that use of external sources might be more helpful for better innovation results - as pointed by our reference studies - due to public organizations' interactivity with external agents and their networked operations (Hartley, 2005; Langergaard \& Scheuer, 2009; Börzel, 2011). This is coherent with multi-agent frameworks developed by Gallouj and Weinstein (1997) and Windrum and García-Goñi (2008) for service innovation, although this would not be in line with Battisti et al. (2014) when showing the higher importance for internal sources (size and R\&D) for private sector innovation in services. We expect a different relationship this time since public sector innovation cannot rely on R\&D, unlike companies seeking for radical innovations do. Therefore, our second hypothesis is:

H2: Use of external sources of information for innovation development has a greater effect on introduction of services that are new to the whole public sector than using internal sources.

Two research hypotheses are addressed to the observation of new-to-the-whole-sector services. This is based on the classification of public organizations used in reporting the results of the Innobarometer 2010 Survey (European Commission 2011), from where it was obtained the data for empirical analysis. The survey report makes the classification focusing on organizations' service innovations, while not making any remark on this matter from their innovations in processes and organizational and communication methods. Hence, organizations are labeled as leading innovators, trailing innovators and not innovators. The essential characteristic of a leading innovator is that it has introduced a new service before any other public organization within their country. Trailing innovators do implement service innovations, either they are new or significantly improved services, but they have never pioneered the introduction of a new service. Finally, those organizations that do not implement service innovations are called not-innovators (although, they have certainly introduced process, communication or organizational innovations).

Searching for competitive advantage leads private sector firms to design and implement more and better innovations than other firms, becoming innovation leaders. Due to a lack of competitive incentives ${ }^{11}$, public sector organizations might not be similarly interested as

\footnotetext{
11 There are some market-like incentives for public innovation and they are based on the idea that public organizations which show a better performance will be rewarded with a bigger budget. Competition among public organisations can exist to enhance budget through improving effectiveness, efficiency and productivity (Hartley, 2005; Roste, 2005). However, this view of public management as replicating private firms' incentives oriented to market goals is out of the framework of analysis of this study as it has been
} 
private firms in reaching a leading position; however those public sector organizations with better innovation strategies will end up in taking leading positions, even if they have not intentionally looked for it. Studying public organizations as they approach to introduce innovations not only at their own operational practices but to the whole public sector might help to identify to which extent the use of internal and external sources of information contribute to innovation performance in public sector.

The definition of innovation understood in the applied analysis method is the one indicated by the Innobarometer 2010 Survey. The survey report explains that innovation has been taken to mean any novel or significantly improved service, communication or organizational method. It also remarks that the emphasis is on applicability: any significant improvement in operational practices (either in the product/service range or in support structures) can be classified as an innovation. It is easy to see that the Innobarometer definition share essential features with the definition of public innovation provided in the introductory chapter, particularly by understanding innovation as a significant change and also by identifying the many ways in which innovation can be implemented: either at the service (product) level or as a method for organizing and/or communicating.

\section{Methodology and data description}

The data used for this analysis comes from the Innobarometer Survey on Innovation in Public Administration, which was carried out by the European Commission in October 2010. For the Innobarometer Survey 4.063 organizations were surveyed from the 27 Member States of the European Union and also Norway and Switzerland. Eligible respondents of the questionnaire were senior managers responsible for strategic decision-making: typically, general managers or strategic directors of the institutions. Only organizations declaring to be a public organization will be considered for the analysis. Also, those cases which failed to report any type of innovation since January 2008 will be removed. This leaves for the analysis 3.310 available observations on public organizations that have recently implemented any type of innovation.

The analysis method will be carried out in two stages. First, a set of variables about sources of information for public innovation will be subject to component analysis, in order to obtain a reduced number of variables that could be interpreted in the sense expressed by research hypotheses. Next, components will be used for probability estimation as explicative variables in a bivariate probit regression with sample selection. Results from regression will be helpful in addressing how important are external and internal sources of information for implementing innovation into the public sector.

\subsection{Component Analysis}

The component analysis technique that will be used is known as Categorical Principal Component Analysis (CATPCA). More commonly used, Principal Component Analysis (PCA)

shown that public sector organizations do not share with private firms the same incentives towards their final objectives (Recascino, 2002). 
requires making some assumptions ${ }^{12}$ about data that are not adequate for variables that are not measured in a numeric scale (interval or ratio scale). Thinking of any set of suggested answers in a questionnaire as categories (measured in a nominal or ordinal scale), CATPCA gives a solution for carrying out the PCA while overcoming the restrictions imposed on data in the component extraction process ${ }^{13}$. CATPCA is based on a technique known as optimal quantification which quantifies categories by assigning to each one a new value, so the new values are expressed as an interval scale while preserving the relations observed in the original values. That means that magnitudes of categories' quantifications in a nominal variable will not be required to observe a pre-established ordering, neither are they needed to keep proportional intervals between one to another. Same way, magnitudes of a quantified ordinal variable are not needed to keep proportional intervals but they do show the same ordering observed in the original variable. Linting et al. (2007) provides with an in depth technical explanation of the CATPCA method and a case for practical application and interpretation.

The Innobarometer Survey questionnaire includes questions about drivers and strategies for innovations implemented since January 2008. There is one question asking about the level of importance of some information sources for the development of innovations. The variables that will be subject to CATPCA will be drawn from it. A list of sources is suggested after asking "Since January 2008, how important were the following information sources for the development of your innovations?" Respondents answer to each of them by choosing one of options ranging from 1 to 3, whose correspondent labels are Not important, Somewhat important and Very important. Sources asked for in the survey are: Ideas from management; Ideas from staff; Examples of best practice by another government organisation; Professional organisations; Visits to conferences; Enterprises as suppliers; Enterprises as clients or users; and Citizens as clients or users.

The first three information and knowledge sources can be categorised internal driven sources within public administrations while the rest can be categorised as external driven sources or combined driven sources according to our theoretical framework. The examples of best practices by another government organizations can represent a bit of a mix of internal and external since they are internal to the sector but external to the organizations that want to build on, although in any case it is about information flow seek by the public organization for further development internally. For statistical purposes we merge the external and combined categories in a single one since the survey does not permit to work with a clear distinction between those two.

The Don't know option is also available to respond to the level of importance of suggested information sources. Don't know is a difficult category to manage in an ordinal scale. To solve that problem, these answers were treated as missing values and imputed with the Not

\footnotetext{
12 PCA variable reduction problem assumes a linear relation between variables. Also, the objective of PCA is to reproduce as much as variance is possible from the original variables, while variance is a concept applied only to continuous numeric variables. See Linting et al. (2007).

${ }^{13}$ For a detailed and technical overview of CATPCA - also known as nonlinear PCA - see Meulman et al. (2004).
} 
important category, assuming that an important information source is likely to be remembered. This decision follows the Arundel and Hollanders (2011) criteria - where the same data was used for a PCA.

\subsection{Probability estimation with sample selection}

Once components have been extracted their scores will be saved and used for probability estimation. A bivariate probit regression with sample selection was chosen as estimation model in order to fit the structure in data from the Innobarometer Survey. It can be verified that the survey addresses a strong relation of dependence between organizations being identified as introducing services that are new to the whole sector and the fact that they are previously identified as implementing service innovations. Therefore, a bivariate probit regression with sample selection (also known as Heckman's probit) will estimate the probability of being an organization that introduces services new to the whole sector, conditioned to be and organization that implements service innovations. That will be more accurate than estimating probabilities with conventional probit estimations. The estimation model is then represented as follows:

$P(Z=1 \mid Y=1)=\beta_{0}+\beta_{i}$ Component $_{i} \quad[1]$

$P(Y=1)=\beta_{0}+\beta_{1}$ Size $+\beta_{2}$ Area $+\beta_{i}$ Component $_{i}$

The dependent variable $Y$ in the selection equation [2] identifies public organisations implementing service innovations and the dependent variable $Z$ in the objective equation [1] identifies organizations that have introduced a service which is new within the whole public sector. The variable identifying organizations implementing innovations is obtained after the question "Since January 2008, did your organisation introduce any new or significantly improved services?" Those that gave an affirmative response are then asked "To the best of your knowledge, did your organization introduce a new service before any other public administration in your country since January 2008?" This last question gives the variable that identifies organizations that have implemented a new service before any other public organization (named 'leading innovators' in the Innobarometer Survey report).

Additionally, two variables will complement the analysis in order to control for the influence that organizations' size (measured by the number of its employees) and area of responsibility might have in the final results:

Organizations' size: It indicates whether organization's true number of employees is between 10 and 49, between 50 and 99, between 100 and 249, between 250 and 499, between 500 and 999, or 1000 or more.

Organizations' geographic area: It indicates whether organizations' serve at the local, regional or national area.

As pointed out, all variables taking part in the empirical analysis were drawn from the Innobarometer Survey. Typically, among suggested responses in the survey there is a Don't know/No answer option. Whenever responses of this kind were detected among our variables (dependent and independent variables as well), they were turned into missing values. 


\section{Results}

\subsection{Component extraction}

The main feature of our CATPCA application for component extraction is in quantification of variables. If quantified ordinal variables (now transformed in a numerical scale) were taken to a conventional PCA the extracted components in the final solution would be exactly the same of those that would be obtained through CATPCA, even though CATPCA process differs from that of conventional PCA. Thus, similar treatments usually made on PCA components for interpretation can also be made on CATPCA components, like rotation and measurement of variable correlation.

The application of CATPCA on the selected variables gives a two component solution accounting for $52,57 \%$ of observed variance. The number of extracted components is based on the greater than 1 eigenvalues criterion. The extracted components are subject to Varimax rotation for making them easier to interpret. Table 2 shows the components loadings. Highest correlations are highlighted in bold.

Table 2. CATPCA loadings for variables and extracted components.

\begin{tabular}{|l|c|c|}
\hline & External sources & Internal sources \\
\hline Ideas from management & 0,088 & $\mathbf{0 , 7 8 8}$ \\
\hline Ideas from staff & 0,123 & $\mathbf{0 , 8 0 1}$ \\
\hline $\begin{array}{l}\text { Examples of best practice by another government } \\
\text { organisation }\end{array}$ & 0,351 & $\mathbf{0 , 5 2 0}$ \\
\hline Professional organisations & $\mathbf{0 , 5 3 9}$ & 0,360 \\
\hline Visits to conferences & $\mathbf{0 , 6 5 0}$ & 0,114 \\
\hline Enterprises as suppliers & $\mathbf{0 , 7 6 9}$ & 0,043 \\
\hline Enterprises as clients or users & $\mathbf{0 , 7 5 9}$ & 0,174 \\
\hline Citizens as clients or users & $\mathbf{0 , 5 4 4}$ & 0,371 \\
\hline
\end{tabular}

First component appear notably correlated to variables referring to sources of information external to public organizations. Professional organizations as well as conferences are good examples of external sources from which knowledge developed outside internal boundaries flows inside public organizations. At the same time, enterprises in the role of both suppliers and clients they form part of organizations that are contextual to the public sector, but outside of the boundaries of what is understood as 'internal'. Similar can be said about citizens in the role of clients or users. (See Table 1).

The second component shows higher correlations to variables referring to internal sources. It is clear that ideas from public organizations' management and staff can be identified as internal sources for innovation, given that they are part of internal human resources. On the other hand, examples of best practices by other government organizations are considered to 
be an internal innovation source since they exemplify access to external information from internal research efforts (see Table 1), what results coherent with was explained previously.

We let conclude that variance observed in the first component gives evidence on the importance of using external sources of information for innovation development and the second one does the same about internal sources.

\subsection{Probability estimation: testing research hypotheses}

Once components have been extracted and interpreted, their scores are saved and used as explicative variables in a Heckman's probit regression. The estimated variable in the selection equation indicates whether an organization has implemented one or more service innovations. The dependent variable in the conditional model indicates whether or not a public organization has implemented a service which is new to the whole sector within the organization's country. Table 3 shows estimation results.

Table 3. Results of Heckman's probit regression

\begin{tabular}{|c|c|c|}
\hline & Innovate services & $\begin{array}{l}\text { Introduce new } \\
\text { services }\end{array}$ \\
\hline \multicolumn{3}{|l|}{ Size (number of employees) } \\
\hline $10-49$ & base & -- \\
\hline 50-99 & $\begin{array}{c}0,2189^{* * *} \\
(0,072) \\
\end{array}$ & -- \\
\hline $100-249$ & $\begin{array}{l}0,1372^{* *} \\
(0,069)\end{array}$ & -- \\
\hline $250-499$ & $\begin{array}{c}0,4624^{* * *} \\
(0,093)\end{array}$ & -- \\
\hline 500-999 & $\begin{array}{c}0,5191^{* * *} \\
(0,121)\end{array}$ & -- \\
\hline 1000 or more & $\begin{array}{c}0,7795^{* * *} \\
(0,097)\end{array}$ & -- \\
\hline \multicolumn{3}{|l|}{$\begin{array}{l}\text { Organizations' area of } \\
\text { responsibility }\end{array}$} \\
\hline Local & base & -- \\
\hline Regional & $\begin{array}{c}0,1791^{* * *} \\
(0,063)\end{array}$ & -- \\
\hline National & $\begin{array}{l}0,2039^{* *} \\
(0,091)\end{array}$ & -- \\
\hline External information sources & $\begin{array}{c}0,1144^{* * *} \\
(0,025)\end{array}$ & $\begin{array}{c}0,1120^{* * *} \\
(0,029)\end{array}$ \\
\hline Internal information sources & $\begin{array}{l}0,0613^{* *} \\
(0,025)\end{array}$ & $\begin{array}{l}0,0048 \\
(0,026)\end{array}$ \\
\hline Constant & $\begin{array}{c}0,4553^{* * *} \\
(0,032)\end{array}$ & $\begin{array}{c}-0,0960^{* * *} \\
(0,034)\end{array}$ \\
\hline
\end{tabular}

Coefficients of variables that explain the probability of being observed (i.e. being identified as an organization that has recently introduced service innovations) are all significant. Results 
suggest that organizations' size has an important effect on the probability, this especially true for larger organizations. To be serving in a larger area (regional or national, as opposed to local) also has a relevant effect.

With respect to variables about using internal and external sources, it can be seen in estimation results that use of internal sources has a significant effect over organizations implementing service innovations, but not over organizations implementing services that are new to the whole sector. In turn, use of external sources is a significant aspect for organizations introducing services new to the public sector. This evidence helps to support the idea suggested in our first hypothesis: that the use of external sources of information has a significant effect in the implementation of services that are new to the whole public sector.

Coefficients are, however, a partial reading of the estimation results. A more revealing way to analyze relevance of components about information sources is in calculating their marginal effects from Heckman's probit estimations. Table 4 shows effects predicted by average values of the two components, at representative values of organizations' size (number of employees) and area of responsibility. It can be observed that the probability of implementing a service new-to-the-whole-sector for an organization with a number of employees between 10 and 49 and in a local area will increase by 0,083 from a one unit increase in the External sources of information component, while probability will increase by 0,061 for an organization with more than 1000 employees in a national area. In turn, most of marginal effects predicted for change in the Internal sources of information component are not statistically significant.

Table 4. Marginal effects at representative values of size and area of responsibility ${ }^{\text {a) }}$

\begin{tabular}{|c|c|c|c|c|c|c|}
\hline External sources of information ${ }^{\text {b) }}$ & $10-49$ & $50-99$ & $100-249$ & $250-499$ & $500-999$ & 1000 or more \\
\hline Local & 0,082 & 0,081 & 0,082 & 0,074 & 0,072 & 0,064 \\
\hline Regional & 0,081 & 0,076 & 0,079 & 0,068 & 0,067 & 0,059 \\
\hline National & 0,081 & 0,076 & 0,078 & 0,068 & 0,066 & 0,058 \\
\hline Internal sources of information ${ }^{\text {b) }}$ & $10-49$ & $50-99$ & $100-249$ & $250-499$ & $500-999$ & 1000 or more \\
\hline Local & 0,019 & 0,017 & 0,018 & 0,014 & 0,013 & 0,010 \\
\hline Regional & 0,018 & 0,015 & 0,016 & 0,012 & 0,011 & 0,008 \\
\hline National & 0,018 & 0,015 & 0,016 & 0,011 & 0,011 & 0,008 \\
\hline
\end{tabular}

a) Effects highlighted in bold are statistically significant at a minimum of $90 \%$ confidence level. Noticeably, external sources' effects are all significant at $99 \%$ confidence level.

b) $d y / d x$ are for a one unit increase, predicted for conditional probability in Heckman's probit estimation.

Magnitudes of marginal effects are larger when predicted for smaller organizations and for organizations serving in local areas. It could then be expected greater effects for smaller organizations on the likelihood to introduce services new-to-the-whole-sector from the use of external information sources for innovation development - this among organizations implementing service innovations. This finding provides evidence to suggest that use of external sources can enhance innovation capabilities of public organizations. However, a new empirical approach (with a new model and variables that allow for observing organizations' capabilities) is needed in order to have concluding statements on that matter. 
Results of marginal effects show differences in the impacts over the probability of implementing services new-to-the-whole-sector from the use of external and internal sources of information. These results give evidence to support the idea stated in our second hypothesis: use of external sources has a stronger effect on the introduction of services that are new the whole sector.

\section{Concluding remarks}

Increasing studies on external sources and open innovation have strongly emerged in the last few years in the area of private sector mainly. For private manufacturing firms it means to rely less in internally driven R\&D and to raise efforts towards external search and more collaborative work. On the other hand, the use of external sources might play a more relevant role in innovation due to the interactive character of service delivery and the fact that many service firms rarely count on organized internal R\&D. But, in public sector, the use of external sources could be the core issue in innovation development. External influences driving public sector organizations to innovate such as technological improvements, societal challenges and demands from citizens, along with the need for interactivity in service delivering and a broader concept of what is to be considered as an innovation within the public sector, leads to expect that the use of external sources will have greater power in driving innovation development among public organizations in context of multi-agent frameworks where collaborations with private firms, third sector and citizens can play a major role.

We have proposed a framework in which public service innovation can take benefit from using external sources, in contexts of lack of market incentives and other specific characteristics (such as service users, suppliers and third sector organisations playing a role under a multiagent approach). The use of external sources in public sector has distinctive characteristics with respect to private sector but it also shares some communalities, especially when private based service innovation is considered. The framework proposes three types of knowledge creation and implementation depending on the use of internal-drive sourcing, external sources and combined forms of internal plus external. Current trends show a movement from internal to external and from external to combined, like in the case of public-private sector innovation networks (Gallouj et al., 2013).

Results from our empirical analysis show that use of external sources is a highly relevant aspect for public organizations to introduce services that are new to the whole sector, while the use of internal sources has a significant effect on the implementation of service innovation but does not appear to be significant for introducing services that are new-to-the-wholesector. This evidence is helpful to support the statements of our hypothesis: that the use of external sources of information is a key element driving development of services that are new to the whole public sector and that its effect on new service development will be greater than that of using internal sources.

The relation found between use of external sources and the implementation of services new to the whole sector takes us to believe that a good way to improve innovativeness of 
organizations delivering public services is to bring them to take advantage of flows of information and knowledge coming from external sources.

Organizations' size and area of responsibility also affect probabilities that an organization might be introducing services new-to-the-whole-sector. Coefficients in estimation results indicate that bigger organizations and organizations in bigger areas of responsibility will more likely be implementing service innovations than their smaller counterparts in local areas, which make them more likely eligible for introducing services that are new to the sector. However, results of conditional marginal effects show larger effects from the use of external information sources for smaller organizations and organizations in local areas of responsibility (see Table 4). While empirical evidence give reasons to believe that the bulk of public sector innovation takes place in bigger public organizations (with more employees, in bigger areas of responsibility), this does not necessarily mean that the use of external sources should not be promoted at all levels of public administrations, especially when results also give evidence to believe that the effect of the use of external sources of information on the likelihood to introduce services new-to-the-whole-sector might be of greater value for smaller organizations. 


\section{Chapter3. Differences in effects from implementation of public service innovations}




\section{Introduction}

Research on public sector innovation has gained relevance over the last years. Studies already acknowledge some distinctive features of public innovation, such as factors having an influence in innovation generation, factors enabling the innovation process and also barriers counteracting the innovation process. Among the latter is frequently and remarkably mentioned a high risk aversion in decision making of public authorities, which causes the avoidance of practices that might bring with it failure and waste.

A growing interest in benefits expected from innovation has led to emphasize the power of innovation for improvement while suggesting some guidings for a more innovative public sector and pointing to the gap that still divides the innovation levels observable in public organization and private firms, respectively. However, it has not been enough mentioned the consequences for public accountability from a public sector that dares too much with innovation risks. Private firms will advocate resources for development of new products and new methods and technology as long as they can expect a net economic benefit from their innovations. On the other hand, public administration decisions are not oriented to pecuniary objectives but to public accountability objectives. That is at the root of public sector's high risk aversion and the innovation gap between public organizations and private firms. One could then question if - thinking in terms of public accountability - public sector innovation should match the level of innovation of private firms, or to which extent improvements achieved through innovation make up for waste and negative effects derived from its uncertain and risky nature.

Before to give an answer to such questions, however, it is necessary to know some more about the effects that could be expected from public sector innovation. It is necessary to have a reference about the potential of innovation within public organizations for generating improvements, and the risk of obtaining unwanted effects lying underneath. That is what this chapter will try to address.

The aim of this research work is to present empirical evidence for helping to support assumptions about the power of public sector innovations to achieve some positive effects along with the risk of suffering some negative effects. For that purpose, the followed method consists in the estimation of the probability of occurrence of positive and negative effects reported after the implementation of service innovations by public organizations represented in the Innobarometer 2010 Survey (European Comission, 2011). Variables used for probability esrtimation give information on implemented service innovations and on organizations' characteristics related to their capability towards innovation. It is expected that results will help to address a relation between willingness of an organization to engage in innovations with higher degree of novelty (assuming these imply higher risk) and the effects obtained from innovation implementation, while referring to the importance of organizations' resource availability as enabling positive effects and limiting the negative ones.

The chapter is organized as follows. After this introductory part, Section 2 contains antecedents on public innovation literature building our theoretical framework. Section 3 presents the research hypotheses addressing the study. Section 4 widely describes the methodology that will be applied for testing hypotheses and also the data base in use. In 
Section 5 results are presented and interpreted. The concluding statements correspond to Section 6.

\section{Antecedents: The counteracting consequences of risk}

Risk and uncertainty are claimed to be among the main forces acting against public innovation, since a high aversion has been identified among public sector organizations (Borins, 2001; Mulgang and Albury, 2003; Koch and Hauknes, 2005). It can be verified that fear of the consequences of failure in the experimentation process carried to innovate is counteracting the levels of innovation in public sector (Potts, 2009; European Comission, 2011; Brown and Osborne 2013).

One could simply think of risk as the probability of something bad to happen. This conception of risk implies that the unwanted event is known and there are formed expectations about its occurrence (Brown and Osborne, 2013). On the other hand, the concept of uncertainty reflects the unpredictable occurrence of multiple outcomes, either they are good or bad (Brown and Osborne, 2013). Uncertainty and risk are two parallel - yet different - concepts. The main difference is on what can be known and what can't be known. In entrepreneurial organizations (private and public as well), an often used management strategy to deal with uncertainty is to gather as much information as possible in order to turn the unmanageable uncertainty into manageable risk (Bhatta, 2003, Brown and Osborne, 2013), trying to limit the unforeseen effects.

From an individual focused perspective, public innovation initiatives are stifled because public organizations' employees are not rewarded enough for taking risks. Retaliation due to failure is greater than encouragement of experimentation and a risk rewarding system remains almost inexistent (Borins, 2001, 2006; Potts, 2009). From a policy focused perspective, avoidance of risky and uncertain strategies - such as innovation - is strongly related to efficiency criteria leading public policy. Public sector accountability demands maximizing efficiency (Potts, 2009); this translates in preferring the implementation of proven strategies rather than those whose results might cause failure and waste of resources. Novelty placed in innovation brings with it lack of previous knowledge of the possible outcomes. Emphasis placed in public sector development through efficiency improvements results in avoidance of initiatives whose consequences are unforeseen.

Policy based on efficiency criteria corresponds to a static vision of the economy of the public sector, where an equilibrium point determines a maximum level of efficiency and changes introduced in public organizations are addressed to take their performances closer to that maximum (Potts, 2009). Therefore, implemented changes are required to be previously known as successful methods for achieving the expected outcomes, thus, avoiding any kind of waste and failure (Potts, 2009). However, a more adequate understanding of public sector development is on the dynamic vision of evolutionary economics, which consider multiple successive equilibrium points led by a constantly changing environment. This makes critical the existence of innovative processes for - at least - keeping current standards in public activities (Potts, 2009). For that reason, innovation becomes compulsory for public organizations in 
order to adapt to their changing context and being able of keeping up in value and quality of services delivered to citizens.

The latter brings a problem of choice for public accountability: between opposing strategies alternatively driven by efficiency or innovation. To this respect, Potts (2009) refers to the situation of innovation being stifled because of efficiency driven policies and he explains how letting waste and failure derived from innovation can even result in increasing efficiency. He proposes a solution to the risk/efficiency choice problem consisting on selecting a level of innovation that adapts to environmental changes (just for keeping up), which implies dealing with risk towards innovation in public sector is something desirable, but yet cautiously and moderately. We will go back to Potts' solution in the discussion part of the article.

\section{Leading vs. trailing innovators}

As said before, innovation is recognized so far as it is new for the relevant unit of adoption. Hence, it is considered to be an innovation not only that which introduces an element of novelty to the whole sector for the first time, but also that which introduces an element of novelty to any organization in particular, even though it has been implemented somewhere else before (OECD, 2005). That is why public organizations implementing an innovation previously developed by another organization can also be considered innovators.

A way to recognize organizations introducing innovations new to the public sector, among all public organizations that innovate, is to classify them according to the degree of novelty of the innovations they implement. This can be observed in an ad-hoc classification of public organizations used in reporting the results of the Innobarometer 2010 Survey (European Commission 2011). The survey report makes the classification basing on organizations' service innovations, while not making any remark on this matter from their innovations in processes and organizational and communication methods. Hence, organizations are labeled as leading innovators, trailing innovators and not innovators. The essential characteristic of a leading innovator is that it has introduced a new service before any other public organization within their country. Trailing innovators do implement service innovations, either they are new or significantly improved services, but they have never pioneered the introduction of a new service. Finally, those organizations that do not implement service innovations are called notinnovators (although, they have certainly introduced process, communication or organizational innovations). Later, in our empirical analysis we are going to take back this classification based on service innovations.

It is expected that the search for competitive advantage will bring private sector firms to design and implement more and better innovations than other firms, looking for greater differentiation through completely new products. Due to a lack of competitive incentives ${ }^{14}$,

\footnotetext{
${ }^{14}$ There are some incentives among public organizations for competing to innovate and they are based on the idea that public organizations with better performance will be rewarded with a bigger budget. Competition among public organizations would be occurring to enhance budget (Hartley 2005, Roste 2005). However, this view of public management as replicating private firms' incentives oriented to market goals is out of the framework of analysis of this study as it has been shown that public sector organizations do not share with private firms the same incentives towards their final objectives (Recascino 2002).
} 
public sector organizations might not be similarly motivated as private firms to enter in an intense process of generation of services that are implemented by first time; however, we know for sure that some public organizations will produce more and better innovation outcomes than the rest, even if they don't do purposely.

\section{Research hypotheses}

Innovation as an instrument of improvement is broadly accepted among private firms and so is the inevitable loses that come from risk in its implementation. Nonetheless, public sector still suffers from an innovation gap, to an important extent due to a high risk aversion.

Concerning private sector, the multiple effects of innovation can be synthesized into profiting measures, such as productivity, efficiency, income (see for example: Gunday et al., 2011; Rosenbusch et al., 2011); however, in public sector, where profitability is not the rule, the effects of implemented innovations need to be seen in a distinct way, attending to specific aspects of public good, like improving quality of services, letting a service to be delivered to more citizens or shifting communication between citizens and public offices. At the same time, negative effects from innovation need to be acknowledged independently, since they pervert public good in different ways. For example, the common effect of user resistance might translate in citizens perceiving service quality diminished, and creating barriers to service delivery from a failed innovation can reduce citizens' access to services. On that matter, the purpose of the present study is to analyze how the chances of getting some specific effects (positive as well as negative) from innovation are affected by public agencies taking risk by implementing innovations with greater novelty. To do so, we propose an empirical analysis addressed to test for the hypotheses that will next be introduced.

In a similar way than innovation literature makes a difference between incremental and radical innovations - whose characterization attends the extent to which the introduced change substantially affects the innovated element - we can make a difference between services 'new to the whole public sector' on one hand and services 'significantly improved' or 'new but previously implemented by another organization' on the other hand, attending to the magnitude of their novelty. Thus, we can think of novelty of services new to the whole sector as greater than that of the rest. Different combinations of risk (in probability of getting bad outcomes) and uncertainty (in not having antecedents of results of implementation) from different levels of newness are expected to lead to differences in resulting effects. Classifying organizations by novelty content in their service innovations can be helpful for analysing the multiple effects of innovation

The Innobarometer 2010 Survey that will help the analysis already suggests a set of effects that an organization could obtain from its implemented innovations. The survey asks to every organization which of them they have experienced. Thus, the analysis method of the present study is closer to the observation of risk and not that much of uncertainty, as these two concepts were previously defined. It focuses on a set of known outcomes whose probability of occurrence is going to be measured. Consequently, due to its immeasurable nature, uncertainty is going to be left out of research hypotheses and experiment. Moreover, to give a 
theoretically based justification of this decision, one could think of effects presented on a list form as a mean to elude uncertainty by turning unmanageable uncertainty into manageable risk, as explained in the text of Brown and Osborne (2013).

Innobarometer data does not specify number and detail of implemented innovations nor which of them are new to the whole sector ${ }^{15}$. However, it does indicate which organizations have ever introduced services that are new to the whole sector and which have only implemented service improvements or new services that were implemented by another organization before. Also, data does not let to establish a correspondence between each reported effect and the specific implemented innovation that led to it. In consequence, attending to that limitation, the first research hypothesis is stated as follows.

Hypothesis 1: Chances of getting certain positive effects and risk of suffering certain negative effects differ depending on whether organizations have implemented services that are new to the whole public sector.

In explaining efficiency pursuit as the reason behind public innovation being stifled, Potts (2009) mentions three implicit assumptions under the search for the most efficient way to achieve a goal (embedded in a static vision of public sector where policy results can just be replicated and scaled-up and, thus, innovation becomes unnecessary): 1) there is one best way to efficiently achieve a goal, 2) the best way is known or knowable and 3) this best way can be rationally chosen and implemented. This indications show public managers' preference for proven solutions which offer evidence of effectiveness, instead of those that require some experimentation.

Although efficient solutions described by Potts are not innovations in straight sense, we can deduce that innovations previously implemented by other organizations match to some extent Potts' assumptions towards a best way to efficiently achieve a goal. The former might help prevention of risk and approach to the maximum efficiency through the implementation of solutions whose applicability and results can be traced. Nevertheless, there is still a dose of risk to expect from this kind of innovations. If we acknowledge the multiple differences that can be found among organizations and we agree on an ever changing context - as explained by evolutionary economics - innovations cannot be replicated in the exact same circumstances; therefore, there always are some elements that could be source of risk (Brown and Osborne, 2013).

Based on an observable positive relation between the magnitude of the novelty of an implemented change and the risk to which the implementing organization is exposed (Potts, 2009; Brown and Osborne 2013) we can easily believe that leading innovators carry bigger risk than trailing innovators, which makes more likely for them to get negative effects (i.e. undesirable outcomes from the innovation process). Hence, the second research hypothesis is presented with the next form:

\footnotetext{
${ }^{15}$ Survey questionnaire asks to every organization approximately what percentage of the types of services they provide is significantly improved and if they have recently introduced a service which is new within their country's public sector (see European Comission, 2011)
} 
Hypothesis 2: Organizations which have introduced services new to the whole sector bear higher risk of suffering negative effects.

Definitions of innovation consider novelty placed at the level of the unit of implementation to be sufficient (in public as well as private sectors), yet private sector studies give special attention to those innovations with greater sense of novelty among the industry, whose effects positively impact the implementing firm and then spill over the sector. New commercial applications are frequently imitated by other firms to reach a part of the new market and changes in processes and methods are also adopted by other firms to achieve technical improvement. Firms innovating through imitation can succeed in benefiting from innovation as much - or even more - as firms that developed an innovation for the first time (Dosi, 1988). Nonetheless, greater expectations are always placed in new innovations, since they are more powerful for creating market opportunities in favor of the developing firm (Dosi, 1988).

It is of interest to know about differences on the probability of getting positive effects that might respectively hold innovations new to the whole sector and previously implemented by another organization. One could think that a more controlled implementation process will lead to more chances of positive effects in favor of previously implemented innovations. However, proving this assertion require comparing identifiable innovations whose results after implementation are known, which is out of the possibilities of the study because of data restraints. In turn, we are able to know what happen to organizations which have implemented services new to the whole sector compared to those that have only made use of service improvements or new services previously implemented.

First research hypothesis suggests that organizations' chances to obtain some positive effects depend on whether or not they have implemented services new to the whole sector. It is now here suggested that positive effects will more likely be reached by those organizations implementing the new-to-the-whole-sector services. Given that focus of data and of method of analysis is more on organizations' behavior and characteristics and less on single innovations, it is believed that organizations that are able to develop and implement innovations new to the whole sector possess better strategies and resources that allow them to take more advantage of innovation as an instrument of improvement. Indeed, organizations' capabilities are an important feature affecting innovation results (Berry, 1994; McAdam and Donaghy, 1999; Damanpour and Schneider, 2006). Thus, third and final hypothesis suggests:

Hypothesis 3: Organizations which have introduced services new to the whole sector have greater chance of obtaining positive effects.

For helping our understanding in the current analysis, the definition of innovation is going to be drawn from the Innobarometer 2010 Survey Report (European Commission, 2011), since the information that is going to shape our empirical analysis was gathered by this survey application. The survey report explains that "innovation has been taken to mean any novel or significantly improved (without indicating what a significant improvement might be) service, communication or organizational method". It also remarks that "the emphasis is on applicability: any significant improvement in operational practices (either in the product/service range or in support structures) can be classified as an innovation". 


\section{Data and Methodology}

The data used for this analysis comes from the Innobarometer Survey on Innovation in Public Administration, which was carried out by the European Commission in October 2010. For the Innobarometer Survey 4.063 organizations were surveyed from the 27 Member States of the European Union and also Norway and Switzerland. Eligible respondents of the questionnaire were senior managers responsible for strategic decision-making: typically, general managers or strategic directors of the institutions. Only organizations declaring to be a public organization will be considered for the analysis. Also, those cases which failed to report any type of innovation since January 2008 will be removed. This leaves for the analysis 3.342 available observations on public organizations that have recently implemented any type of innovation.

The Innobarometer Survey questionnaire includes questions about effects of innovation. The set of variables that will help to test our hypotheses will be drawn from these. A list of effects is suggested after asking "Have any of your new or significantly improved services, introduced since January 2008, had a major positive effect by..." Respondents answer to each of them by choosing one out of three options: Yes, No, Don't know. They are allowed to answer 'Yes' to more than one item. Hence, effects are turned into binary variables indicating affirmative answers. Positive effects suggested in the survey are:

c) Enabling your organization to offer services to more or new types of users.

d) Enabling your organization to better target its services.

e) Improving user satisfaction.

f) Improving user access to information.

g) Enabling faster delivery of services.

The list includes the items 'Other positive effect' and 'No positive effect', but their estimation was found troubling; so, it was decided to let in the analysis only those which refer to a specific effect.

In the exact same way, binary variables representing negative effects are obtained after the question "Have any of your new or significantly improved services, processes or organizational methods, introduced since January 2008, had a sustained major negative effect by..." Listed negative effects that will be taken to analysis are:

a. Creating additional administrative costs.

b. Reducing the type or flexibility of your services.

c. Leading to slower delivery of services.

d. Creating user resistance or dissatisfaction.

Negative effects list also includes the items "Other negative effect" and "No negative effect" and they were also left out of empirical analysis. 
An important annotation here is that the way questions are formulated makes listed positive effects to result only from service innovations, while listed negative effects might be a consequence of either service or process or organizational innovations. This matching problem may cause difficulties in comparing estimation results, thus affecting the validity of the subsequent analysis. However, one should always mind that in our empirical model probability of an effect depends on whether an organization has ever implemented some kind of innovation; it does not acknowledges the single innovation that might have caused the effect neither its qualities (type and degree of novelty). Therefore, whatever the effect under analysis, it is going to be related to whether or not public organizations have introduced a new-to-the-whole-sector service. This view does allow for comparing results. It will also define the focus of the analysis.

Survey questionnaire asks to respondents "Since January 2008, did your organisation introduce any new or significantly improved services?" Those that gave an affirmative response are then asked "To the best of your knowledge, did your organization introduce a new service before any other public administration in your country since January 2008?"

This last question gives the explicative variable that will base our empirical analysis. The variable identifies organizations that have implemented a new service before any other public organization in their own country (named 'leading innovators' in the survey report). It does not make specific whether they developed and implemented a service which is completely new or they were able to copy a service that was before implemented outside the country (it is a first time implementation within their own country, but it was not originally developed by the implementing organization).

Additionally, some variables will complement the analysis in order to control for the influence that the number of innovations implemented by an organization and the size and ability of its workforce might have in the final results.

Percentage of innovated services: Respondents to the survey questionnaire were asked what percentage among all different types of services they provide were significantly improved since January 2008. The corresponding variable indicates whether respondents believed the right percentage was lower to $25 \%$, between 25 and $49 \%$, between 50 and $74 \%$, or $75 \%$ or more.

Employees meeting in innovation groups: Respondents were asked what per cent of their employees are taking part in groups that meet to develop innovations. Available responses are: less than $25 \%$, between 25 and $49 \%$, between 50 and $75 \%, 75 \%$ or more.

Employees with university degree: Respondents were asked what per cent of their employees have a university degree. Available responses are: None, between 1 and 9\%, between 10 and $24 \%$, between 25 and $49 \%$, between 50 and $74 \%, 75 \%$ or more.

Organizations' size: It indicates whether organization's true number of employees is between 10 and 49, between 50 and 99, between 100 and 249, between 250 and 499, between 500 and 999, or 1000 or more. 
Organizations' area of responsibility: It indicates whether operations of an organization are taking place at the local, regional or national level.

Organizations' country: It indicates the country of origin of respondent organizations. It is expected that country differences will lead to differences in innovation capabilities.

As pointed out, all variables taking part in the empirical analysis were drawn from the Innobarometer Survey. Typically, among suggested responses in the survey there is a 'Don't know/No answer' option. Whenever responses of this kind were detected among our variables (dependent and independent variables as well), they were turned into missing values.

The analysis method consists in estimating probabilities on the set of variables about effects that an organization might experience from implemented innovations, using probit models. In order to structure the probability we must take into account that this will happen when the organization has implemented a service innovation. This probability will be based on a number of specific characteristics of the organization and a set of unobservable characteristics. In this context, the model reduces to:

$$
\begin{aligned}
& Y_{i}^{*}=\beta^{\prime} X_{i}+u_{i}, \\
& S_{i}^{*}=\gamma Z_{i}+v_{i},
\end{aligned}
$$

With $S_{i}=1\left[\gamma Z_{i}+v_{i}>0\right] ; Y_{i}=1\left[\beta^{\prime} X_{i}+u_{i}>0\right] S_{i}, \forall S_{i}=1 ; Y_{i}$ is not observable, $\forall S_{i}=0$. Where $Y_{i}=1$ for organizations that experience an effect from implemented innovations; $S_{i}=1$ for organizations that introduce a service innovation. $u_{i}$ and $v_{i}$ are, respectively, the error terms for equations [1] and [2] which are distributed according to a bivariate normal with zero mean and unit variance and $\rho=\operatorname{Corr}\left(u_{i}, v_{i}\right)$. The model allows for correlation between unobservable information of equations [1] and [2]. As is well known, when $\rho \neq 0$, standard probit model applied to the equation [1] provides biased results, and, meanwhile, the probit model with sample selection provides consistent and asymptotically efficient estimators for all model parameters. If $\rho=0$, standard probit model applied to the equation [1] provide consistent and asymptotically efficient estimators for all model parameters.

Equation [2] is going to be defined by variables which are expected to have an effect on the innovation capability of public organizations; that is, variables giving information on workforce size and ability: organization's area of responsibility, organization's size, number of employees with university degree, number of employees meeting in innovation groups, and also a variable controlling for spatial effects in the country of origin. In turn, equation [1] is going to be defined by variables giving information on the quantity and degree of novelty of implemented service innovations: percentage of innovated services and a dummy variable that indicates organizations that have introduced a new-to-the-whole-sector service. In addition, the variable about employees meeting in innovation groups will also be part of equation [1]. It is expected that this variable will also have a significant impact on the estimated probabilities of the innovation effects, given that public innovation theory mentions the importance of employee participation for enhanced innovation outcomes. At the same time, it might work as an indicator of a better planned innovation process, which ultimately leads organizations to implement successful innovations while being aware of potential risk. 


\section{Results}

The analysis method relies on a set of variables from the Innobarometer 2010 Survey, about effects (positive and negative effects) that an organization might experience from implemented innovations. These are binary variables indicating whether or not an organization has experienced the concerned effect; they will be subjected to probability estimation. Analysis is especially focused on the impact on probabilities of a variable that indicates organizations that have implemented services new-to-the-whole-sector. Probability estimation includes variables controlling for number of implemented innovations and organizations' workforce capability. Results from regressions will be helpful in addressing how it affects willingness of an organization of taking part in the more risky process of new-the-whole-sector innovation to the effects obtained from innovation implementation, while referring to the importance of organizations' capability as enabling positive effects and limiting the negative ones.

As first part of the analysis, tables $1 \mathrm{a}$ and $1 \mathrm{~b}$ show the results of Heckman's probit estimations on positive effects obtained from service innovation (equation [1]). Table 1a contains estimation coefficients and results for the test of independent equations, which validates the use of Heckman's sample selection. Estimation results that correspond to selection equation were omitted given that they are not essential for the analysis and in order to simplify presentation; however, they are shown in Annex I and they will be subsequently referred. Correspondent marginal effects are in table $1 b$.

Table 1a. Results of Heckman probit estimations for identified positive effects of service innovations

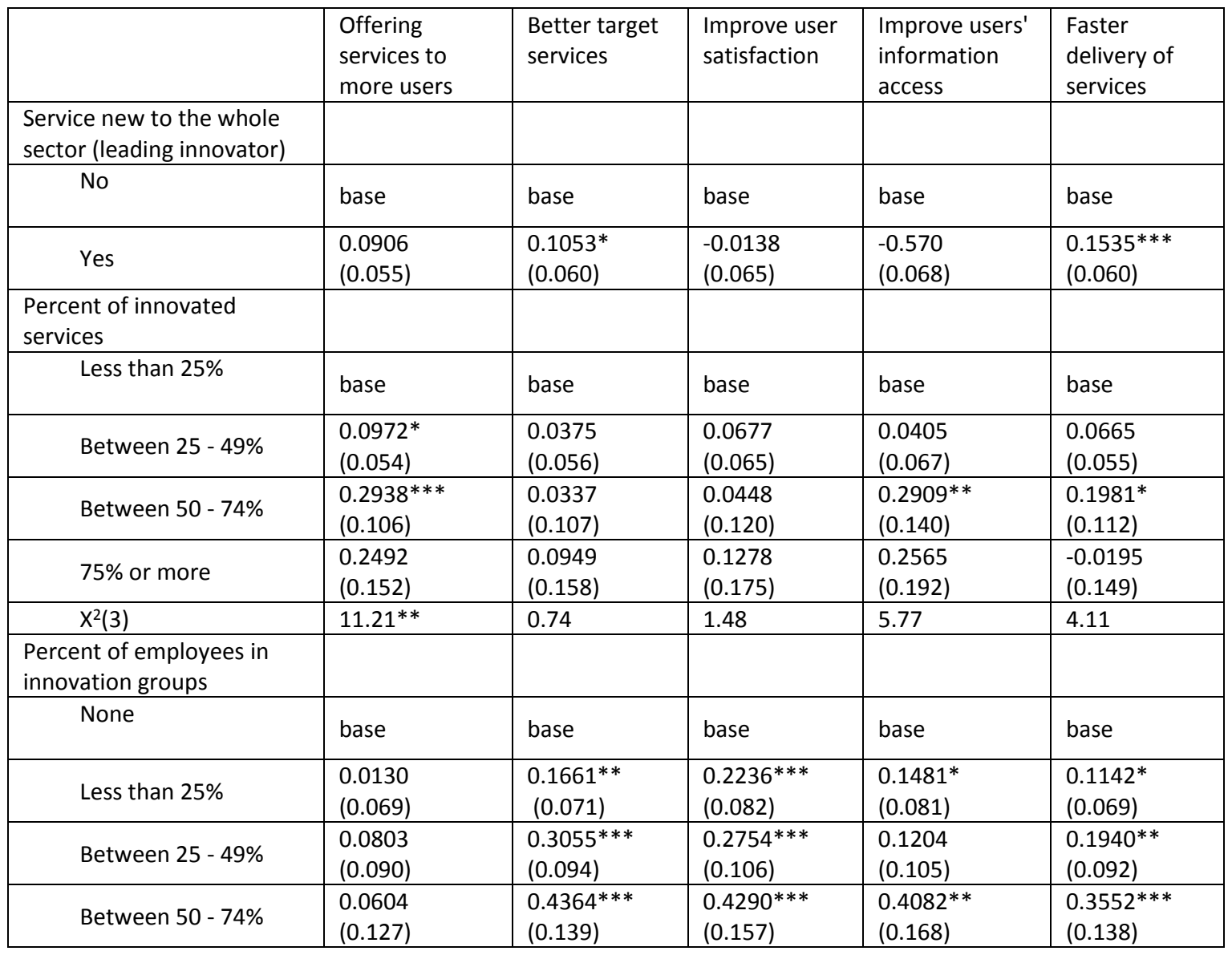




\begin{tabular}{|c|c|c|c|c|c|}
\hline $75 \%$ or more & $\begin{array}{l}0.0844 \\
(0.122)\end{array}$ & $\begin{array}{l}0.4742 * * * \\
(0.133)\end{array}$ & $\begin{array}{l}0.3483^{* *} \\
(0.145)\end{array}$ & $\begin{array}{l}0.0571 \\
(0.140)\end{array}$ & $\begin{array}{l}0.1357 \\
(0.123)\end{array}$ \\
\hline$X^{2}(4)$ & 1.35 & $21.73 * * *$ & $12.66^{* *}$ & 7.29 & 8.69* \\
\hline
\end{tabular}

* $90 \%$ confidence level; $* *$ 95\% confidence level; *** 99\% confidence level

Table 1b. Heckman probit marginal effects for identified positive effects of service innovations ${ }^{\text {a) }}$

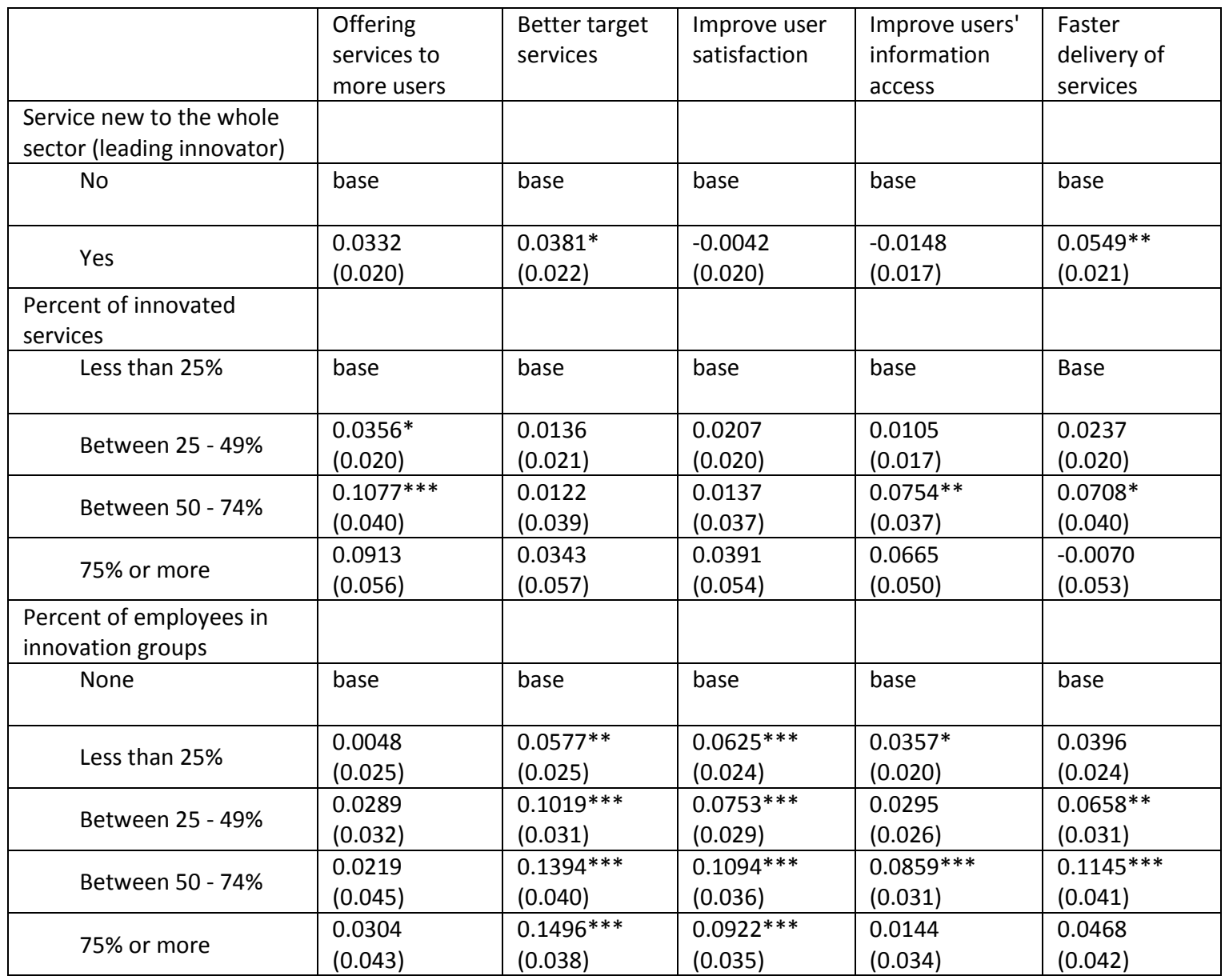

* $90 \%$ confidence level; ** $95 \%$ confidence level; *** $99 \%$ confidence level.

a) Calculated for discrete change of dummy variable from 0 to 1 .

Overall, results of estimations show certain levels of significance for variables explaining probabilities of experiencing the listed positive effects. Since variables are factor defined, it is important to know not only individual significance of each of factors' coefficients but also joint significance of factor groups formed by each variable. Results of chi squared joint significance tests alert that the right specification for estimating each of effects' probabilities might be different; however, the purpose in this analysis is not to estimate the most efficient specification, but to compare the explicative power of each of variables addressed to the concerned innovation effects. In that sense, the leading innovator dummy variable appears to be relevant in explaining two of the listed positive effects: enabling to better target services and enabling faster delivery of services. Confidence levels are strictly indicated at the usual cuts; however, we would like to remark that significance of the leading innovator coefficient is 
in the very limit of the $90 \%$ confidence level when estimating the effect of enabling to offer services to more or new types of users. Percentage of innovated services seem to be especially relevant in explaining the effect of offering services to more users (once again, significance of the ' $75 \%$ or more' coefficient is very close to the $90 \%$ confidence level). In turn, percentage of employees taking part in groups that meet for developing innovations is especially relevant in explaining probabilities of better targeting services, improving user satisfaction, faster delivery of services and improving users' access to information.

Looking at the marginal effects, it can be seen that the impact of the leading innovator variable on the estimated probabilities is modest. There is more to expect from organizations with more than $50 \%$ of innovated services, this particularly true for the effect of offering services to more users. Likewise, having more than $50 \%$ of employees taking part in innovation groups seem to be more important than the fact that the organization has implemented a service which is new to the whole sector. Moreover, it looks like percentage of employees in innovation groups is the variable that more contributes to explain probabilities of listed positive effects, except for 'offering services to more users', where the impact of the percentage of innovated services dominates.

As for the results on the estimation of the selection equation, variables about organizations' size (number of employees), organizations' country and percentage of employees meeting in innovation groups are highly significant and show a wide impact in the estimated selection condition (being an organization that has implemented any service innovation). Unexpectedly, organizations' area of responsibility and the percentage of employees with university degree have not reached statistical significance in any of the estimations. One could then conclude that, together with differences in innovation performance due to country differences, organizations' size and percentage of employees in innovation groups are strongly conditioning organizations to implement service innovations. It is easy to believe that a bigger organization, with a bigger area of responsibility, whose employees are better prepared and more involved in the innovation process, will more probably be taking part in service innovations and will also obtain better results from implementation. Nonetheless, empirical evidence does not go along with this assertion in what can be related to employees' formal education and organizations' area of responsibility.

Tables $2 \mathrm{a}$ and $2 \mathrm{~b}$ show the results of Heckman's probit estimations on negative effects obtained from service innovation. As in the case of positive effects, estimation results that correspond to selection equation were here omitted and are presented in Annex I. An important annotation here is that Heckman's estimations on the effects of reducing type or flexibility of services and creating user resistance or dissatisfaction have failed the test of independence equations. In order to obtain consistent and asymptotically efficient estimators, standard probit regressions were applied on these two negative effects, following the specification of equation [1].

Similarly to previous results on the selection for estimating positive effects, variables about organizations' size, organizations' country and percentage of employees meeting in innovation groups are highly significant and show a wide impact in the estimated selection condition, 
while organizations' area of responsibility and the percentage of employees with university degree have not reached statistical significance in any of the estimations.

Table 2a. Results of Heckman probit estimations for identified negative effects of service innovations

\begin{tabular}{|c|c|c|c|c|}
\hline & $\begin{array}{l}\text { Additional } \\
\text { administrativ } \\
\text { e costs }\end{array}$ & $\begin{array}{l}\text { Reduce services } \\
\text { type or } \\
\text { flexibility }^{a}\end{array}$ & $\begin{array}{l}\text { Slower } \\
\text { delivery of } \\
\text { services }\end{array}$ & $\begin{array}{l}\text { User resistance } \\
\text { or } \\
\text { dissatisfaction }^{\text {a) }}\end{array}$ \\
\hline \multicolumn{5}{|l|}{$\begin{array}{l}\text { Service new to the } \\
\text { whole sector (leading } \\
\text { innovator) }\end{array}$} \\
\hline No & base & base & Base & base \\
\hline Yes & $\begin{array}{l}0.2704^{* * *} \\
(0.067)\end{array}$ & $\begin{array}{l}0.4326^{* * *} \\
(0.088)\end{array}$ & $\begin{array}{l}0.5108^{* * *} \\
(0.111)\end{array}$ & $\begin{array}{l}0.3166^{* * *} \\
(0.074)\end{array}$ \\
\hline \multicolumn{5}{|l|}{$\begin{array}{l}\text { Percent of innovated } \\
\text { services }\end{array}$} \\
\hline Less than $25 \%$ & base & base & Base & base \\
\hline Between 25 - 49\% & $\begin{array}{l}-0.1288^{*} \\
(0.072)\end{array}$ & $\begin{array}{l}-0.0037 \\
(0.096)\end{array}$ & $\begin{array}{l}-0.0158 \\
(0.109)\end{array}$ & $\begin{array}{l}-0.0147 \\
(0.079)\end{array}$ \\
\hline Between 50 - 74\% & $\begin{array}{l}-0.0476 \\
(0.129)\end{array}$ & $\begin{array}{l}0.1449 \\
(0.163)\end{array}$ & $\begin{array}{l}0.1294 \\
(0.191)\end{array}$ & $\begin{array}{l}-0.0789 \\
(0.144)\end{array}$ \\
\hline $75 \%$ or more & $\begin{array}{l}-0.1859 \\
(0.184)\end{array}$ & $\begin{array}{l}0.0543 \\
(0.232)\end{array}$ & $\begin{array}{l}-0.2626 \\
(0.328)\end{array}$ & $\begin{array}{l}-0.1212 \\
(0.202)\end{array}$ \\
\hline$X^{2}(3)$ & 3.80 & 0.87 & 1.23 & 0.60 \\
\hline \multicolumn{5}{|l|}{$\begin{array}{l}\text { Percent of employees in } \\
\text { innovation groups }\end{array}$} \\
\hline None & base & base & Base & base \\
\hline Less than $25 \%$ & $\begin{array}{l}0.1180 \\
(0.092)\end{array}$ & $\begin{array}{l}0.2924^{* *} \\
(0.138)\end{array}$ & $\begin{array}{l}-0.2125 \\
(0.137)\end{array}$ & $\begin{array}{l}0.3028^{* * *} \\
(0.111)\end{array}$ \\
\hline Between 25 - 49\% & $\begin{array}{l}0.0643 \\
(0.117)\end{array}$ & $\begin{array}{l}0.0874 \\
(0.168)\end{array}$ & $\begin{array}{l}-0.4781^{* * *} \\
(0.180)\end{array}$ & $\begin{array}{l}0.2290^{*} \\
(0.133)\end{array}$ \\
\hline Between 50 - 74\% & $\begin{array}{l}-0.1304 \\
(0.169)\end{array}$ & $\begin{array}{l}-0.2417 \\
(0.252)\end{array}$ & $\begin{array}{l}-1.0990^{* * *} \\
(0.368)\end{array}$ & $\begin{array}{l}0.0856 \\
(0.182)\end{array}$ \\
\hline $75 \%$ or more & $\begin{array}{l}0.1474 \\
(0.145)\end{array}$ & $\begin{array}{l}0.1502 \\
(0.206)\end{array}$ & $\begin{array}{l}-0.7597^{* * *} \\
(0.280)\end{array}$ & $\begin{array}{l}0.3556^{* *} \\
(0.164)\end{array}$ \\
\hline$x^{2}(4)$ & 4.52 & $10.85^{* *}$ & $17.22^{* * *}$ & $9.46^{*}$ \\
\hline Constant & $\begin{array}{l}-1.1710^{* * *} \\
(0.097)\end{array}$ & $\begin{array}{l}-1.7863^{* * *} \\
(0.131)\end{array}$ & $\begin{array}{l}-1.3121^{* * *} \\
(0.240)\end{array}$ & $\begin{array}{l}-1.3778^{* * *} \\
(0.104)\end{array}$ \\
\hline $\begin{array}{l}\text { Test of independent } \\
\text { equations }(r h o=0)\end{array}$ & $10.67^{* * *}$ & & $2.75^{*}$ & \\
\hline
\end{tabular}

* $90 \%$ confidence level; ${ }^{* *} 95 \%$ confidence level; *** $99 \%$ confidence level

a) Results from standard probit regressions, after failed test of independence equations in Heckman's estimations. 
Table 2 b. Heckman probit marginal effects for identified negative effects of service innovations ${ }^{a)}$

\begin{tabular}{|c|c|c|c|c|}
\hline & $\begin{array}{l}\text { Additional } \\
\text { administrative } \\
\text { costs }\end{array}$ & $\begin{array}{l}\text { Reduce services } \\
\text { type or } \\
\text { flexibility }^{\text {b) }}\end{array}$ & $\begin{array}{l}\text { Slower } \\
\text { delivery of } \\
\text { services }\end{array}$ & $\begin{array}{l}\text { User resistance or } \\
\text { dissatisfaction }^{\text {b) }}\end{array}$ \\
\hline \multicolumn{5}{|l|}{$\begin{array}{l}\text { Service new to the whole } \\
\text { sector (leading innovator) }\end{array}$} \\
\hline No & base & base & Base & base \\
\hline Yes & $\begin{array}{l}0.0543^{* * *} \\
(0.014)\end{array}$ & $\begin{array}{l}0.0509 * * * \\
(0.016)\end{array}$ & $\begin{array}{l}0.0862 * * * \\
(0.025)\end{array}$ & $\begin{array}{l}0.0602 * * * \\
(0.021)\end{array}$ \\
\hline \multicolumn{5}{|l|}{$\begin{array}{l}\text { Percent of innovated } \\
\text { services }\end{array}$} \\
\hline Less than $25 \%$ & base & base & Base & base \\
\hline Between 25 - 49\% & $\begin{array}{l}-0.0259^{*} \\
(0.016)\end{array}$ & $\begin{array}{l}-0.0003 \\
(0.008)\end{array}$ & $\begin{array}{l}-0.0027 \\
(0.019)\end{array}$ & $\begin{array}{l}-0.0022 \\
(0.012)\end{array}$ \\
\hline Between 50 - 74\% & $\begin{array}{l}-0.0096 \\
(0.026)\end{array}$ & $\begin{array}{l}0.0133 \\
(0.017)\end{array}$ & $\begin{array}{l}0.0218 \\
(0.032)\end{array}$ & $\begin{array}{l}-0.0115 \\
(0.020)\end{array}$ \\
\hline $75 \%$ or more & $\begin{array}{l}-0.0374 \\
(0.038)\end{array}$ & $\begin{array}{l}0.0046 \\
(0.021)\end{array}$ & $\begin{array}{l}-0.0443 \\
(0.057)\end{array}$ & $\begin{array}{l}-0.0172 \\
(0.026)\end{array}$ \\
\hline \multicolumn{5}{|l|}{$\begin{array}{l}\text { Percent of employees in } \\
\text { innovation groups }\end{array}$} \\
\hline None & base & base & base & base \\
\hline Less than $25 \%$ & $\begin{array}{l}0.0254 \\
(0.019)\end{array}$ & $\begin{array}{l}0.0306^{* *} \\
(0.013)\end{array}$ & $\begin{array}{l}-0.0311 \\
(0.025)\end{array}$ & $\begin{array}{l}0.0570^{* * *} \\
(0.020)\end{array}$ \\
\hline Between 25 - 49\% & $\begin{array}{l}0.0134 \\
(0.024)\end{array}$ & $\begin{array}{l}0.0076 \\
(0.015)\end{array}$ & $\begin{array}{l}-0.0580^{*} \\
(0.031)\end{array}$ & $\begin{array}{l}0.0412^{*} \\
(0.024)\end{array}$ \\
\hline Between 50 - 74\% & $\begin{array}{l}-0.0242 \\
(0.030)\end{array}$ & $\begin{array}{l}-0.0157 \\
(0.015)\end{array}$ & $\begin{array}{l}-0.0868^{* *} \\
(0.037)\end{array}$ & $\begin{array}{l}0.0140 \\
(0.031)\end{array}$ \\
\hline $75 \%$ or more & $\begin{array}{l}0.0322 \\
(0.032)\end{array}$ & $\begin{array}{l}0.0139 \\
(0.020)\end{array}$ & $\begin{array}{l}-0.0756^{* *} \\
(0.035)\end{array}$ & $\begin{array}{l}0.0692^{* *} \\
(0.035)\end{array}$ \\
\hline
\end{tabular}

* $90 \%$ confidence level; ** $95 \%$ confidence level; *** $99 \%$ confidence level.

a) Calculated for discrete change of dummy variable from 0 to 1 .

b) Results from standard probit regressions, after failed test of independence equations in Heckman's estimations.

Estimation results of negative effects show the leading innovator variable to be significant and positive in every case. The percentage of improved services was not found statistically significant in explaining the probability of negative effects. It was expected that higher proportions of innovated services would help organizations to reduce the probability of getting negative effects (as greater experience in implementing innovations could help organizations to identify and avoid some risks). In turn, the percentage of employees in innovation groups is statistically significant in three of the negative effects; however, its impact on the estimated probability goes in two directions: positive for reducing types and flexibility of services and creating user resistance or dissatisfaction, and negative for slower delivery of services.

Heckman's probit regressions estimate innovation effects' probabilities only from those organizations that have recently implemented service innovations. Among these, some organizations - named 'leading innovators' - are known to have introduced a new service 
which was implemented by first time within the whole country's public sector. Findings in the explicative variable identifying leading innovators suggests that probability of experiencing one of the previously listed positive effects will be higher whenever innovating organizations have implemented a service which is new within the whole country's public sector. Findings are, however, limited for making a strong concluding statement in that sense, given that levels of individual significance and magnitude of marginal effects tell about short and not always significant impacts over positive effects' probabilities. At the same time, results from the leading innovator variable suggests that probability of experiencing the previously listed negative effects will be higher whenever innovating organizations have implemented a service new to the whole country's sector. This is a conclusion that is better supported by levels of significance in estimations results; nonetheless, marginal effects still show a short impact of the observed variable over probabilities of negative effects.

Other variables that also have an impact on estimated probabilities are the percentage of innovated services and the percentage of employees meeting in innovation groups. There were good reasons to think that bigger proportions of innovated services and bigger proportions of employees taking part in the innovation process should be helpful for reaching the positive effects and for avoiding the negative ones. However, the percentage of innovated services was only found significant for one of the positive effects (offering services to more users), while no significance on this variable was found when estimating the negative effects. On the other hand, the percentage of employees in innovations groups is significant for most of positive and negative effects; however, it strongly calls the attention that - opposite to expected - estimation results from this variable suggest that it mostly raises the probability of negative effects.

An overall conclusion until here is that risk of suffering the listed negative effects is significantly depending on the fact that organizations had implemented service innovations that are new to the whole sector, while positive effects can also be positively affected by the introduction of new services, but not as much as negative effects are. It looks like the mere fact of being involved to new-to-the-whole-sector innovations is enough to expose organizations to risk of negative effects, while this degree of novelty is not a guarantee for positive ones. At the same time, a strategy such as having groups of employees developing innovations can be particularly helpful to enhance the probability of obtaining positive effects. Meanwhile, a strategy such as having groups of employees developing innovations can help to alleviate the risk of negative effects.

\section{Discussion and final remarks}

As for the three research hypotheses proposed in this article, the empirical experiment gives evidence in favor of the three of them. First one implies that probability of getting certain positive and negative effects from innovation implementation significantly differs depending on whether public organizations have implemented services that are new for all the public sector. Thus, results of probability estimations show high significance and relevance of influence of organizations' characterization on probabilities of studied positive and negative effects. 
Second and third research hypotheses imply that risk of suffering negative effects will be higher for organizations introducing services new to the whole sector than for organizations which have only implemented service improvements or new services previously implemented by another public organization, while chance of getting positive effects will be greater for those organizations introducing services new for the whole public sector. The extent to which these are supported by the empirical method is next going to be discussed.

Results suggest to some extent that being an organization that has implemented services that are new to the whole sector give an extra chance to achieve positive effects from innovation. However, results of the experiment also suggest that workforce taking part in innovation development is more relevant to explain probability of positive effects. Hence, probability of getting some determined positive results is not just a matter of organizations undertaking new-to-the-whole-sector innovations, but that innovations are implemented by an organization with better workforce capabilities.

Therefore, it is believed that positive effects from innovation are to a greater extent a consequence of organizations' ability and capability. Nonetheless, since introducing services new to the sector has also shown a relevant effect, we still believe there are better results to expect due to innovations' newness.

Also, results shows that being an organization that has implemented services that are new to the whole sector have a strong influence on the risk to suffer a negative effect from innovation. Organizations that did not introduce new services will be much lesser exposed to risk of negative effects. Results of estimations do not show the association previously found between innovation effects and organizations' capabilities. Therefore, it is believed that negative effects from innovation certainly are a consequence of novelty implied in public organizations' implemented innovations.

The paradigm of innovation is a promise of opportunities for improvement, brought by new ways of doing things. Indeed, novelty is a central aspect of innovation, but novelty is not enough for achieving expected improvement. Novelty is useful in creating opportunities, but opportunities must be worked out. To do so, organizations must manage an adequate development and implementation process, which demands organization and employee abilities in order to realize improvement opportunities. In turn, innovation also brings some risks that are a result of the 'unknown' implied by novelty. Risk, derived from uncertainty, is a concept strongly attached to novelty. Risk in novelty can be managed as it can be measured and known in its causes and consequences, and that is - again - something that demands some abilities. However, risk will always be jeopardizing results of innovation, especially when novelty implied in it is greater.

Conclusions led by the empirical experiment are helpful to illustrate why public organizations fear novel solutions and the reason behind risk avoidance counteracting the levels of public sector innovation. In this context, what are the incentives for public organizations to undertake new-to-the-whole-sector innovations? Does it make sense to encourage a rising of public sector innovation? Some indications to answer these questions are in the texts of Potts (2009) and Brown and Osborne (2013). There, avoidance of risk of innovation is understood (and someway proven right) under public accountability. But it is also said that principles of public 
accountability should not be taken as far to restraint the necessary changes to go with changing society and demands for public services. In particular, Potts suggest that levels of public innovation and experimentation should at least keep pace with changes in economy and society (what he calls "the red queen solution" (see Potts, 2009)).

Studies about public innovation tell about a gap of innovation between private firms and public organizations; however, the extent to which this gap should be shortened has not been properly discussed. A step in that direction is to always have in mind that innovation is an instrument addressed to an objective of improvement, and not the objective itself. It is necessary to make a difference between the two natures of private firms and public organizations, respectively leaded by profitability and public accountability. These two will determine the role of innovation towards organizations' goals and how much of risk they are willing to take to achieve them. Based on the results of the present study and the suggestions of previous publications, willingness of public organizations to undertake new-to-the-wholesector innovations should at least meet changes in the many dimensions (societal, economic, technological, etc.) that affect public functions. 
Annex I. Heckman's probit selection estimations

Table. Heckman probit estimations on selection equation, for positive effects of service innovations

\begin{tabular}{|c|c|c|c|c|c|}
\hline & $\begin{array}{l}\text { Offering } \\
\text { services to } \\
\text { more users }\end{array}$ & $\begin{array}{l}\text { Better target } \\
\text { services }\end{array}$ & $\begin{array}{l}\text { Improve user } \\
\text { satisfaction }\end{array}$ & $\begin{array}{l}\text { Improve users' } \\
\text { information } \\
\text { access }\end{array}$ & $\begin{array}{l}\text { Faster } \\
\text { delivery of } \\
\text { services }\end{array}$ \\
\hline $10-49$ & base & base & base & base & base \\
\hline $50-99$ & $\begin{array}{c}0.3780 * * * \\
(0.080)\end{array}$ & $\begin{array}{c}0.3927 * * * \\
(0.083)\end{array}$ & $\begin{array}{c}0.4808 * * * \\
(0.085)\end{array}$ & $\begin{array}{c}0.4494 * * * \\
(0.086)\end{array}$ & $\begin{array}{c}0.4037^{* * *} \\
(0.082)\end{array}$ \\
\hline $250-499$ & $\begin{array}{c}0.4744 * * * \\
(0.121)\end{array}$ & $\begin{array}{c}0.5269 * * * \\
(0.1123)\end{array}$ & $\begin{array}{c}0.5855^{* * * *} \\
(0.127)\end{array}$ & $\begin{array}{c}0.5615^{* * *} \\
(0.128)\end{array}$ & $\begin{array}{c}0.4931 * * * \\
(0.125)\end{array}$ \\
\hline $500-999$ & $\begin{array}{c}0.6201 * * * \\
(0.155)\end{array}$ & $\begin{array}{c}0.6690 * * * \\
(0.155)\end{array}$ & $\begin{array}{c}0.7287^{* * * *} \\
(0.159) \\
\end{array}$ & $\begin{array}{c}0.7558 * * * \\
(0.159) \\
\end{array}$ & $\begin{array}{c}0.7034 * * * \\
(0.135) \\
\end{array}$ \\
\hline \multicolumn{6}{|l|}{$\begin{array}{l}\text { Percent of employees with } \\
\text { university degree }\end{array}$} \\
\hline $0 \%$ & base & Base & base & base & base \\
\hline Between 1 - 9\% & $\begin{array}{l}-0.0376 \\
(0.090) \\
\end{array}$ & $\begin{array}{l}0.0154 \\
(0.092) \\
\end{array}$ & $\begin{array}{l}-0.0427 \\
(0.101) \\
\end{array}$ & $\begin{array}{l}-0.0574 \\
(0.102) \\
\end{array}$ & $\begin{array}{l}0.0290 \\
(0.093) \\
\end{array}$ \\
\hline Between $10-24 \%$ & $\begin{array}{l}0.0870 \\
(0.105) \\
\end{array}$ & $\begin{array}{l}0.0673 \\
(0.108) \\
\end{array}$ & $\begin{array}{l}0.0365 \\
(0.115) \\
\end{array}$ & $\begin{array}{l}0.0604 \\
(0.117) \\
\end{array}$ & $\begin{array}{c}0.1175 \\
(0.1087) \\
\end{array}$ \\
\hline Between $25-49 \%$ & $\begin{array}{l}-0.0418 \\
(0.112) \\
\end{array}$ & $\begin{array}{l}0.0185 \\
(0.114) \\
\end{array}$ & $\begin{array}{l}-0.0431 \\
(0.123) \\
\end{array}$ & $\begin{array}{l}-0.0216 \\
(0.126) \\
\end{array}$ & $\begin{array}{l}0.0640 \\
(0.114) \\
\end{array}$ \\
\hline \multicolumn{6}{|l|}{$\begin{array}{l}\text { Percent of employees in } \\
\text { innovation groups }\end{array}$} \\
\hline None & base & base & base & base & Base \\
\hline Less than $25 \%$ & $\begin{array}{c}0.2605 * * * \\
(0.072)\end{array}$ & $\begin{array}{c}0.2239 * * * \\
(0.173)\end{array}$ & $\begin{array}{c}0.2375 * * * \\
(0.073)\end{array}$ & $\begin{array}{c}0.2243 * * * \\
(0.073)\end{array}$ & $\begin{array}{c}0.2302 * * * \\
(0.072)\end{array}$ \\
\hline Between 25 - 49\% & $\begin{array}{c}0.4307^{* * *} \\
(0.098) \\
\end{array}$ & $\begin{array}{c}0.4072 * * * \\
(0.099) \\
\end{array}$ & $\begin{array}{c}0.4070 * * * \\
(0.099) \\
\end{array}$ & $\begin{array}{c}0.3972 * * * \\
(0.099) \\
\end{array}$ & $\begin{array}{c}0.3884 * * * \\
(0.099) \\
\end{array}$ \\
\hline Between 50 - 74\% & $\begin{array}{c}0.3557 * * * \\
(0.138) \\
\end{array}$ & $\begin{array}{c}0.2866 * * \\
(0.140) \\
\end{array}$ & $\begin{array}{c}0.3200 * * \\
(0.142) \\
\end{array}$ & $\begin{array}{c}0.3050 * * \\
(0.141) \\
\end{array}$ & $\begin{array}{c}0.2900 * * \\
(0.140) \\
\end{array}$ \\
\hline $75 \%$ or more & $\begin{array}{c}0.4401 * * * \\
(0.135)\end{array}$ & $\begin{array}{c}0.4149 * * * \\
(0.136)\end{array}$ & $\begin{array}{c}0.4139 * * * \\
(0.138)\end{array}$ & $\begin{array}{c}0.3854 * * * \\
(0.138)\end{array}$ & $\begin{array}{c}0.4093 * * * \\
(0.134)\end{array}$ \\
\hline$x^{2}(4)$ & $24.38 * * *$ & $20.56 * * *$ & $20.73 * * *$ & $19.24^{* * *}$ & $19.95^{* * *}$ \\
\hline \multicolumn{6}{|l|}{ Area of responsibility } \\
\hline Local & base & base & base & base & base \\
\hline Regional & $\begin{array}{l}-0.0515 \\
(0.078)\end{array}$ & $\begin{array}{l}-0.0586 \\
(0.082)\end{array}$ & $\begin{array}{l}-0.0607 \\
(0.086)\end{array}$ & $\begin{array}{l}-0.0480 \\
(0.086)\end{array}$ & $\begin{array}{l}-0.0525 \\
(0.082) \\
\end{array}$ \\
\hline National & $\begin{array}{l}-0.0549 \\
(0.124) \\
\end{array}$ & $\begin{array}{l}-0.0879 \\
(0.127) \\
\end{array}$ & $\begin{array}{l}-0.1383 \\
(0.135)\end{array}$ & $\begin{array}{l}-0.1146 \\
(0.135)\end{array}$ & $\begin{array}{l}-0.0699 \\
(0.128)\end{array}$ \\
\hline $\mathrm{X}^{2}(2)$ & 0.55 & 0.85 & 1.33 & 0.90 & 0.60 \\
\hline \multicolumn{6}{|l|}{ Country } \\
\hline
\end{tabular}




\begin{tabular}{|c|c|c|c|c|c|}
\hline Italy & $\begin{array}{c}0.5269 * * * \\
(0.106)\end{array}$ & $\begin{array}{c}0.5312^{* * *} \\
(0.109)\end{array}$ & $\begin{array}{c}0.4899 * * * \\
(0.115)\end{array}$ & $\begin{array}{c}0.5753 * * * \\
(0.116)\end{array}$ & $\begin{array}{c}0.8358 * * * \\
(0.107)\end{array}$ \\
\hline Luxembourg & $\begin{array}{c}-0.9503^{* *} \\
(0.466) \\
\end{array}$ & $\begin{array}{c}-0.2753 \\
(0.446) \\
\end{array}$ & $\begin{array}{r}-0.0377 \\
(0.452) \\
\end{array}$ & $\begin{array}{r}-0.0093 \\
(0.459) \\
\end{array}$ & $\begin{array}{l}0.3268 \\
(0.420) \\
\end{array}$ \\
\hline Denmark & $\begin{array}{c}-0.2538 \\
(0.216) \\
\end{array}$ & $\begin{array}{c}-0.2011 \\
(0.224) \\
\end{array}$ & $\begin{array}{c}-0.2538 \\
(0.231) \\
\end{array}$ & $\begin{array}{c}-0.2016 \\
(0.234) \\
\end{array}$ & $\begin{array}{l}0.0349 \\
(0.230) \\
\end{array}$ \\
\hline Ireland & $\begin{array}{l}0.1803 \\
(0.242) \\
\end{array}$ & $\begin{array}{l}0.3258 \\
(0.244) \\
\end{array}$ & $\begin{array}{l}0.2016 \\
(0.254) \\
\end{array}$ & $\begin{array}{l}0.2863 \\
(0.255) \\
\end{array}$ & $\begin{array}{c}0.5528^{* *} \\
(0.247) \\
\end{array}$ \\
\hline United Kingdom & $\begin{array}{l}0.1377 \\
(0.139) \\
\end{array}$ & $\begin{array}{l}0.2293 \\
(0.142) \\
\end{array}$ & $\begin{array}{l}0.0823 \\
(0.150) \\
\end{array}$ & $\begin{array}{l}0.1731 \\
(0.151) \\
\end{array}$ & $\begin{array}{c}0.5070^{* * *} \\
(0.143) \\
\end{array}$ \\
\hline Greece & $\begin{array}{r}-0.0089 \\
(0.148) \\
\end{array}$ & $\begin{array}{l}0.0234 \\
(0.151) \\
\end{array}$ & $\begin{array}{r}-0.0943 \\
(0.162) \\
\end{array}$ & $\begin{array}{r}-0.0125 \\
(0.165) \\
\end{array}$ & $\begin{array}{c}0.3338^{* *} \\
(0.150) \\
\end{array}$ \\
\hline Spain & $\begin{array}{c}0.6162 * * * \\
(0.151)\end{array}$ & $\begin{array}{c}0.6618^{* * *} \\
(0.153) \\
\end{array}$ & $\begin{array}{c}0.5771^{* * *} \\
(0.158) \\
\end{array}$ & $\begin{array}{c}0.6718^{* * *} \\
(0.159) \\
\end{array}$ & $\begin{array}{c}0.9859 * * * \\
(0.153)\end{array}$ \\
\hline Portugal & $\begin{array}{c}1.1043^{* * *} \\
(0.286)\end{array}$ & $\begin{array}{c}1.2372^{* * *} \\
(0.284)\end{array}$ & $\begin{array}{c}1.1298^{* * *} \\
(0.291)\end{array}$ & $\begin{array}{c}1.1958 * * * \\
(0.296)\end{array}$ & $\begin{array}{c}1.5412^{* * *} \\
(0.283) \\
\end{array}$ \\
\hline Finland & $\begin{array}{c}-0.2778^{*} \\
(0.151) \\
\end{array}$ & $\begin{array}{r}-0.2036 \\
(0.160) \\
\end{array}$ & $\begin{array}{c}-0.4214^{* *} \\
(0.172) \\
\end{array}$ & $\begin{array}{c}-0.4219^{* *} \\
(0.177) \\
\end{array}$ & $\begin{array}{l}0.0948 \\
(0.159) \\
\end{array}$ \\
\hline Sweden & $\begin{array}{c}-0.4887^{* * *} \\
(0.177) \\
\end{array}$ & $\begin{array}{c}-0.4002^{* *} \\
(0.187) \\
\end{array}$ & $\begin{array}{c}-0.5175^{* * *} \\
(0.198) \\
\end{array}$ & $\begin{array}{c}-0.4093^{* *} \\
(0.197) \\
\end{array}$ & $\begin{array}{r}-0.0672 \\
(0.184) \\
\end{array}$ \\
\hline Austria & $\begin{array}{r}-0.0437 \\
(0.169) \\
\end{array}$ & $\begin{array}{r}-0.0650 \\
(0.178) \\
\end{array}$ & $\begin{array}{r}-0.0496 \\
(0.183) \\
\end{array}$ & $\begin{array}{l}0.0449 \\
(0.187) \\
\end{array}$ & $\begin{array}{l}0.1966 \\
(0.181) \\
\end{array}$ \\
\hline Cyprus & $\begin{array}{c}-0.7473 \\
(0.472) \\
\end{array}$ & $\begin{array}{r}-0.3533 \\
(0.519) \\
\end{array}$ & $\begin{array}{c}-0.5022 \\
(0.553) \\
\end{array}$ & $\begin{array}{c}-0.4205 \\
(0.555) \\
\end{array}$ & $\begin{array}{c}-0.0382 \\
(0.518) \\
\end{array}$ \\
\hline Czech Republic & $\begin{array}{c}-0.1158 \\
(0.167)\end{array}$ & $\begin{array}{c}-0.1458 \\
(0.169)\end{array}$ & $\begin{array}{l}0.1515 \\
(0.179) \\
\end{array}$ & $\begin{array}{l}0.1049 \\
(0.189) \\
\end{array}$ & $\begin{array}{c}0.4553^{* * *} \\
(0.170)\end{array}$ \\
\hline Estonia & $\begin{array}{c}-0.0591 \\
(0.213) \\
\end{array}$ & $\begin{array}{l}0.0233 \\
(0.217) \\
\end{array}$ & $\begin{array}{l}-0.3135 \\
(0.257) \\
\end{array}$ & $\begin{array}{c}-0.0173 \\
(0.234) \\
\end{array}$ & $\begin{array}{l}0.2780 \\
(0.221) \\
\end{array}$ \\
\hline Hungary & $\begin{array}{c}-0.4035^{* *} \\
(0.162)\end{array}$ & $\begin{array}{c}-0.3139 * * \\
(0.159)\end{array}$ & $\begin{array}{c}-0.5448 * * * \\
(0.164) \\
\end{array}$ & $\begin{array}{c}-0.4580^{* * *} \\
(0.170) \\
\end{array}$ & $\begin{array}{c}-0.0089 \\
(0.129) \\
\end{array}$ \\
\hline Latvia & $\begin{array}{l}0.1821 \\
(0.213) \\
\end{array}$ & $\begin{array}{l}0.2882 \\
(0.216)\end{array}$ & $\begin{array}{l}0.1318 \\
(0.227) \\
\end{array}$ & $\begin{array}{l}0.3159 \\
(0.225) \\
\end{array}$ & $\begin{array}{c}0.4071^{* *} \\
(0.219)\end{array}$ \\
\hline Lithuania & $\begin{array}{r}-0.3369 \\
(0.214) \\
\end{array}$ & $\begin{array}{c}-0.3028 \\
(0.229) \\
\end{array}$ & $\begin{array}{c}-0.4617^{*} \\
(0.247) \\
\end{array}$ & $\begin{array}{c}-0.2918 \\
(0.250) \\
\end{array}$ & $\begin{array}{l}-0.0386 \\
(0.220) \\
\end{array}$ \\
\hline Malta & $\begin{array}{l}0.4603 \\
(0.625) \\
\end{array}$ & $\begin{array}{l}0.5824 \\
(0.621)\end{array}$ & $\begin{array}{l}0.4693 \\
(0.661) \\
\end{array}$ & $\begin{array}{l}0.5241 \\
(0.650)\end{array}$ & $\begin{array}{l}0.6155 \\
(0.674) \\
\end{array}$ \\
\hline Poland & $\begin{array}{r}-0.0095 \\
(0.109) \\
\end{array}$ & $\begin{array}{l}0.0199 \\
(0.112) \\
\end{array}$ & $\begin{array}{l}0.0086 \\
(0.119) \\
\end{array}$ & $\begin{array}{l}0.1555 \\
(0.121) \\
\end{array}$ & $\begin{array}{c}0.4627^{* * *} \\
(0.111) \\
\end{array}$ \\
\hline Slovakia & $\begin{array}{r}-0.1134 \\
(0.159) \\
\end{array}$ & $\begin{array}{l}0.0116 \\
(0.163) \\
\end{array}$ & $\begin{array}{l}0.0592 \\
(0.172) \\
\end{array}$ & $\begin{array}{l}0.1474 \\
(0.175) \\
\end{array}$ & $\begin{array}{c}0.4431 * * * \\
(0.161) \\
\end{array}$ \\
\hline Slovenia & $\begin{array}{c}0.5071^{*} \\
(0.271)\end{array}$ & $\begin{array}{c}0.6185^{* *} \\
(0.273)\end{array}$ & $\begin{array}{c}0.5416^{*} \\
(0.280)\end{array}$ & $\begin{array}{c}0.6305^{* *} \\
(0.283)\end{array}$ & $\begin{array}{c}0.8378^{* * *} \\
(0.276)\end{array}$ \\
\hline Bulgaria & $\begin{array}{l}0.0024 \\
(0.167) \\
\end{array}$ & $\begin{array}{l}0.0403 \\
(0.169) \\
\end{array}$ & $\begin{array}{c}-0.0163 \\
(0.180)\end{array}$ & $\begin{array}{l}0.0737 \\
(0.182) \\
\end{array}$ & $\begin{array}{c}0.3394^{* *} \\
(0.169)\end{array}$ \\
\hline Romania & $\begin{array}{c}-0.4994 * * * \\
(0.164) \\
\end{array}$ & $\begin{array}{c}-0.2338 \\
(0.170) \\
\end{array}$ & $\begin{array}{c}-0.4341^{* *} \\
(0.185) \\
\end{array}$ & $\begin{array}{r}-0.2052 \\
(0.183) \\
\end{array}$ & $\begin{array}{l}-0.0573 \\
(0.175) \\
\end{array}$ \\
\hline Norway & $\begin{array}{c}-0.4069 * * \\
(0.187) \\
\end{array}$ & $\begin{array}{c}-0.3916^{*} \\
(0.200) \\
\end{array}$ & $\begin{array}{c}-0.6560 * * * \\
(0.234) \\
\end{array}$ & $\begin{array}{c}-0.5887 * * * \\
(0.226) \\
\end{array}$ & $\begin{array}{l}-0.1417 \\
(0.177) \\
\end{array}$ \\
\hline Switzerland & $\begin{array}{r}-0.1089 \\
(0.229) \\
\end{array}$ & $\begin{array}{l}0.1757 \\
(0.225) \\
\end{array}$ & $\begin{array}{l}0.1070 \\
(0.230) \\
\end{array}$ & $\begin{array}{l}0.2226 \\
(0.231) \\
\end{array}$ & $\begin{array}{l}0.1282 \\
(0.241) \\
\end{array}$ \\
\hline$X^{2}(28)$ & $170.01^{* * *}$ & $148.81^{* * *}$ & $151.57^{* * *}$ & $152.43^{* * *}$ & $185.82 * * *$ \\
\hline Constant & $\begin{array}{l}0.1592 \\
(0.104) \\
\end{array}$ & $\begin{array}{l}0.0891 \\
(0.106) \\
\end{array}$ & $\begin{array}{l}0.1590 \\
(0.110) \\
\end{array}$ & $\begin{array}{l}0.0711 \\
(0.115) \\
\end{array}$ & $\begin{array}{c}-0.2445^{* *} \\
(0.111) \\
\end{array}$ \\
\hline $\begin{array}{l}\text { Test of independent } \\
\text { equations }(r h o=0)\end{array}$ & $25.46 * * *$ & $21.20 * * *$ & $17.67 * * *$ & $16.76 * * *$ & $59.72 * * *$ \\
\hline
\end{tabular}


Table. Heckman probit estimations on selection equation, for negative effects of service innovations

\begin{tabular}{|c|c|c|}
\hline & $\begin{array}{l}\text { Additional } \\
\text { administrative } \\
\text { costs }\end{array}$ & $\begin{array}{l}\text { Slower delivery of } \\
\text { services }\end{array}$ \\
\hline \multicolumn{3}{|c|}{ Size (number of employees) } \\
\hline $10-49$ & base & base \\
\hline $50-99$ & $\begin{array}{c}0.4180 * * * \\
(0.088)\end{array}$ & $\begin{array}{c}0.4099 * * * \\
(0.091)\end{array}$ \\
\hline $100-249$ & $\begin{array}{c}0.2509 * * * \\
(0.093)\end{array}$ & $\begin{array}{c}0.2567 * * * \\
(0.096)\end{array}$ \\
\hline $250-499$ & $\begin{array}{c}0.5512 * * * \\
(0.130)\end{array}$ & $\begin{array}{c}0.5572^{* * *} \\
(0.132)\end{array}$ \\
\hline $500-999$ & $\begin{array}{c}0.7034^{* * *} \\
(0.161)\end{array}$ & $\begin{array}{c}0.7220^{* * *} \\
(0.163)\end{array}$ \\
\hline 1000 or more & $\begin{array}{c}0.7229 * * * \\
(0.143)\end{array}$ & $\begin{array}{c}0.6749 * * * \\
(0.149)\end{array}$ \\
\hline $\mathrm{X}^{2}(5)$ & $55.93 * * *$ & $49.83 * * *$ \\
\hline \multicolumn{3}{|l|}{$\begin{array}{l}\text { Percent of employees with } \\
\text { university degree }\end{array}$} \\
\hline $0 \%$ & base & base \\
\hline Between 1 - 9\% & $\begin{array}{l}-0.0505 \\
(0.103) \\
\end{array}$ & $\begin{array}{l}-0.0964 \\
(0.105) \\
\end{array}$ \\
\hline Between $10-24 \%$ & $\begin{array}{l}0.0504 \\
(0.120)\end{array}$ & $\begin{array}{l}0.0149 \\
(0.122)\end{array}$ \\
\hline Between 25 - 49\% & $\begin{array}{l}-0.0643 \\
(0.127) \\
\end{array}$ & $\begin{array}{l}-0.0981 \\
(0.130) \\
\end{array}$ \\
\hline Between $50-74 \%$ & $\begin{array}{l}-0.0385 \\
(0.135) \\
\end{array}$ & $\begin{array}{l}-0.0857 \\
(0.138) \\
\end{array}$ \\
\hline $75 \%$ or more & $\begin{array}{l}0.0207 \\
(0.144)\end{array}$ & $\begin{array}{l}-0.0295 \\
(0.148)\end{array}$ \\
\hline$x^{2}(5)$ & 2.33 & 2.80 \\
\hline \multicolumn{3}{|l|}{$\begin{array}{l}\text { Percent of employees in } \\
\text { innovation groups }\end{array}$} \\
\hline None & base & base \\
\hline Less than $25 \%$ & $\begin{array}{c}0.2257^{* * *} \\
(0.073)\end{array}$ & $\begin{array}{c}0.2598^{* * *} \\
(0.074)\end{array}$ \\
\hline Between 25 - 49\% & $\begin{array}{l}0.3957^{* * *} \\
(0.100)\end{array}$ & $\begin{array}{c}0.4385^{* * *} \\
(0.101)\end{array}$ \\
\hline Between 50 - 74\% & $\begin{array}{l}0.2546^{*} \\
(0.143) \\
\end{array}$ & $\begin{array}{c}0.3520 * * \\
(0.143)\end{array}$ \\
\hline $75 \%$ or more & $\begin{array}{c}0.4140 * * * \\
(0.138)\end{array}$ & $\begin{array}{c}0.4536 * * * \\
(0.138)\end{array}$ \\
\hline $\mathrm{X}^{2}(4)$ & $19.28^{* * *}$ & $23.70 * * *$ \\
\hline \multicolumn{3}{|l|}{ Area of responsibility } \\
\hline Local & base & base \\
\hline Regional & $\begin{array}{l}-0.0396 \\
(0.087)\end{array}$ & $\begin{array}{l}-0.0640 \\
(0.090)\end{array}$ \\
\hline National & $\begin{array}{l}-0.0281 \\
(0.135) \\
\end{array}$ & $\begin{array}{l}-0.1009 \\
(0.138) \\
\end{array}$ \\
\hline $\mathrm{X}^{2}(2)$ & 0.22 & 0.88 \\
\hline \multicolumn{3}{|l|}{ Country } \\
\hline France & base & base \\
\hline Belgium & $\begin{array}{c}0.5237 * * \\
(0.252)\end{array}$ & $\begin{array}{c}0.5502^{* *} \\
(0.251) \\
\end{array}$ \\
\hline The Netherlands & $\begin{array}{c}0.6744^{* * *} \\
(0.235)\end{array}$ & $\begin{array}{c}0.6906^{* * *} \\
(0.237)\end{array}$ \\
\hline Germany & $\begin{array}{l}-0.1818 \\
(0.116) \\
\end{array}$ & $\begin{array}{l}-0.1835 \\
(0.119) \\
\end{array}$ \\
\hline Italy & $\begin{array}{c}0.5546 * * * \\
(0.119)\end{array}$ & $\begin{array}{c}0.6403 * * * \\
(0.122)\end{array}$ \\
\hline
\end{tabular}




\begin{tabular}{|c|c|c|}
\hline Luxembourg & $\begin{array}{l}-0.1748 \\
(0.483) \\
\end{array}$ & $\begin{array}{l}-0.0825 \\
(0.487) \\
\end{array}$ \\
\hline Denmark & $\begin{array}{l}-0.3580 \\
(0.242) \\
\end{array}$ & $\begin{array}{l}-0.2874 \\
(0.247) \\
\end{array}$ \\
\hline Ireland & $\begin{array}{l}0.2865 \\
(0.256)\end{array}$ & $\begin{array}{l}0.2347 \\
(0.265)\end{array}$ \\
\hline United Kingdom & $\begin{array}{l}0.2360 \\
(0.152) \\
\end{array}$ & $\begin{array}{l}0.1032 \\
(0.157) \\
\end{array}$ \\
\hline Greece & $\begin{array}{l}-0.0142 \\
(0.173) \\
\end{array}$ & $\begin{array}{l}-0.1231 \\
(0.178) \\
\end{array}$ \\
\hline Spain & $\begin{array}{c}0.6736 * * * \\
(0.161)\end{array}$ & $\begin{array}{c}0.6427^{* * *} \\
(0.163)\end{array}$ \\
\hline Portugal & $\begin{array}{c}1.1722^{* * *} \\
(0.298)\end{array}$ & $\begin{array}{c}1.1602 * * * \\
(0.297) \\
\end{array}$ \\
\hline Finland & $\begin{array}{l}-0.1896 \\
(0.177) \\
\end{array}$ & $\begin{array}{l}-0.2704 \\
(0.181) \\
\end{array}$ \\
\hline Sweden & $\begin{array}{c}-0.5065^{* *} \\
(0.205) \\
\end{array}$ & $\begin{array}{c}-0.3931^{*} \\
(0.206) \\
\end{array}$ \\
\hline Austria & $\begin{array}{l}-0.0351 \\
(0.194) \\
\end{array}$ & $\begin{array}{l}-0.1171 \\
(0.199) \\
\end{array}$ \\
\hline Cyprus & $\begin{array}{l}-0.5486 \\
(0.599) \\
\end{array}$ & $\begin{array}{l}-0.2849 \\
(0.583) \\
\end{array}$ \\
\hline Czech Republic & $\begin{array}{c}0.3303^{* *} \\
(0.181)\end{array}$ & $\begin{array}{l}0.3144^{*} \\
(0.184)\end{array}$ \\
\hline Estonia & $\begin{array}{l}0.1367 \\
(0.234)\end{array}$ & $\begin{array}{l}-0.0120 \\
(0.246)\end{array}$ \\
\hline Hungary & $\begin{array}{c}-0.4303^{* *} \\
(0.179) \\
\end{array}$ & $\begin{array}{c}-0.4614^{* *} \\
(0.186)\end{array}$ \\
\hline Latvia & $\begin{array}{l}0.3512 \\
(0.227) \\
\end{array}$ & $\begin{array}{l}0.2680 \\
(0.233) \\
\end{array}$ \\
\hline Lithuania & $\begin{array}{l}-0.2309 \\
(0.257) \\
\end{array}$ & $\begin{array}{l}-0.3297 \\
(0.268)\end{array}$ \\
\hline Malta & $\begin{array}{l}0.5460 \\
(0.648)\end{array}$ & $\begin{array}{l}0.5261 \\
(0.659)\end{array}$ \\
\hline Poland & $\begin{array}{l}0.1733 \\
(0.124)\end{array}$ & $\begin{array}{l}0.1337 \\
(0.127)\end{array}$ \\
\hline Slovakia & $\begin{array}{l}0.2294 \\
(0.174) \\
\end{array}$ & $\begin{array}{l}0.2783 \\
(0.184) \\
\end{array}$ \\
\hline Slovenia & $\begin{array}{c}0.6809^{* *} \\
(0.280)\end{array}$ & $\begin{array}{c}0.5970^{* *} \\
(0.288)\end{array}$ \\
\hline Bulgaria & $\begin{array}{c}0.3083^{*} \\
(0.177)\end{array}$ & $\begin{array}{l}0.1807 \\
(0.184)\end{array}$ \\
\hline Romania & $\begin{array}{l}-0.0136 \\
(0.181)\end{array}$ & $\begin{array}{c}-0.1280 \\
(0.187)\end{array}$ \\
\hline Norway & $\begin{array}{c}-0.6761 * * * \\
(0.238)\end{array}$ & $\begin{array}{c}-0.7092^{* * *} \\
(0.246)\end{array}$ \\
\hline Switzerland & $\begin{array}{l}0.1470 \\
(0.239) \\
\end{array}$ & $\begin{array}{l}0.1610 \\
(0.242) \\
\end{array}$ \\
\hline $\mathrm{X}^{2}(28)$ & $146.90 * * *$ & $155.93 * * *$ \\
\hline Constant & $\begin{array}{l}0.0716 \\
(0.117) \\
\end{array}$ & $\begin{array}{l}0.1112 \\
(0.118) \\
\end{array}$ \\
\hline $\begin{array}{l}\text { Test of independent } \\
\text { equations }(r h o=0)\end{array}$ & $10.67^{* * *}$ & $2.75^{*}$ \\
\hline
\end{tabular}




\section{Chapter 4. The way of public innovation in developing countries: An approach for Mexican local governments}




\section{Understanding public innovation in developing countries}

All work reviewed before give a useful insight into the issue of public innovation. However, this is largely based in situations and applications in the context of developed countries. It is common to find in them references to OECD countries, Commonwealth countries (Australia and the United Kingdom, in particular) and western European countries. Therefore, one could reasonably ask: what is innovation about public institutions in developing countries?

Public innovation studies highlight the need for more flexible public organizations that allow for experimentation, waste and failure (Borins, 2006; Potts 2009; Brown and Osborne, 2013), in such a way that innovation is enabled. At the same time, there is a claim for reforming public administration, so institutional bureaucratization might not be a barrier for implementing technical instruments and managerial strategies that help for increased efficiency, quality and effectiveness in public administration. This kind of observations recall highly regulated organizations with strong hierarchic patterns of authority and whose views on policy and accountability makes them to avoid implementations that represent a chance of failure. However, what could be expected about promotion and implementation of innovation in organizations that do not resemble the latter?

Expectations for development and improvement make implementation of innovations something desirable at all levels of all kinds of organizations. This is also true for regions where society, economy and public institutions remain at a developing state. Therefore, it arise a question on whether the understanding of processes enabling public innovation - acquired in developed contexts - is the same valid for organizations in developing regions, where weakness of public institutions might place more barriers to successful implementations.

As said before, it is little what have been said about the issue of public innovation relying on evidence from developing regions. Some publications, however, have documented results on the efforts for reforming public institutions and the elements that might have conditioned success or failure. This review let to know some important features of developing public institutions that differ from the context where public innovation is commonly observed and might lead to a different understanding of the innovation process. For example: Samaratunge and Bennington (2002) review the situation of Sri Lanka after a period of reform, Manning (2001) makes an analysis from many developing regions, Arellano (2000) explains the situation of Mexican local government institutions and Cabrero (1997) focus in the case of Latin American countries facing reforms. Their findings are similar in what makes durable sustainable reforms a difficult task.

Even if they are democratic states, it is common that local authorities in developing countries are taken by interest groups that dominate the local stage, which result in discretional governs that use public administration as a political tool. Thus, articulation of levels of governance that should be given by law and institutionalization of authority is replaced by negotiation between local and central powers (Arellano, 2000). Public administration accountability is an issue in civil servants' discourse; however, without the adequate instruments for citizens' participation and lack of transparency in budget expense, accountability becomes a simulated compliance (Cabrero, 2005; Arzaluz, 2013). Hence, technical guiding is missed in policy planning, execution and evaluation (Samaratunge and Bennington, 2002; García, 2005). 


\section{The case of Mexican local government}

Some deficiencies in Mexican local governments concerning to innovation development can be understood through a revision of the history of political and administrative arrangements since colonial times and after Mexico's independence. Arellano (2000) describes the idea of patromonialistic values at the root of incapacity (or unwillingness) of Mexican municipalities to bear successful reform and innovation. Arellano explains patrimonialism as a tradition continued by those that held discretional authority and power in local regions since governance was configured during the Spanish colony. According to this, caciques and similar forms of local domination have developed the ability to adapt to successive State reforms and keep their privileges: in patrimonialism legitimacy is kept by tradition and the capacity of dominant groups to present themselves as advocators of a charity ethic (or welfare state) (Arellano, 2000, p. 116).

The technocratic vision of government administration as a body led by policy planning and oriented to efficient and effective goals is not valid in the Mexican case, where public administration is an instrument for fighting the political arena and public accountability works as an appeal for justifying discretional decisions in favor of groups and individuals whose collective benefits are not that clear (Arellano, 2002). In this context there is little place for processes - such as innovation - based on technical aspects like planning, efficiency, quality, measure and so.

There is a trend for institutionalize public innovation, framed by theories of change and reform in governmental institutions. Trying to embed these ideas into the context of Mexico's public administration has frequently worked as a mean to reinforce a discretional way for policy implementation, rather than one guided by technical aspects. In this sense, there is an official speech claiming for change, reform and innovation as objectives for public administration improvement, while reform is carried in such a way that the arrangements that serve to keep a discretional public administration remain unaltered: "change is for all to stay the same".

Additional to heritage in political uses, lack of social development has led to shortages in institutional development of Mexican public administration. This is even more sensitive in municipalities, with less faculties and resource availability than agencies from states or federal government. Deficiencies of municipal government can be observed in factors at the operative level, such as: lack of formal education (especially higher education) of employees, high mobility of personnel in public office positions, lack of learned and established proceedings, deficient organization and lack of tools and resources for carrying tasks (computing systems, vehicles, technical support, etc.). Cabrero (2004) details some facts that help to make a picture of institutional under-development of Mexican municipalities. These can be read in Table 1. 


\begin{tabular}{|l|}
\hline $\begin{array}{l}\text { The majority of Mexican municipalities are characterized by a weak normative and } \\
\text { compulsory framework: }\end{array}$ \\
\hline $64 \%$ of the country's municipalities do not even have basic internal by-laws. \\
\hline Nearly $80 \%$ of municipalities do not have regulations for planning. \\
\hline $52 \%$ of municipalities do not have regulations for public services. \\
\hline $20 \%$ of municipalities do not have strategic planning. \\
\hline Obsolete administrative systems dominate the municipal scene: \\
\hline $\begin{array}{l}60 \% \text { of the country's municipalities do not have an administrative area specialized in } \\
\text { expenditure, evaluation and supervision. }\end{array}$ \\
\hline Almost half of the municipalities recognize having a goal-fulfillment level of less than $75 \%$. \\
\hline $65 \%$ of municipalities do not have a Department of Personnel. \\
\hline Most municipalities recognize having collected taxes and duties $75 \%$ below the estimations. \\
\hline $17 \%$ of municipalities still do not have a single computer for administrative work. \\
\hline Mayors and civil servants are of a weak professional level: \\
\hline $\begin{array}{l}18 \% \text { of local government leaders do not have middle or higher education studies in any } \\
\text { professional field. }\end{array}$ \\
\hline Half of local government leaders do not have any previous experience in public administration. \\
\hline $\begin{array}{l}\text { Executive civil servants in municipal administration have little accumulated experience in their } \\
\text { jobs: } 30 \% \text { have been working in their jobs for less than one year, } 55 \% \text { for less than three years; } \\
\text { only } 5 \% \text { have been working for more than five years in their job. }\end{array}$ \\
\hline $\begin{array}{l}\text { Like local government leaders, half of the civil servants of primary level do not have any } \\
\text { previous experience in public administration either. }\end{array}$ \\
\hline
\end{tabular}

Source: Cabrero (2004)

Rigid bureaucracies are mentioned in studies on public innovation as a barrier to innovation, since they do not allow for experimentation and 'try and error' processes, needed for successful innovation implementations to emerge. Thus, claims for a more innovative public sector imply the opposite: norms and authorities (managers, directors, presidents and any decision maker) that tolerate certain levels of waste and failure and that encourage employees to come up with new ideas (and take part in their development) in order to let the innovation process to take its way (Borins, 2006; Potts, 2009). To this respect, Garcia (2005) argues:

While the need to make a bureaucratic apparatus more flexible might be a goal in some spheres of Mexico's public administration, in the great majority of the municipalities the need to break the bureaucratic inertia in order to be able to innovate does not exist. This need does not exist because a bureaucratic organization has not yet been developed. ( $p$. 3)... Most local governments have not yet developed an organizational capacity that could even be defined as bureaucratic, nor do they have the necessary technical, organizational and institutional tools to face the expectations and needs of their citizens. (p. 4)

In his work Garcia explains that the lack of systematized procedures and institutional tools in Mexican municipalities is the reason why they are constantly making use of "innovation" as a way to sidestep restrictions and policy challenges. However, these innovations - he says - are no more than temporary solutions to permanent problems. They act as a remedy for a lacking rational structure and in many times they will not be continued farther than the one period of governance in which they are implemented. Garcia claims that most of innovations taking 
place in Mexico's local governments do not occur in spite of bureaucratic rigidity but rather because of its absence. He makes a proposition that contradicts typical arguments of literature of public innovation in developed countries: in order to achieve durable higher leveled innovations Mexico's municipalities should regress in the classic sense of promotion of innovation; that is: to promote systematization, solid organizational structures and a regulatory framework that allow for innovation sustainability.

Another inconvenience that Mexican municipalities face towards innovation implementation is the impossibility to combine objectives of efficiency and govern legitimation in implementation of innovative initiatives. Legitimation is pursued through actions addressed to highlight efficiency and effectives of performance and to promote citizen's participation in public policy planning (Cabrero, 1997). However, there is frequently the case in developing countries' local governments, such as Mexico, that actions addressed to improve public efficiency generate conflict and deteriorate government-citizen relations, while actions addresses to improve government-citizen relations tend to counteract public efficiency (Cabrero, 1997).

Focusing in the case of Mexican local governments, reviewed publications suggest some strategies for fixing the institutional weakness of local public administrations and help for effective sustainable reforms and higher level innovations that can actually bring expected development and improvement. These refer to instruments that allow for citizens' participation in favor of an authentic democratic government, increasing transparency in administration for reducing discretional budget expense, actions for improving competencies of public servants (such as reducing mobility in job places due to change of governance periods and improving levels of preparation and formal education in public servants), establishing systems, norms and processes that can be a reference for operations after every end of governance periods.

Propositions aiming for more flexible chains of authority and a management style that encourages experimentation and is more tolerant to waste and failure, they would be futile in the context of Mexican local governments, where authority relations (from federal to local) are elusive, experimentation is the way to go and public accountability does not constraint for waste and failure. A similar situation can be verified in other developing regions (e.g. Manning 2001; Ziccardi, 2004). Therefore, contrary to relaxing solid bureaucracies, promotion of innovation within developing public institutions requires reforms that lead to institutional consolidation and advance in democracy and participation.

\section{Mexican local governments in the way for successful innovation}

In his work, Garcia (2005) points out differences in capabilities of Mexican municipalities according to their levels of social development. He suggests that some municipalities with certain demographic and development features are closer to bureaucratic institutions resembling those depicted in publications on management reform and public innovation while others remain in a pre-bureaucratic state. His propositions lead to believe that implementation of innovative initiatives is more feasible in big municipalities with higher levels 
of social development, while small municipalities with low levels of development do not provide the institutional foundations for useful sustainable innovations.

The next step in the analysis is to present some evidence on the achievements of Mexican municipalities towards implementation of innovative governance initiatives. To do so, it is going to be drawn information from the Government and Local Management Award ${ }^{16}$ (Premio Gobierno y Gestión Local). As explained in its own institutional web page, this is a yearly award, addressed for giving recognition to those programs and local government policies which show a positive and remarkable impact in design and implementation. Its objective is on identify, analyze, recognize and disseminate the best local governance experiences in order to contribute to their institutionalization and for developing better practices of management and democracy. For being considered for award recognition, municipalities should go through the award's submission proceeding by filling in basic information of the initiatives they want to propose. It is allowed that one single municipality proposes multiple initiatives in the same year (and it has been the case that one municipality has obtained more than one initiative awarded). These are recently implemented initiatives and - overall - addressed to improve attention to citizen needs, to solve a particular problem or to enhance local governance. Thus, novelty and significance at unit of implementation are constant elements in initiatives taking part in the contest.

The present analysis is going to rely on information gathered from all participating initiatives between years 2005 and 2011. We count on small briefings (less than one page) providing highlights of each of 2.301 initiatives participating in the award along seven years. This information is going to be complemented with demographic information specifically referred to population size and social development. Measures of social development come from the National Population Council' ${ }^{17}$ (CONAPO). CONAPO offers a measure that classifies country regions and municipalities according to five stages of exclusion ${ }^{18}$ suffered by their population: 1. High, 2. Medium-high, 3. Medium, 4. Medium-low, and 5. Low. Exclusion is revised every 5 years. During the period that covers the analysis, exclusion reports were released in 2005 and 2010. However, in order to keep consistence in descriptive statistics, and given the low rates of change in classification, the classification of 2005 will be defined for the whole seven years period. Likewise, basing on information from the National Institute of Statistic and Geography ${ }^{19}$, the National System of Municipal Information ${ }^{20}$ classifies municipalities according to the size and concentration of their population ${ }^{21}: 1$. Rural, 2. Semi-urban, 3. Mixed, 4.

\footnotetext{
${ }^{16}$ http://www.premiomunicipal.org.mx

17 Consejo Nacional de Población http://www.conapo.org.mx

${ }^{18}$ For an overview of the 'exclusion' technical definition and calculation method see document in http://www.conapo.gob.mx/work/models/CONAPO/indices_margina/marg_local05/libro/IndiceMargLo c2005.pdf

${ }^{19}$ Instituto Nacional de Estadística y Geografía http://www.inegi.org.mx

${ }^{20}$ Sistema Nacional de Información Municipal http://www.snim.rami.gob.mx

${ }^{21}$ Metropolis: more than $50 \%$ of population lives in towns with more than 1 million of inhabitants. Bigurban: more than $50 \%$ of population lives in towns with more than 100 thousand and less than 1 million of inhabitants. Medium-urban: more than $50 \%$ of population lives in towns with more than 15 thousand and less than 100 thousand of inhabitants. Semi-urban: more than $50 \%$ of population lives in towns with more than 2.500 and less than 15 thousand of inhabitants. Rural: more than $50 \%$ of population lives in towns with less than 2.500 inhabitants. Mixed: population is found distributed as in previous categories, but none of them gathers more than $50 \%$ of population.
} 
Medium-urban, 5. Big-urban, and 6. Metropolis. Measures on social exclusion and population will be used as reference to give an idea of differences in capabilities of local administrations. It can be observed different levels of institutional development among Mexican local governments, this presumably linked to the level of economic development and the size and concentration of their respective populations. According to municipalities' size and levels of social development, it can be observed differences in resource availability, civil servants capability and bureaucratization of organizations.

After reviewing the innovation panorama provided by initiatives participating in the award, a more detailed analysis will be carried by reviewing finalist initiatives. The second stage of the award contest consists of a pre-selection of initiatives. A specialized commission is in charge of evaluating participant initiatives and selecting some that show greatest potential according to the objective of the award. Selected initiatives will go through an in-depth evaluation at the places they are being implemented and the awarded initiatives will be nominated afterwards (around five initiatives are awarded each year). Finalist initiatives: those that were preselected by the specialized commission, they are going to be the base for the next part of the analysis.

For the analysis of finalist initiatives they will only be selected those submitted by municipalities at opposite ends of CONAPO's classification of social exclusion: High and Low. This is under the assumption that municipalities at ends of the classification are better comparable due to sizes of population and government apparatus, given that metropolis and big urban centers (with much bigger budgets and more complex government organization) are found in middle levels of the exclusion classification. The analysis has as purpose to identify relevant features in design and implementation of innovative initiatives, as read in their briefings, and build a characterization of initiatives implemented by low and highly excluded municipalities (different in development of their government institutions). The objective is to compare characterization with the ideas explained before on innovation and institutional development.

\subsection{Frequencies and percentages of participant and finalist initiatives of the award}

The contest for the Government and Local Management Award is carried every year since 2001. For the present analysis we count on information from initiatives between years 2005 and 2011. Total participant initiatives in that period of time sum up for 2.301 in all award categories, while total finalist initiatives sum up for 175 (a twenty each year, approximately). Initiatives are classified in categories that indicate the field of government action framing their implementation (category is selected by submitting municipalities when filling in submission). However, it can be verified that initiatives generally are not entirely delimited by one single category, due to the extent of application. Therefore, categories are just a guiding reference. Graphic-1 shows the sharing of categories among all participant and finalist initiatives during our period of time. 
Graphic 1 - Share of categories in total participating and finalist initiatives

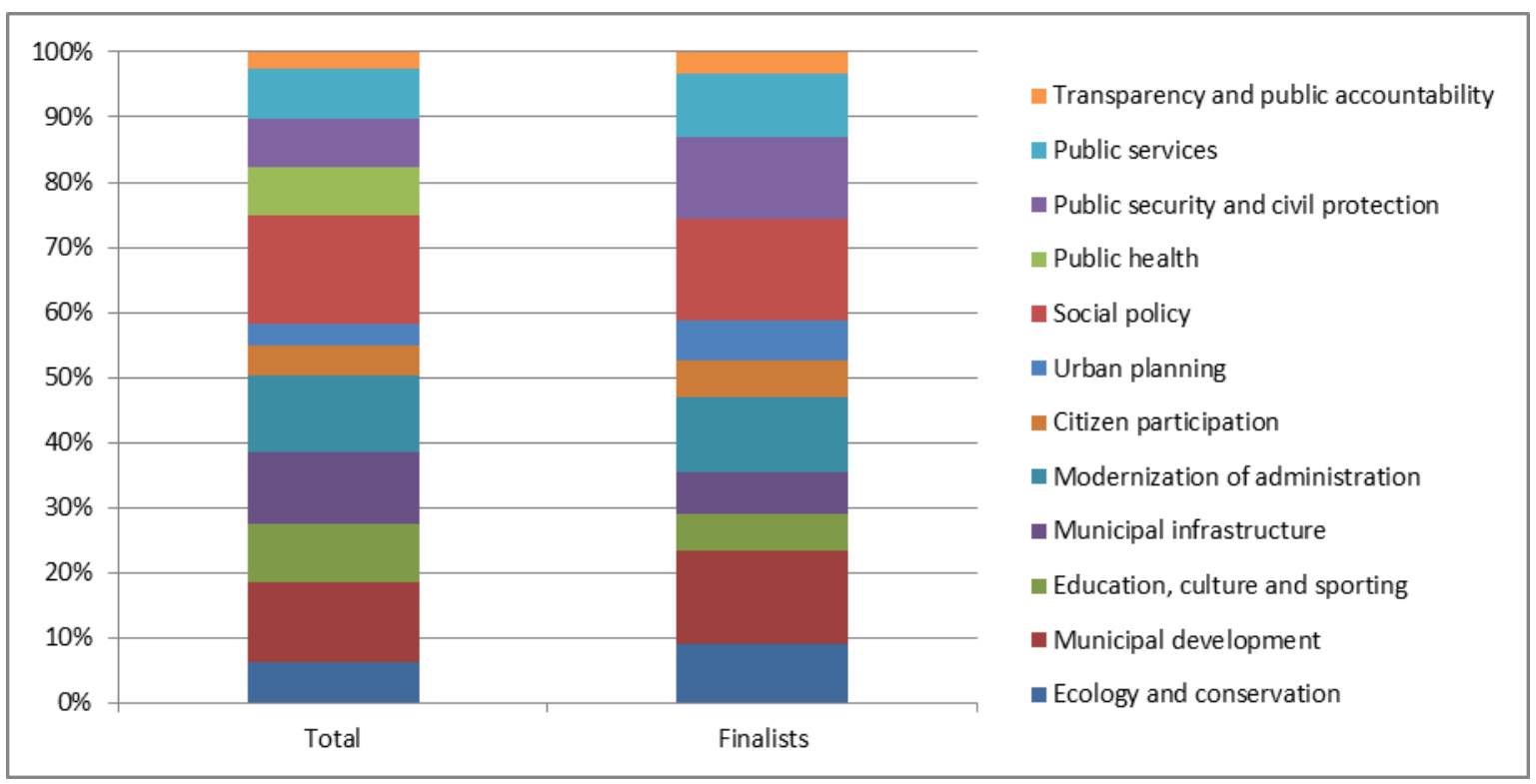

Four out of twelve categories gather around half of total participating initiatives: Social policy (16\%), Municipal development (12\%), Modernization of administration (12\%) and Municipal infrastructure (11\%). The image turns to be more or less similar when we account only for finalist initiatives: Social policy (15\%), Municipal development (14\%), Public security (13\%) and Modernization of administration (11\%).

Graphic-2 shows percentages of all participating and finalist initiatives, by size and concentration of population in submitting municipalities. The column called 'National' does not account for initiatives, but for the total number of municipalities within the country (2.454). It works for comparison purposes, between proportion of submitted initiatives and proportion of country's municipalities. It calls the attention that more than $50 \%$ of total initiatives come from municipalities classified as 'Big-Urban'. That is also true for finalist initiatives. At the same time, initiatives from municipalities classified as 'Metropolis' account for $12 \%$ and $14 \%$ of finalist and total participant initiatives, respectively. This observation is quite remarkable, since Metropolis represent less than $1 \%$ of the number of municipalities in the whole country. Likewise, Big-urban represents $4.5 \%$ of country's municipalities. Therefore, around $70 \%$ of total and finalist initiatives come from Metropolis and Big-urban municipalities, which these roughly represent $5 \%$ of the whole number of municipalities in the country. Another remarkable observation is that 'Rural' represents around $60 \%$ of municipalities in the country, while initiatives coming from rural municipalities barely account for $7 \%$ and $12 \%$ of total and finalist initiatives, respectively. 


\section{Graphic 2 - Percentages of participating and finalist initiatives by types of population}

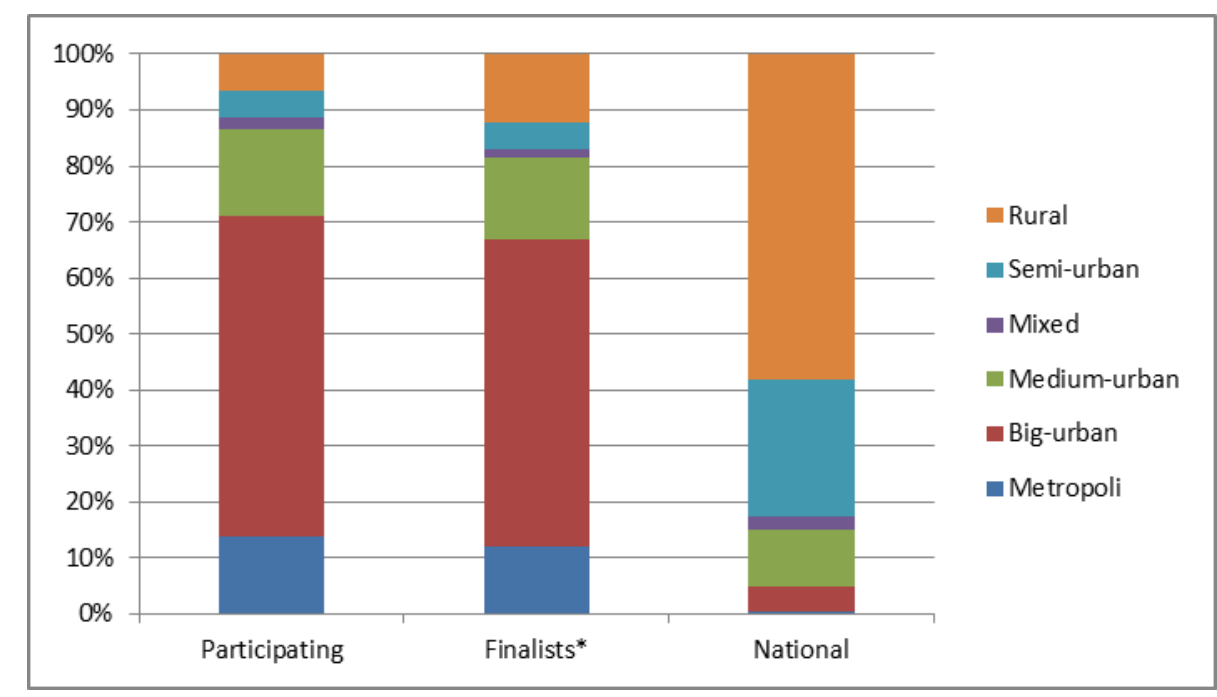

*Three initiatives, simultaneously submitted by multiple municipalities, were left out.

Same inverse relation can be observed when setting initiatives and municipalities according to levels of social exclusion, as shown in Graphic-3 ('National' column is for comparison purposes, like in previous chart). It can be verified that almost $90 \%$ of total participating initiatives come from municipalities with low and medium-low levels of social exclusion, while these kinds of municipalities account for less than a third of total country's municipalities. At the same time, those with high and medium-high levels of exclusion account for $5 \%$ and $10 \%$ of total participating and finalist initiatives, while same levels of exclusion affect to half of country's municipalities.

Graphic-4 shows shares of award's categories among all initiatives submitted from municipalities with high and low levels of exclusion. These are compared to the total amount of initiatives submitted by Metropolis. All Metropolis within the country suffer from mediumlow levels of social exclusion and account for $0,5 \%$ of total country's municipalities. It is remarkable that initiatives submitted by Metropolis surpass initiatives respectively submitted by municipalities with low and high levels of exclusion. Three categories gather around a half of total initiatives from low exclusion municipalities: Municipal infrastructure (19\%), Social policy (14\%) and Municipal development (13\%). Four categories gather around $70 \%$ of total initiatives from highly excluded municipalities: Municipal development (40\%), Municipal infrastructure (10\%), Citizen's participation (10\%) and Social policy (10\%).

Five categories gather $65 \%$ of total initiatives from municipalities classified as Metropolis: Social policy (21\%), Education, culture and sports (13\%), Modernization of administration (12\%), Public security (10\%) and Municipal development (9\%). 


\section{Graphic 3 - Percentages of participating and finalist initiatives by level of exclusion}

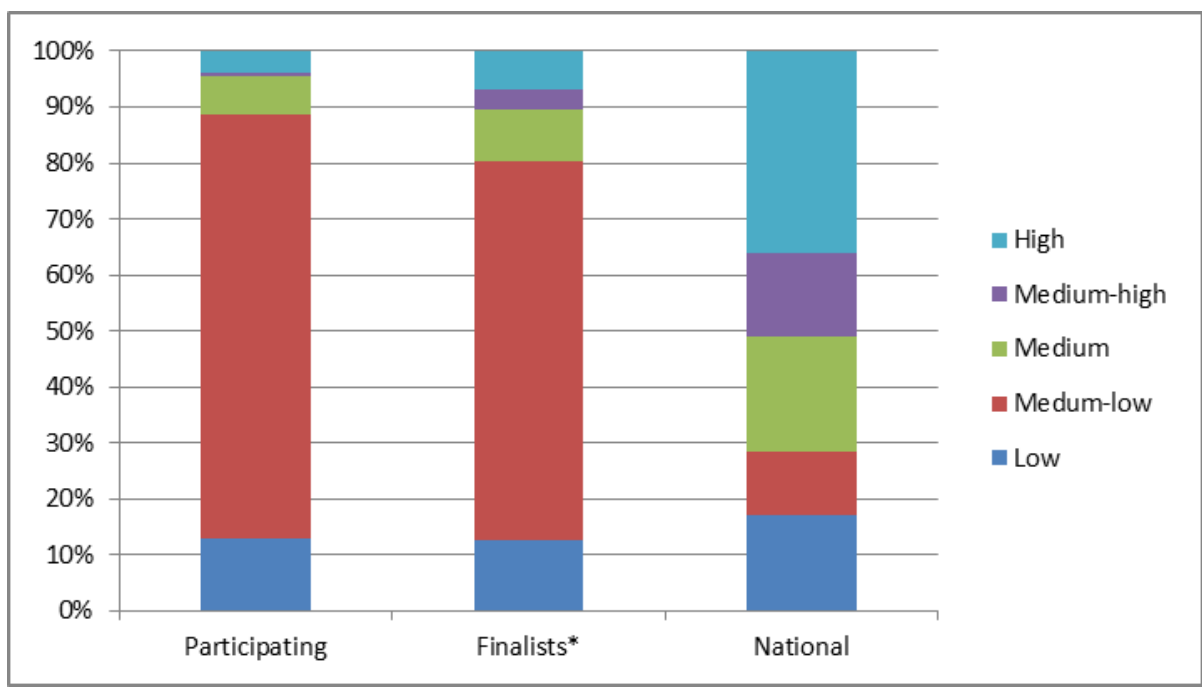

*Three initiatives, simultaneously submitted by multiple municipalities, were left out.

Graphic 4 - Share of categories in initiatives submitted by highly and lowly excluded municipalities and Metropolis

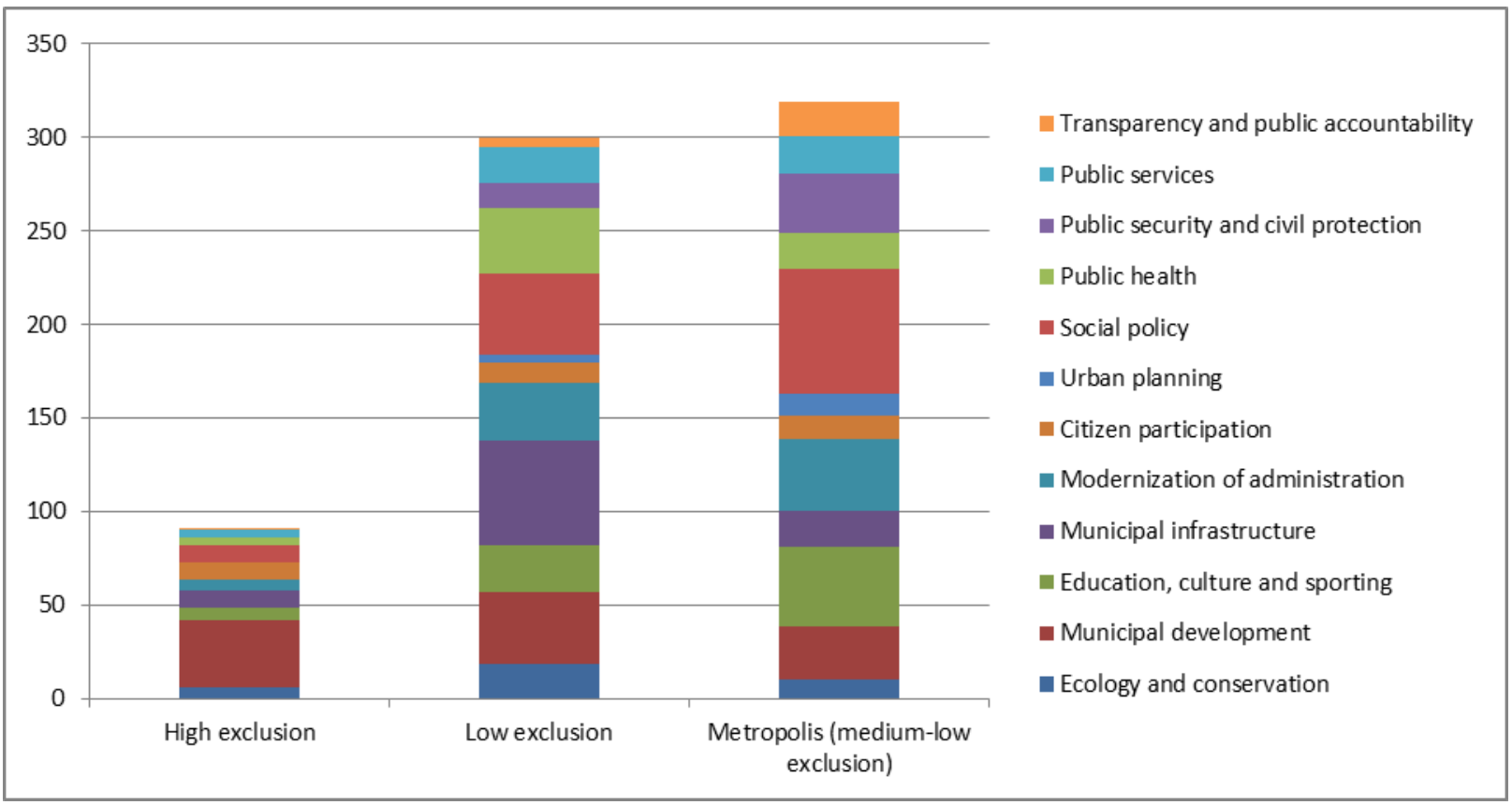

\section{Semifinalist initiatives from highly excluded municipalities:}

Within the seven year period covering our analysis, 174 initiatives were pre-selected for the final stage of the award contest. From these, 12 initiatives (7\%) were submitted by municipalities suffering from high levels of social exclusion. In Table 2 are presented short descriptions of each of these finalist initiatives and their submitting municipalities. Among these, half of municipalities are classified as 'Rural', according to their low size of concentrated population. Rural municipalities suffering from high levels of social exclusion are the most 
frequent within the country ( $28 \%$ from total number of country's municipalities). As seen before, highly excluded rural municipalities are shortly represented among award's total participating and finalist initiatives.

Table 2. Semifinalist initiatives from highly excluded municipalities

\begin{tabular}{|c|c|c|c|c|c|}
\hline State & Municipality & Population & Type & Initiative short description & $\begin{array}{c}\text { Award } \\
\text { category }\end{array}$ \\
\hline Oaxaca & $\begin{array}{l}\text { Santiago } \\
\text { Comaltepec }\end{array}$ & 1386 & $\mathrm{RU}$ & $\begin{array}{l}\text { Child music band. It was } \\
\text { created to preserve traditional } \\
\text { music and to breed values into } \\
\text { child. Instruments were bought } \\
\text { thanks to collaboration in } \\
\text { funding from other public } \\
\text { instances. }\end{array}$ & $\begin{array}{l}\text { Education, } \\
\text { culture and } \\
\text { sports }\end{array}$ \\
\hline Oaxaca & $\begin{array}{l}\text { Santiago } \\
\text { Yosondúa }\end{array}$ & 7197 & $\mathrm{RU}$ & $\begin{array}{l}\text { New ecological nature park. The } \\
\text { project was started by a civil } \\
\text { association and sponsored by } \\
\text { municipal government. Citizen } \\
\text { assemblies and funds from } \\
\text { higher government instances } \\
\text { took part in the development } \\
\text { process. }\end{array}$ & $\begin{array}{l}\text { Municipal } \\
\text { development }\end{array}$ \\
\hline Jalisco & $\begin{array}{l}\text { Cabo } \\
\text { Corrientes }\end{array}$ & 9034 & $\mathrm{RU}$ & $\begin{array}{l}\text { New eco-tourism attractions. } \\
\text { Implementation of new touring } \\
\text { routes and attractions. It } \\
\text { includes training for local } \\
\text { producers, promoting local } \\
\text { tourism and restoring public } \\
\text { spaces. }\end{array}$ & $\begin{array}{l}\text { Municipal } \\
\text { development }\end{array}$ \\
\hline $\begin{array}{l}\text { San Luis } \\
\text { Potosí }\end{array}$ & Matlapa & 29548 & RU & $\begin{array}{l}\text { Actions for reducing death in } \\
\text { birth labor. Actions are focused } \\
\text { in diagnosis, information } \\
\text { workshops and legal } \\
\text { counseling. }\end{array}$ & Public health \\
\hline Michoacán & Chilchota & 30299 & SU & $\begin{array}{l}\text { Education program for } \\
\text { indigenous people. It includes } \\
\text { building classrooms and new } \\
\text { school spaces and buying new } \\
\text { materials. State government } \\
\text { participates in literacy activities } \\
\text { and it was also created a } \\
\text { 'municipal commission for } \\
\text { education'. }\end{array}$ & $\begin{array}{l}\text { Education, } \\
\text { culture and } \\
\text { sports }\end{array}$ \\
\hline Michoacán & La Huacana & 31774 & $\mathrm{RU}$ & $\begin{array}{l}\text { Municipal development } \\
\text { strategy. It suggests and } \\
\text { implements actions for } \\
\text { introducing sustainability in all } \\
\text { local government functions. }\end{array}$ & $\begin{array}{l}\text { Municipal } \\
\text { development }\end{array}$ \\
\hline Michoacán & Huetamo & 41239 & $\mathrm{MU}$ & $\begin{array}{l}\text { Program of economic } \\
\text { incentives. Gives counseling } \\
\text { and financial aid to the main } \\
\text { economic activities of the } \\
\text { region. }\end{array}$ & $\begin{array}{l}\text { Municipal } \\
\text { development }\end{array}$ \\
\hline
\end{tabular}




\begin{tabular}{|c|c|c|c|c|c|}
\hline Yucatán & Tizimín & 69553 & $\mathrm{MU}$ & $\begin{array}{l}\text { Delivery of basic public } \\
\text { infrastructure. Financial } \\
\text { resources from a Federal fund } \\
\text { were taken to deliver basic } \\
\text { public infrastructure to an area } \\
\text { with high social exclusion. }\end{array}$ & Social policy \\
\hline Chiapas & Cintalapa & 73668 & $\mathrm{MU}$ & $\begin{array}{l}\text { Transparent public } \\
\text { accountability program. } \\
\text { Promotes access to information } \\
\text { through a web page and a TV } \\
\text { cast and also allows for } \\
\text { participation of citizens in } \\
\text { planning development and } \\
\text { investment programs. }\end{array}$ & $\begin{array}{l}\text { Transparency } \\
\text { and public } \\
\text { accountabilit } \\
\text { y }\end{array}$ \\
\hline México & $\begin{array}{l}\text { San José del } \\
\text { Rincón }\end{array}$ & 79945 & $\mathrm{RU}$ & $\begin{array}{l}\text { Civilian recruitment for policy } \\
\text { functions. Neighbors in } \\
\text { communities with greatly } \\
\text { dispersed population are } \\
\text { enrolled to help in policy } \\
\text { functions. }\end{array}$ & $\begin{array}{l}\text { Public } \\
\text { security and } \\
\text { civil } \\
\text { protection }\end{array}$ \\
\hline Chiapas & $\begin{array}{l}\text { Villaflores } \\
\text { (1) }\end{array}$ & 93023 & $\mathrm{MI}$ & $\begin{array}{l}\text { Municipal development } \\
\text { planning. Design of the plan for } \\
\text { development and investment } \\
\text { was carried through collective } \\
\text { participation of citizens after a } \\
\text { hundred of meetings in many } \\
\text { areas of the municipality. }\end{array}$ & $\begin{array}{l}\text { Citizen } \\
\text { participation }\end{array}$ \\
\hline Chiapas & $\begin{array}{l}\text { Villaflores } \\
\text { (2) }\end{array}$ & 93023 & $\mathrm{MI}$ & $\begin{array}{l}\text { Forest fire prevention program. } \\
\text { It is based on improvement of } \\
\text { technical and material } \\
\text { capabilities and participation of } \\
\text { citizens and civil organizations. }\end{array}$ & $\begin{array}{l}\text { Ecology and } \\
\text { conservation }\end{array}$ \\
\hline
\end{tabular}

$\mathrm{RU}=$ Rural, $\mathrm{SU}=$ Semi-urban, $\mathrm{MI}=$ Mixed, $\mathrm{MU}=$ Medium-urban

Finalist initiatives from Matlapa, Chilchota, and San Jose del Rincon are good examples of implementations addressed to improve citizen's life conditions along with basic public service provision, not by its technical design nor by strategic investment, but by creative new ways to deal with resource scarcity and lack of institutionalism.

Remarkable are cases based on extensive citizen participation for designing and implementing policies and programs. Initiatives from Santiago Yosondua, Cintalapa and Villaflores (2) put in practice participation at early stages of implementation or as an instrument for an accountable application of core initiative actions. Meanwhile, the initiative from Villaflores (1) stands out from its vast implementation of participation strategies. Only the initiative from Villaflores (2) mentions collaboration of no-state entities.

Initiatives rarely mention considerable investments or great use of technical and financial resources in implementation. Nonetheless, in few cases where considerable investments are needed they are provided by funds from higher levels of governance.

Santiago Comaltepec, Santiago Yosondua and Cabo Corrientes are the smallest municipalities submitting a finalist initiative; their population size makes them to be classified as 'Rural'. 
Thus, their initiatives appear to be simple idea applications with little bureaucratic complexity (with significant positive effects, nonetheless). Here, social capital seems to be more relevant than govern institutionalism in idea generation and implementation.

Bureaucratic appeal is more evident in initiatives from bigger municipalities, with greater size and population concentration, such as the ones from Chilchota, La Huacana, Huetamo, Tizimin, Cintalapa and Villaflores (2).

No initiative seems to be addressed to improve efficiency in public administration. In turn, it seems that initiatives are addressed to strengthen links between public instances and citizens and to develop local government as institution; that is: increasing effectiveness in delivering to citizens' needs and a transparent management of public resources.

There is one particular case where highly excluded municipalities take part in an association with municipalities with low levels of exclusion; it will be described in the next section.

Highlights of finalist initiatives from municipalities with high levels of exclusion can be summarized as follows: i) Improvisation and ad-hoc strategies, ii) Citizen participation is a highlighting feature, iii) Investment and use of technical resources are low: social capital seems to be more relevant, iv) Initiatives acquire a more bureaucratic appeal as they grow in population, v) Goals for administrative efficiency seem to be absent in finalist initiatives, vi) Associating with other municipalities for service delivering, vii) Initiatives addressed to meet citizens' needs and to a more transparent use of public resources.

\section{Semifinalist initiatives of municipalities with low exclusion:}

Among 174 initiatives pre-selected for the final stage of the award contest 24 (14\%) were submitted by municipalities with low levels of social exclusion. In Table 3 are presented short descriptions of each of these finalist initiatives and their submitting municipalities. In average, municipalities in here are bigger than highly excluded municipalities submitting finalist initiatives. However, the size gap is not as big as could be observed with respect of municipalities with medium-low and medium levels of social exclusion. Nonetheless, it calls the attention that medians of municipalities'population in Table- 2 and Table-3 are very close.

Table 3. Semifinalist initiatives from municipalities with low exclusion

\begin{tabular}{|l|l|c|c|l|l|}
\hline \multicolumn{1}{|c|}{ State } & Municipality & Population & Type & \multicolumn{1}{|c|}{ Initiative short description } & \multicolumn{1}{c|}{$\begin{array}{c}\text { Award } \\
\text { category }\end{array}$} \\
\hline Oaxaca & $\begin{array}{l}\text { Capulálpam } \\
\text { de Méndez }\end{array}$ & 1313 & RU & $\begin{array}{l}\text { Municipal development program. } \\
\text { Design of the program is based in } \\
\text { high citizen participation, not just in } \\
\text { planning of actions but also in its } \\
\text { implementation. }\end{array}$ & $\begin{array}{l}\text { Municipal } \\
\text { development }\end{array}$ \\
\hline Jalisco & El Limón & 5410 & SU & $\begin{array}{l}\text { Inter-municipal actions for restoring } \\
\text { Ayuquila river. A trusteeship and a } \\
\text { technical commission were created. } \\
\text { For carrying the job, complementary } \\
\text { financing was obtained and citizens' } \\
\text { participation was enabled. }\end{array}$ & $\begin{array}{l}\text { Ecology and } \\
\text { conservation }\end{array}$ \\
\hline Tlaxcala & Ixtenco & 6279 & SU & $\begin{array}{l}\text { Citizen council for public account } \\
\text { supervision. Creation of a citizen } \\
\text { council with the objective to keep } \\
\text { surveillance over municipal public }\end{array}$ & $\begin{array}{l}\text { Citizen } \\
\text { participation }\end{array}$ \\
\hline
\end{tabular}




\begin{tabular}{|c|c|c|c|c|c|}
\hline & & & & accountancies. & \\
\hline México & Tonatico & 10901 & SU & $\begin{array}{l}\text { Keeping links with emigrated people. } \\
\text { Actions addressed to help emigrated } \\
\text { people to stay linked to their } \\
\text { community. Some other public } \\
\text { organizations took part. }\end{array}$ & $\begin{array}{l}\text { Municipal } \\
\text { development }\end{array}$ \\
\hline Tlaxcala & Panotla & 22368 & SU & $\begin{array}{l}\text { Recondition public spaces for sport } \\
\text { practice. Financial resources from the } \\
\text { three levels of governance were } \\
\text { taken to enable spaces to be used for } \\
\text { sport practicing. }\end{array}$ & $\begin{array}{l}\text { Municipal } \\
\text { infrastructure }\end{array}$ \\
\hline Jalisco & $\begin{array}{l}\text { Ixtlahuacán } \\
\text { de los } \\
\text { Membrillos }\end{array}$ & 23420 & $\mathrm{RU}$ & $\begin{array}{l}\text { Increasing revenues in real property } \\
\text { taxes. A program of incentives for tax } \\
\text { payers was implemented. It helped } \\
\text { to overcome a situation where tax } \\
\text { revenues were inferior to costs of } \\
\text { collecting property taxes. }\end{array}$ & $\begin{array}{l}\text { Modernizatio } \\
\mathrm{n} \text { of } \\
\text { administratio } \\
\mathrm{n}\end{array}$ \\
\hline Guanajuato & $\begin{array}{l}\text { Jaral del } \\
\text { Progreso (1) }\end{array}$ & 31780 & $\mathrm{MU}$ & $\begin{array}{l}\text { Scholarships program. Sponsoring } \\
\text { education through scholarships. }\end{array}$ & $\begin{array}{l}\text { Education, } \\
\text { culture and } \\
\text { sports }\end{array}$ \\
\hline Guanajuato & $\begin{array}{l}\text { Jaral del } \\
\text { Progreso (2) }\end{array}$ & 31780 & $\mathrm{MU}$ & $\begin{array}{l}\text { Citizen access. Opening access to } \\
\text { citizenry by enabling special modules } \\
\text { for attention and giving information } \\
\text { on municipality's tasks. }\end{array}$ & \\
\hline Jalisco & Tuxpan & 32462 & $\mathrm{MU}$ & $\begin{array}{l}\text { Inter-municipal development plan. } \\
\text { Design of the plan was coordinated } \\
\text { between municipalities. It included } \\
\text { participation of local producers and } \\
\text { civil organizations. Links to } \\
\text { universities and technology transfer } \\
\text { is a remarkable part of the plan. }\end{array}$ & $\begin{array}{l}\text { Municipal } \\
\text { development }\end{array}$ \\
\hline Jalisco & $\begin{array}{l}\text { Tamazula de } \\
\text { Gordiano }\end{array}$ & 35987 & $\mathrm{MI}$ & $\begin{array}{l}\text { Broadcasting council sessions. A TV } \\
\text { channel was created for broadcasting } \\
\text { sessions of the municipal council. }\end{array}$ & $\begin{array}{l}\text { Municipal } \\
\text { development }\end{array}$ \\
\hline Guerrero & Pungarabato & 36466 & $\mathrm{MU}$ & $\begin{array}{l}\text { Inter-municipal actions for } \\
\text { development. Include various actions } \\
\text { framed by a whole development } \\
\text { program: urban waste management, } \\
\text { delivering basic services, sponsoring } \\
\text { entrepreneurial projects. }\end{array}$ & $\begin{array}{l}\text { Municipal } \\
\text { development }\end{array}$ \\
\hline Zacatecas & Ojocaliente & 37545 & $\mathrm{MU}$ & $\begin{array}{l}\text { Hepatitis prevention program. } \\
\text { Program includes latrines installation, } \\
\text { information rounds and medical } \\
\text { analysis and diagnosis. }\end{array}$ & Public health \\
\hline $\begin{array}{l}\text { Coahuila de } \\
\text { Zaragoza }\end{array}$ & Parras & 44715 & $\mathrm{MU}$ & $\begin{array}{l}\text { Enabling delegations to help } \\
\text { communication between scattered } \\
\text { communities and municipality head. }\end{array}$ & $\begin{array}{l}\text { Modernizatio } \\
\mathrm{n} \text { of } \\
\text { administratio } \\
\mathrm{n}\end{array}$ \\
\hline Jalisco & $\begin{array}{l}\text { Zapotlanejo } \\
\text { (1) }\end{array}$ & 55827 & $\mathrm{MU}$ & $\begin{array}{l}\text { Urban development program. } \\
\text { Building and restoring urban } \\
\text { facilities. It includes participation of } \\
\text { the three levels of governance and } \\
\text { also private organizations and } \\
\text { universities. }\end{array}$ & $\begin{array}{l}\text { Urban } \\
\text { planning }\end{array}$ \\
\hline Jalisco & $\begin{array}{l}\text { Zapotlanejo } \\
\text { (2) }\end{array}$ & 55827 & $\mathrm{MU}$ & $\begin{array}{l}\text { Integral health program. It includes } \\
\text { itinerant health services, prevention } \\
\text { campaigns, building and restoring } \\
\text { clinics and sponsoring eye surgeries. }\end{array}$ & Public health \\
\hline
\end{tabular}




\begin{tabular}{|c|c|c|c|c|c|}
\hline Veracruz & Coatepec & 79787 & $\mathrm{MU}$ & $\begin{array}{l}\text { Forest and water conservation. } \\
\text { Creation of a trusteeship for forest } \\
\text { and water conservation purposes. }\end{array}$ & $\begin{array}{l}\text { Ecology and } \\
\text { conservation }\end{array}$ \\
\hline Guerrero & $\begin{array}{l}\text { Iguala de la } \\
\text { Independen- } \\
\text { cia }\end{array}$ & 128444 & UG & $\begin{array}{l}\text { Inter-municipal urban waste } \\
\text { management. It emerged in the } \\
\text { context of an already existent } \\
\text { association of municipalities. Being in } \\
\text { an association has allowed obtaining } \\
\text { funds from higher levels of } \\
\text { governance. }\end{array}$ & $\begin{array}{l}\text { Municipal } \\
\text { infrastructure }\end{array}$ \\
\hline Hidalgo & $\begin{array}{l}\text { Tulancingo } \\
\text { de Bravo }\end{array}$ & 129935 & $\mathrm{MU}$ & $\begin{array}{l}\text { Paths for no-motor mobility. Setting } \\
\text { of paths to help mobility among } \\
\text { communities by means of no-motor } \\
\text { vehicles. }\end{array}$ & $\begin{array}{l}\text { Municipal } \\
\text { infrastructure }\end{array}$ \\
\hline Sonora & Navojoa & 144598 & $\mathrm{BU}$ & $\begin{array}{l}\text { Actions for restoring the Mayo river. } \\
\text { Implementing actions to solve river } \\
\text { deterioration }\end{array}$ & $\begin{array}{l}\text { Ecology and } \\
\text { conservation }\end{array}$ \\
\hline Veracruz & Córdoba & 186623 & $\mathrm{BU}$ & $\begin{array}{l}\text { Restoring the urban area known as } \\
\text { "Alameda Murillo Vidal" }\end{array}$ & $\begin{array}{l}\text { Municipal } \\
\text { infrastructure }\end{array}$ \\
\hline $\begin{array}{l}\text { Quintana } \\
\text { Roo }\end{array}$ & $\begin{array}{l}\text { Othón P. } \\
\text { Blanco }\end{array}$ & 219763 & $\mathrm{BU}$ & $\begin{array}{l}\text { Construction of community area. } \\
\text { Financial resources from a Federal } \\
\text { fund were taken to build and } \\
\text { recondition a community urban area. }\end{array}$ & $\begin{array}{l}\text { Urban } \\
\text { planning }\end{array}$ \\
\hline Puebla & Tehuacán & 260923 & $\mathrm{BU}$ & $\begin{array}{l}\text { New 'Intra-family violence attention } \\
\text { center'. Creation of a center for } \\
\text { aiding and counseling people that } \\
\text { suffers from family violence. }\end{array}$ & Social policy \\
\hline Michoacán & Uruapan & 279229 & $\mathrm{BU}$ & $\begin{array}{l}\text { New 'Council for municipal } \\
\text { development'. A council was created } \\
\text { with people representing territories } \\
\text { of the municipality. Its purpose is to } \\
\text { join citizen participation into } \\
\text { planning of infrastructure building. }\end{array}$ & $\begin{array}{l}\text { Municipal } \\
\text { infrastructure }\end{array}$ \\
\hline Guerrero & $\begin{array}{l}\text { Acapulco de } \\
\text { Juárez }\end{array}$ & 717766 & $\mathrm{BU}$ & $\begin{array}{l}\text { Childs' municipal council. New } \\
\text { council that meets regularly for ruling } \\
\text { on childhood issues. }\end{array}$ & $\begin{array}{l}\text { Citizen } \\
\text { participation }\end{array}$ \\
\hline
\end{tabular}

$\mathrm{RU}=$ Rural, $\mathrm{SU}=$ Semi-urban, $\mathrm{MI}=$ Mixed, $\mathrm{MU}=$ Medium-urban, $\mathrm{BU}=$ Big-urban

Implementation of initiatives from municipalities with low exclusion looks more complex in management and proceedings (they have a more bureaucratic appeal). This is more or less observable among all initiatives, but especially evident in initiatives such as the ones from El Limon, Ixtlahuacan de los Membrillos, Tuxpan, Pungarabato and Tehuacan.

Initiatives demanding citizens' participation are also common here. Initiatives from Ixtenco, Uruapan and Acapulco de Juarez incorporate participation into the formal organization of the local government. Collaboration of no-state entities is rare. They are mentioned taking part in initiatives from Tuxpan and Zapotlanejo (1).

The use of technical and financial resources is more evident in finalist initiatives from municipalities with low exclusion, like those from El Limon, Panotla, Jaral del Progreso (1), Tuxpan, Ojocaliente and Navojoa. Also, from initiatives that go through widening public infrastructure, one could deducepublic expense is bigger in initiatives from lowly excluded municipalities. Initiatives from Panotla, Zapotlanejo (1), Cordoba and Othon P. Blanco are good examples of it. 
Initiatives based in unions of municipalities are frequent. Some of these are made up for services provision, particularly urban waste management. Award's contesting allows municipalities to submit initiatives that are implemented together with other municipalities, as did by El Limon, Tuxpan, Pungarabato and Iguala de la Independencia. However, municipalities associated in the implementation of an initiative are allowed to submit and contest simultaneously. There are two finalist initiatives with significant presence of municipalities with low exclusion (see Table 4). Noticeably, in one of them appear highly excluded municipalities taking part.

Overall, initiatives seem addressed to strengthen local government institution (through promoting transparency and participation) and to improve citizens' living quality. Initiatives addressed to improve efficiency or promote modernization of public instances are not specially highlighted. Certainly, one could think of municipalities associating for service delivering (waste management, in particular) as driven by management efficiency. Nevertheless, the initiative from Ixtlahuacan de los Membrillos is the only one that features the spirit of an efficient public administration (as it is subscribed to the 'Modernization of administration' category). This one of a kind among all finalist initiatives from low and highly excluded municipalities.

Table 4. Semifinalist initiatives from jointly municipalities' submissions

\begin{tabular}{|c|c|c|c|c|c|}
\hline State & Municipalities & Exclusion & Type & Initiative & Category \\
\hline Jalisco & $\begin{array}{l}\text { Concepción de Buenos Aires, } \\
\text { Santa María del Oro, La } \\
\text { Manzanilla de la Paz, Mazamitla, } \\
\text { Quitupan, Tizapan el Alto, } \\
\text { Tuxcueca, Valle de Juárez }\end{array}$ & $\begin{array}{l}L, H, L, L, H, \\
L, L, L\end{array}$ & $\begin{array}{l}\text { SU, RU, RU, } \\
\text { SU, RU, SU, } \\
\text { SU,SU }\end{array}$ & $\begin{array}{l}\text { Inter-municipal } \\
\text { urban waste } \\
\text { management }\end{array}$ & $\begin{array}{l}\text { Public } \\
\text { services }\end{array}$ \\
\hline Mexico & $\begin{array}{l}\text { Amecameca, Atlautla, Ayapango, } \\
\text { Cocotitlán, Chalco, Ecatzingo, } \\
\text { Ixtapaluca, Juchitepec, Ozumba, } \\
\text { Temamatla, Tenango del Aire, } \\
\text { Tepetlixpa, Tlalmanalco, Valle } \\
\text { ChalcoSolidadridad }\end{array}$ & $\begin{array}{l}L, L, L, M L, L \\
M, M L, L, L \\
L, L, L, M L \\
M L\end{array}$ & $\begin{array}{l}\text { MU, SU, RU, } \\
\text { SU, BU, SU, } \\
\text { BU, SU, MU, } \\
\text { SU, SU, SU, } \\
\text { MI, BU }\end{array}$ & $\begin{array}{l}\text { Municipal } \\
\text { association for } \\
\text { development }\end{array}$ & $\begin{array}{l}\text { Municipal } \\
\text { developme } \\
\text { nt }\end{array}$ \\
\hline
\end{tabular}

$\mathrm{L}=$ Low, $\mathrm{ML}=$ Medium-low $\mathrm{M}=$ Medium, $\mathrm{H}=$ High,

$\mathrm{RU}=$ Rural, $\mathrm{SU}=$ Semi-urban, $\mathrm{MI}=$ Mixed, $\mathrm{MU}=$ Medium-urban; $\mathrm{BU}=$ Big-urban

Highlights of finalist initiatives from municipalities with low levels of exclusion can be summarized as follows: i) Initiatives look more complex in management and proceedings (they have a more bureaucratic appeal), ii) Citizens' participation is incorporated into formal government organization, iii) Investment and use of technical resources are higher than in highly excluded municipalities' initiatives, iv) Unions of municipalities are frequent, v) Initiatives are mostly addressed to enhance effectiveness in meeting citizens' needs and to pursue legitimation; however, efficiency goals are also featured, to a lesser extent.

\section{Discussion}

Statistics show very low participation rates of initiatives from highly excluded rural municipalities. On the other hand, initiatives from big urban centers - typically with medium- 
low or low levels of exclusion - they show an extensive participation. This is opposed to the proportion that these kinds of municipalities represent among the total number of municipalities within the country. Suitable reasons for this to be the case might come from bias in award's promotion of participation, lack of municipalities' interest for taking part in the contest (together with lack of awareness), or that this actually is an indicator of capabilities and un-capabilities of Mexican local governments. Borins $(2001,2006)$ makes his analysis basing on information from the Innovations in American Government Awards ${ }^{22}$ : a contest with a format very similar to that of the Government and Local Management Award. Borins (2008, p. 4) says about information from the American Government Award: "Because the awards program casts its net so widely and generates so much interest, we can be confident that its pool of applicants represents the range of trends in innovation in government". Having Borins argument as reference, if we assume that what can be read from the Local Management Award is a true image of local governments at national level, one could then interpret the small participation rates of highly excluded rural municipalities as evidence of their low capacity for generating novel and significant government actions, while large participation rates of big urban centers might on the contrary be evidencing a larger capacity.

When grouping initiatives by characteristics of submitting municipalities, it can be observed different tendencies in award's categories where initiatives are subscribed. Social policy and Municipal development are among most frequent categories. This point to the importance of local government actions addressed to give attention to vulnerable population and to supplement backwardness of citizens' life conditions. On the other hand, categories more related with local government institutional appeal, such as Transparency and public accountability and Urban planning, they are less frequent.

It is remarkable that more than a third of initiatives from highly excluded municipalities are in the Municipal development category. In turn, the most frequent category among initiatives from municipalities with low exclusion is Municipal infrastructure, while initiatives from metropolis give some importance to categories that are less relevant among other kinds of municipalities, such as Education, culture and sporting and Modernization of administration. This gives support to believe that municipalities with low social exclusion (presumably, more institutionally developed) and metropolis (with larger financial capacity and more complex organizations) they have partially overcome the pre-bureaucratic stage that hinders the application of novel, sustainable and significant governance initiatives.

In general terms, initiatives encompass to a certain degree the previously described settings of Mexican local governments counteracting efficient-effective administrations' performance. To this respect, the 2011 executive report of the award remarks: Our municipalities tend to high rotation in civil servants' positions, to give little or no continuity to the work of previous administrations and to start every new governance period with new personnel and new organization models... The challenge of our local governments is to lead to good results in short time and with scarce resources. This is embedded in reviewed initiatives, where sidestepping and ad-hoc design are still noticeable. However, those initiatives submitted by municipalities with low levels of social exclusion appeal governmental organizations with greater institutional

\footnotetext{
${ }^{22}$ http://www.ash.harvard.edu/Home/Programs/Innovations-in-Government/Awards
} 
strength: perhaps a consequence from greater social development. Initiatives that formally incorporate citizens' participation into government organization, higher levels of expense and use of technical resources and certain efficiency pursuing features give evidenced in that direction.

In municipalities with high levels of exclusion weakness of the local governance institution (in what is been called the pre-bureaucratic stage) is more tangible. However, the profile of their finalist initiatives show some interesting characteristics that suggest innovative initiatives can be a way to enhance local government capability and, in the long run, allow for sustainable improvement through innovation. High levels of citizens' participation, use of social capital, aim for development and association with municipalities with better capabilities give evidence in that direction.

Initiatives from municipalities with low and high levels of exclusion have in common the aim for pursuing actions whose results lead to develop life conditions and government legitimacy, while actions towards a more efficient administration are rare in municipalities with low exclusion and inexistent in highly excluded municipalities. Here we might have additional evidence on the dichotomy between efficiency and legitimation. As it can be seen, legitimation is much more appealed in reviewed initiatives, which lead to believe that strengthening local government institution is still much needed among Mexican municipalities and it is still a fundamental objective. It is a requirement for a more efficient public administration, which allows for sustainable higher leveled innovation.

\section{Concluding remarks}

Organizations responsible for public administration in developing countries suffer from lack of legitimacy and institutional weakness. In the particular case of Mexican local government, where lack is more tangible than in higher levels of governance, institutional weakness lead to public administrations performing in discretional ways. Lacks in regulation, continuation and systematization of activities lead to innovation as a policy strategy: innovation is a consequence of a groping and sidestepping management style. Thus, in most part, innovation in Mexican local governments does not appear as a virtuous process that brings improvement and technical enhancement, but as a process that encompasses inefficiency, backwardness and under use of public resources in its way to achieve some results.

An innovative implementation needs an institutional frame that allow for its systematization and continuity (i.e. solid institutions and strong regulations). Thus, for innovation to be successful in improvement it is necessary that public organizations previously went through a process in a way somewhat opposed to that of innovation: strengthening hierarchies and authority, processes and regulations, in such a way that they let for well-defined and established operations that can go over organizational changes due to changes in administration after elections (and such that it helps to moderate the dynamics of change). Hence, the paradigm of efficiency and improvement found in innovation require overcoming the pre-bureaucratic stage of public institutions, where excessive flexibility and lack of regulation make "innovation" the usual mean to operate. This situation leads to inefficient 
results and scarce chances to develop improvements. However, in so called pre-bureaucratic institutions innovation can be of special value and lead to sustainable efficiency and development when it is addressed to institutional strengthening. That is to say, when creative initiatives and search for alternative ways generate sustainable processes and help to more solid institutions.

Observation of initiatives taking part in the Government and Local Management Award gives evidence to believe that Mexican municipalities with low levels of social exclusion (presumably with higher institutional development) have more appropriate institutional characteristics for successfully implementing innovation as a tool for public service improvement. And, on the contrary, poorly developed Mexican municipalities find more difficulties to achieve improvement and development through innovation. Observation of initiatives also yields an important conclusion: Innovation can be of special benefit for poorly developed municipalities when it is addressed to strengthen the institutional founding of local governments. 
Concluding remarks 
Public innovation studies have gained relevance over the last years. There is already an important bulk of literature laying the basis for a systematic knowledge about the issue. Public innovation studies are approached from diverse theoretical perspectives. These include the organizational perspective, the policy perspective, the managerial perspective and also some well-known theoretical traditions, such as innovation theory and service industry theory.

At the same time, the observation of the innovation process (from idea generation to implementation) is focused in view of the different actors intervening in the innovation process, how ideas are generated and how the process is leaded. To this respect, the top-down approach put emphasis in the hierarchical nature of public organizations by suggesting that innovation processes start in the form of authority mandates and goes down in the hierarchic structure to its implementation by middle-level managers and staff. In turn, the bottom-up approach sees innovation started by staff employees, whose ideas are supported by middlelevel managers and approved by authorities for its implementation. These two approaches are good to illustrate on the one side the importance of hierarchy, authority and policy goals and, on the other side, the importance of staff participation, entrepreneurship and involvement of organizations' managers.

Both approaches described above are in line with a particular way to understand the objectives and activities of public sector organizations: Traditional Public Administration, where activities and goals are oriented by policy decisions and organizations are highly hierarchical (bureaucratic) resting on legal rational authority and oriented towards procedures. However a more recent understanding that can be observed in studies on public sector organizations sees their operations in the form of networks, which makes public beneficiaries and suppliers (citizens and private organizations in either case) to also play an important role in the innovation process, from idea generation to implementation.

Thus, it ca be observed diverse sets of factors influencing and enabling innovation generation as well as diverse agents intervening in the process and diverse approaches helping the understanding of innovation. This diversity obeys to a wide conceptualization of public innovation, as explained in the introductory part of the dissertation.

The theoretical foundation of research carried in this thesis dissertation corresponds to the many approaches previously described. Applied empirical methodologies use a simplified and compact framing that gathers together concepts and ideas from the many perspectives found in studies addressed to public innovation. Thus, along with the applied aim under empirical research methods, there was also the aim to help to a more consolidated theory of public innovation (public innovation theory is still on an early stage (Alves, 2013)). Chapters follow a structure where a theoretical frame is build up in first place and then an empirical method is implemented in order to test some hypotheses addressed by provided frameworks. The applied methodologies and theoretical propositions (hypotheses) are set up in order to give answer to questionings about public innovation drivers and enablers, the barriers that implementing organizations have to face and the kinds of effects that can be obtained after implementation. 


\section{Chapters 1 and 2: Drivers and enablers for public innovation}

Drivers and enablers of innovation are of different nature and affect public innovation in different ways and in different phases of the innovation process. It is of interest to know to which extent the many identifiable drivers and enablers can positively help a successful innovation process, until innovation implementation. Data available for testing for such a questioning comes from a large scale survey funded by the European Commission: The Innobarometer 2010 Survey. It contains information on public organizations implementing innovations, from the 27 members of the European Union and also Norway and Switzerland. Information content in the Innobarometer Survey (that is, what can be known about public innovation from the survey) is what determines in an important manner the hypotheses suggested after innovation drivers and enablers and also the empirical modeling helping for testing hypotheses. In particular, the survey does not give information about how the innovation process takes place in every of the surveyed organizations, but it lets to know public organizations that succeeded in innovation implementation. Thus, hypotheses on drivers and enablers refer to how these affects to innovation implementation. They might play different roles in innovation development; however, this cannot be addressed in the empirical modeling and the extent to which drivers and enablers can positively affect public innovation is evaluated by the assessment of a statistical relation between identifiable factors driving and enabling public innovation and the fact that public organizations have achieved innovation implementation. In addition, another important aspect that defines the empirical analysis is that it is focused in the observation of service innovations in particular, given that these are the kind of innovations better observable in Innobarometer data.

Chapter 1 is specially addressed to the assessment of the effects of drivers and enablers on the implementation of service innovations. It is there first presented a summary of factors frequently mentioned in previous literature as relevant for public innovation. From a policy perspective, policy mandates are of special relevance for generating and implementing innovation. New laws and regulations, policy turn-around, responses to crisis from authorities and elected representatives, new trends in public administration; all these are good examples of political factors that can work as an important source for public innovation. From a managerial perspective, involvement of managers is considered to be highly relevant for a successful innovation process. Thus managers are expected to not just command provide with their own ideas, but to support ideas from staff employees for their development and further implementation, and also to take part in the development process with supervision and advice. On the other side, a networked view of public administration suggests that citizens and private organizations (private firms and civil organizations) should also play a relevant role in innovation development, given that their interactions with public organizations as beneficiaries and suppliers is an important input for the development process. Public innovation studies also mention some strategies that are important to observe for helping to achieve more and better innovations. These include rewarding innovative behaviour, taking advantage of experiences and information sources outside the organization, making alliances and networks with other organizations and allowing experimentation and evaluation.

Hypotheses are addressed to test the importance that public innovation drivers and enablers have towards implementation of service innovations: 
H1: Political and legislative factors are a significant driver for implementing public service innovations.

H2: Drivers and enablers that imply active involvement of mangers are significant for implementing public service innovations.

H3: Application of enabling strategies has a significant effect in the implementation of public service innovations.

It is very clear that hypothesis are addressed to the observation of service innovations; however, the empirical analysis carried for hypothesis testing puts particular interest in the observation of implementation of services that are new to the whole public sector. There are two reasons for analyzing new services - which are service innovations in straight sense apart from other kinds of service innovations. First one is a methodological reason; this, following the structure of the Innobarometer Survey questionnaire, where respondents are first asked whether or not they have recently implemented any service innovation and after they give an affirmative answer they are asked if at least one of their service innovations consists in a service which is new to whole country's public sector. Second reason is theoretical. It is believed that services that are new to the whole sector are closer to the understanding of innovation as a paradigm for development, in a similar way that radical innovations are understood in innovation theory. Special interest in observing this type of innovations is because they help to observe how innovation is not just improving one organization in particular, but the whole public sector instead.

The followed method for testing hypotheses consists in estimating the probabilities of being identified as an organization implementing new services among organizations previously identified as implementing service innovations. To do so, a bivariate probit regression with sample selection (also known as Heckman's probit) is applied. Explicative variables for probability estimation are the result of a process of component extraction from 18 ordinal variables in the Innobarometer Survey dataset indicating the level of importance that respondents give to drivers and strategies for innovation in the innovation development process. Resulting components are four and they are interpreted as representing the importance of: Political and legislative factors, Active involvement of managers, Use of external sources of information and Participation of users and staff. In addition to probability estimation, marginal effects were also calculated from estimated equations in order to measure changes in probability from "unitary" changes in components representing drivers and enablers.

Statistical significance and magnitude of results in probability estimation and marginal effects support propositions from second and third hypotheses: active involvement of managers and the application of enabling strategies both are significant for the implementation of service innovations. Results are not significant enough when it comes to the effects of political and legislative factors. These might be considered somewhat important for the implementation of service innovations, but results do not let to evaluate their importance for introducing new services because of lack of statistical significance. This finding strongly calls the attention given that literature frequently mentions political factors as particularly important for generating public innovation. With respect to third hypothesis, Innobarometer data and component 
extraction have let to analyze two strategies in particular: the use of external sources of information and user and staff participation. Both of them show high and significant effects on both the probability of being an organization implementing service innovations and the probability of being an organization introducing services that are new to the whole sector. Nonetheless, the effect of use of external sources of information is remarkable, and even higher than active involvement of managers.

Additional contributions in this chapter are in the methodological field. The component extraction method applied on the Innobarometer variables is known as Categorical Principal Component Analysis (CATPCA). It is based on a variable transformation technique called optimal quantification, which transform ordinal variables into interval scaled variables. This is a more appropriate component extraction method for ordinal variables than conventional component analysis. There are references to previous publications that use PCA on ordinal variables with acceptable results (some examples are mentioned in Arundel and Hollanders, 2011); however, there are not known references to empirical analysis in the approached research fields that use CATPCA. Another methodological contribution is in the application of a bootstrapping process on component extraction. This is an instrument addressed to prove data stability and, therefore, to give robustness to resulting extracted components and the empirical analysis in general.

Chapter 2 continues in the line of deepen the understanding of factors that enable more and better innovations within public organizations. Research questions in this chapter are aimed by one particular finding in previous chapter: the one that points at the use of external sources of information as a highly relevant enabler for service innovation and introduction of services that are new to the whole sector as well. Theoretical antecedents and the networked view of the public sector suggest that there might be an important role for using external sources of knowledge and information in public innovation.

Studying the implications of using external sources is a growing trend in innovation literature; however, this has been mainly developed in studies based on manufacturing and service industry firms. To this respect, one of the key contributions of chapter 2 is in the theoretical side and it consists in the adaptation of revised theoretical frames in private firm studies to a frame that takes into consideration fundamental specificities of public organizations. Testing patterns of use of external sources among public organizations has not the same implications than it does for the manufacturing sector or even for the private services sector. However, it is a useful model for advancing in understanding public innovation. Thus, in chapter 2 is offered a comparative view between revised conceptual frames on innovation from manufacturing business studies, service business studies and public organizations. Differences observed are taken as a basis form proposing a new way to understand organizational boundaries; a new way that corresponds to the specifities of innovation in public organizations. The interesting value added of proposed boundaries understanding is in the identification of three different ways of sources creating knowledge flows for public administrations: internal driven, external driven and mixed (combined) innovations. What establish the differences between them is not so much the type of actors participating in the knowledge and information flows, but the directions these flows are formed. 
Proposed theoretical framework is empirically tested under two hypotheses:

H1: Use of external sources of information in innovation development has a significant effect in the implementation of services that are new to the whole public sector.

H2: Use of external sources of information for innovation development has a greater effect on introduction of services that are new to the whole public sector than using internal sources.

Both research hypotheses are addressed to the observation of new-to-the-whole-sector services. Like in previous chapter, this is aimed by the Innobarometer Survey questionnaire structure and a classification of public organizations used in reporting survey results. Classification is made focusing on organizations' service innovations, while not making any remark on this matter from their innovations in processes and organizational and communication methods. Furthermore, studying public organizations as they approach to introduce innovations to the whole sector might help to identify to which extent the use of internal and external sources of information contribute to innovation performance in public sector.

Hypotheses testing follows a method similar to that applied in chapter one. Ordinal variables about the use of information sources are taken from Innobarometer Survey data and a component extraction process (CATPCA) is applied on them, giving a two component solution. These two components respectively represent the importance of using internal and external information sources in innovation development. Afterwards, a bivariate probit estimation with sample selection is used for estimating probabilities that organizations might be identified as introducing services that are new to the whole sector; this following the structure of the survey questionnaire. Probability estimations are complemented with calculation of marginal effects.

Statistical significance and magnitude of results in probability estimation and marginal effects support propositions from both hypotheses above. Estimation results show that use of internal sources has a significant effect over organizations implementing service innovations, but not over organizations implementing services that are new to the whole sector. In turn, use of external sources is a significant aspect for organizations introducing services new to the public sector. At the same time, results of marginal effects show differences in the impacts over the probability of implementing services new-to-the-whole-sector from the use of external and internal sources of information. This evidence helps to conclude that the use of external sources of information has a significant effect in the implementation of services that are new to the whole public sector and that it has a stronger effect on the introduction of services that are new the whole sector than using internal sources.

Applied empirical method has led to other relevant findings in this chapter. One that deserves particular attention is given by control variables about organizations' size and area of responsibility, used in estimations. Results on them suggest that, even though empirical evidence still gives reasons to believe that the bulk of public innovation takes place in bigger organizations, the effect of using external sources of information on the likelihood to introduce services new-to-the-whole-sector might be of greater value for smaller organizations. 


\section{Chapters 3: Innovation's barriers and effects}

After chapters 1 and 2 - addressed to theoretical understanding and empirical test of public innovation drivers and enablers, chapter 3 takes on the issue of public innovation effects. Research in this chapter has as a purpose to support assumptions about the power of public sector innovations for achieving some positive effects along with the risk of suffering some negative effects. Public sector's high risk aversion is named as one of the main barriers for innovation development. Innovation is often understood as a normative good; something that in essence brings improvement. Thus, there is frequently the case that policy recommendations suggest applying strategies that helps to overcome risk aversion. However, innovation is a costly process because of failure and waste during development process and after implementation. Uncertainty implied in innovation brings to implementing organizations high risk for waste and failure. Risk aversion is due to public accountability; therefore, it becomes necessary to know not only about what can innovation be good for public organizations but also about the bad consequences for public accountability from taking on innovation.

Theoretical antecedents and assumptions on the issue of public accountability and risk and improvement in public innovation have led to three research hypotheses:

H1: Chances of getting certain positive effects and risk of suffering certain negative effects differ depending on whether organizations have implemented services that are new to the whole public sector.

H2: Organizations which have introduced services new to the whole sector bear higher risk of suffering negative effects.

H3: Organizations which have introduced services new to the whole sector have greater chance of obtaining positive effects.

Hypotheses' testing once again relies on European data from the Innobarometer 2010 Survey. Questionnaire asks respondents about effects they might have experienced after innovation implementation. The set of variables helping the empirical analysis is drawn from responses to those questions. The analysis method consists in estimating probabilities on the set of variables about positive and negative effects, using Heckman's probit estimation models. Heckman's probit regressions estimate the probability that organizations implementing service innovations might experience certain positive and negative effects, from the fact that they have (or have not) recently implemented a service which is new to the whole public sector. Like in previously applied methodologies, estimation results are complemented with calculation of marginal effects.

Estimations show that variables explaining probabilities of experiencing the listed positive effects are not always statistically significant. The variable that indicates implementation of new services appears to be relevant in explaining only two of the listed positive effects. Looking at the marginal effects, it can be seen that the impact of the variable on the estimated probabilities is modest. In turn, estimation results of negative effects show the leading 
innovator variable to be significant and positive in every case; nonetheless, marginal effects show that impacts of the observed variable over probabilities of negative effects are yet short.

Empirical results are useful for supporting the idea expressed in first hypothesis: that probability of getting certain positive and negative effects from innovation implementation significantly differs depending on whether public organizations have implemented services that are new for all the public sector. On the other hand, the extent to which results can support second and third hypotheses requires a further discussion.

Second and third research hypotheses imply that risk of suffering negative effects will be higher for organizations introducing services new to the whole sector than for organizations which have only implemented service improvements or new services previously implemented by another public organization, while chance of getting positive effects will be greater for those organizations introducing services new for the whole public sector. Results of the experiment suggest that workforce taking part in innovation development is more relevant to explain probability of positive effects. However, since introducing new services has also shown a significant effect, there are still reasons for expecting better results after implementation due to innovations' newness. On the other hand, results do not show the association previously found between innovation negative effects and organizations' workforce capability. Therefore, it is believed that negative effects from innovation certainly are a consequence of novelty implied in public organizations' implemented innovations.

Results from the applied experiment are helpful to illustrate why public organizations fear novel solutions and the reason behind risk avoidance counteracting the levels of public sector innovation. Indeed, novelty is a central aspect of innovation, but novelty is not enough for achieving expected improvement. Novelty is useful in creating opportunities, but opportunities must be worked out, which demands organization and employee abilities in order to realize improvement opportunities. In turn, novelty also brings an amount of risk that will always be jeopardizing results of innovation and causing waste, especially when novelty is greater. Therefore, does it make sense to encourage a rising of public sector innovation? The texts of Potts (2009) and Brown and Osborne (2013) explain avoidance of innovation's risk under the necessity of keeping public accountability. But, they also suggest that principles of public accountability should not be taken as far to restraint the also necessary changes to go with changing society and demands for public services. In particular, Potts suggest that levels of public innovation and experimentation should at least keep pace with changes in economy and society.

\section{Chapter 4: Public innovation and developing economies}

Using different data, different method of analysis and different theoretical approach, chapter 4 looks somewhat apart from the continuity of previous chapters. However, it shares the same objectives about deepen knowledge on enablers of public innovation and assessing the results of innovation implementation, as explained in the introductory part of this thesis dissertation. Research carried in this chapter is nevertheless guided by a very particular objective: to question and give some evidence on the extent to which findings in public innovation studies holds for public administrations in developing economies. 
Public innovation literature is largely based in situations and applications in the context of developed countries. Studies highlight the need for more flexible public organizations that allow for experimentation, waste and failure and bureaucratization is frequently mentioned as an obstacle for the innovation process. This kind of observations recall highly regulated organizations with strong hierarchies. On the other hand, policy studies focused on public administration in developing economies describe a public sector where policy follows discretional criteria, government use public administration as a political tool, levels of governance are articulated by negotiation between local and central powers, there is a lack of instruments for public accountability and technical guidance is missed in policy planning and evaluation. High levels of regulation and bureaucratization are not the same observable in administrations from developing regions and, therefore, it could be the case that the understanding of processes enabling public innovation might show particular features in organizations where weakness of public institutions might place more barriers to successful implementations.

The analysis method applied for approaching to the question expressed above is based on information from Mexican local government administrations. Thus, a second objective addressing the analysis is to comprehend what makes sustainable innovation in underdeveloped public administrations at the local level of Mexican government.

Research method is based in case-study analysis of finalist and semifinalist initiatives participating in the contest entitled "Local Government and Management Award", between years 2005 and 2011. This contest awards initiatives of Mexican local governments with original design and remarkable positive impact after implementation. These are recently implemented initiatives and overall addressed to improve attention to citizen needs or to solve a particular problem. Thus, novelty and significance at unit of implementation are constant elements in initiatives taking part in the contest. It can be observed different levels of institutional development among Mexican local administrations, this presumably linked to the level of economic development (or marginality) in their respective populations. For the analysis are only selected initiatives from municipalities with the highest and the lowest levels of economic marginality (according to official social development classification). The purpose on this comes from the assumption that municipalities at opposite ends of social development classification are better comparable due to their population and town council size; metropolis and big urban municipalities - with bigger budgets and more complex councils - they are found in middle positions of the classification. Case-study is complemented with descriptive statistics of the total participant local government initiatives, based on demographic characteristics of the municipalities where they were implemented.

Findings in the observed local government initiatives led to conclude that municipalities with low levels of social exclusion have more appropriate institutional characteristics for successfully implementing innovation for public service improvement and poorly developed Mexican municipalities find more difficulties to achieve improvement and development through innovation. However, innovation can be of special benefit for poorly developed municipalities when it is addressed to strengthen the institutional founding of local governments. In order to achieve durable higher leveled innovations, Mexico's municipalities should regress in the classic sense of promotion of innovation; that is: to promote 
systematization, solid organizational structures and a regulatory framework that allow for innovation sustainability (see García, 2005). This might be suggested not just for the case of Mexican municipalities but for all administrations in developing regions.

\section{Conclusion on dissertation}

The central idea in this thesis dissertation - presented in first section of the introductory part suggests a view of public innovation under a multi-agent framework, in such a way that public organizations keep a high degree of interaction with other organizations and individuals. This view should also consider various ways for generating innovative processes, on top of those processes leaded under a rigid hierarchical structure, and should also consider participation of those who will benefit from the resulting innovation and from employees at the bottom of hierarchies. Results and conclusions obtained from empirical analysis in previous four chapters are helpful for supporting validity of the suggested view. The distinct ways for public innovation are reflected in the importance for new service implementation found in factors such as ideas and participation from staff, users and suppliers, and also in support from authorities and middle-level managers. In addition, it has been also shown how social participation can play an important role in idea generation and in development and implementation of innovative initiatives. At the same time, results on the importance of using external sources of information towards implementing new services support an approach for public innovation which concedes a significant role to collaboration and participation from external agents, especially users and suppliers.

\section{Research limitations and caveats}

Research carried in this thesis dissertation bears with some limitations due to lack of theoretical foundation and empirical data. It has frequently been said that - despite there is already a consistent bulk of studies - public innovation theory is still a recent and developing issue. It has not been yet developed an adequate theoretical model for explaining public innovation. Empirical models used for analysis were built under assumptions based on reviewed literature; nevertheless, they did not has as a purpose to represent a theoretical model but to find statistical significance in suggested relations between variables representing some theoretical concepts.

At the same time, there are some other source problems in data that limit validity of empirical results. Released in 2011, Innobarometer 2010 Survey is still the larger available survey data source. Data was collected through a questionnaire which asks public organizations' managers about what they believe to be important in the development process of innovations in the organization they represent. Therefore, data from the survey does not represent what is truly important for public innovation but interviewees' believes about it (although both things might coincide). Another limitation due to data comes from the question from which was obtained the variable identifying organizations that introduced services that are new to the whole public sector: responses do not make specific whether services which are completely new were developed by the implementing organization or they were copied from abroad (i.e. they are a first time implementation within their own country but were not originally developed by the implementing organization). This last observation suggests a careful interpretation of results while making concluding statements about effects of innovation drivers and enablers on 
development of new services. That is the reason why empirical analysis in chapters using Innobarometer data makes too much emphasis on innovation 'implementation'. Implementation is, therefore, interpreted as the culmination of an adequate process of innovation development.

\section{Further research}

There is still much light to shed in researching public innovation. Further research should lead to refine the boundaries of the concept and provide a more solid theoretical framework, for which synthesizing previous approaches may be helpful (like in the case of this thesis dissertation). In particular, it is still needed to converge in a model than can help the analysis.

Results in the present empirical analysis suggest deepening in findings with respect to the networked view of public innovation. It has been demonstrated the importance of participation of citizens and private organizations (as both suppliers and beneficiaries) in the innovation process; thus, it is of special relevance to develop a better understanding of the role they play. On the other hand, from a policy perspective, importance of political factors for driving innovation have been properly justified in theory, but the present empirical analysis was not enough for making and adequate assessment and test of this assumed importance. Further research should also help to evaluate and define how much of a key element political factors might be in public innovation development. 
References 
Alves, H. (2013). Co-creation and innovation in public services. The Service Industries Journal, $33(7-8), 671-682$.

Amara, N. \& Landry, R. (2005) Sources of information as determinants of novelty of innovation in manufacturing firms: evidence from the 1999 statistics Canada innovation survey; Technovation; Vol. 25, Iss: 3, pp. 245-259

Arduini, D., Belotti, F., Denni, M., Giungato, G. \& Zanfei, A. (2010) Technology adoption and innovation in public services the case of e-government in Italy; Information Economics and Policy; 22:257-275

Arellano, D. (2000): Challenges for the New Public Management in Mexico: Patrimonialism and Colonial Values. Ciencia Ergo Sum, Vol. 7, No. 2, 112-120

Arellano, D. (2002): Nueva Gestión Pública: ¿el meteorito que mató al dinosaurio? Lecciones para la reforma administrativa en países como México. Reforma y Democracia, No. 23.

Arundel, A., \& Hollanders, H. (2011). A taxonomy of innovation: How do public sector agencies innovate? Results of the 2010 European Innobarometer survey of public agencies. Pro Inno Europe, Inno Metrics Report. http://ec.europa.eu/enterprise/policies/innovation/files/psistudies/taxonomy-of-innovation-how_en.pdf

Arundel, A.; Hubber, D. (2013): From too little to too much innovation? Issues in measuring innovation in the public sector. Structural Change and Economic Dynamics, 27, 146-159.

Arzaluz, S. (2013): La institucionalización de la participación ciudadana en municipios mexicanos: Notas a partir del premio Gobierno y Gestión Local. Gestión y Política Pública, Vol. 22, No. 1, 161-202.

Barras, R. (1990). Interactive innovation in financial and business services: the vanguard of the service revolution. Research Policy, 19, 215 - 237.

Battisti, G., Gallego, J., Rubalcaba, L., \& Windrum, P. (2014). Open innovation in services: knowledge sources, IPRs and Internationalisation. The Economic of Innovation and New Technology (forthcoming)

Baumol, W.J. (1966). Macroeconomics of unbalanced growth: The anatomy of urban crisis. The American Economic Review, 57(3), 415 - 426.

Baumol, W.J. (2004). Four Sources of Innovation and Stimulation of Growth in the Dutch Economy. In G. Gelauf \& L. Klomp (Eds.), Fostering Productivity: Patterns, Determinants and Policy Implications (pp. 185 - 198).Emerald Group Publishing Limited.

Bhatta, G. (2003) Don't just do something, stand there! Revisiting the issue of risks in innovation in the public sector; The Innovation Journal; Peer reviewed articles 05/05/2003 http://www.innovation.cc/scholarly-style/bhatta-risks.pdf

Barras, R. (1990). Interactive innovation in financial and business services: the vanguard of the service revolution. Research Policy, 19, 215 - 237. 
Berry, F.S. (1994) Innovation in public management: The adoption of strategic planning; Public Administration Review; Vol. 54, No. 4, pp. 322-330

Berry, W.D. (ed.) (1993): Understanding regression assumptions. Newbury Park, CA: Sage.

Bloch, C; Bugge, M.M. (2013): Public sector innovation - From theory to measurement. Structural Change and Economic Dynamics, 27, 133-145.

Bonte, W., \& Keilbach, M. (2005). Concubinage or marriage? Informal and formal cooperation in innovation. International Journal of Industrial Organization, 23, 279- 302.

Borins, S. (2001). Encouraging innovation in the public sector.Journal of Intellectual Capital, 2(3), $310-319$.

Borins, S. (2002). Leadership and Innovation in the Public Sector. Leadership and Organization Development Journal, 23(8), $467-476$.

Borins, S. (2006). The Challenge of Innovating in Government (2nd Ed.) The IBM Center for the Business of Government.

Borins, S. (ed.) (2008): Innovations in government: research recognition and replication. Washington, DC: Brookings Institution Press.

Börzel, T.A. (2011). Networks: Reified metaphor or governance panacea? Public Administration, $89(1), 49-63$.

Bugge, M.M., Mortensen, P.S., \& Bloch, C. (2011). Measuring Public Innovation in Nordic Countries. NIFU, Report 40/2011. http://www.nifu.no/files/2012/11/NIFUrapport2011-40.pdf

Brown, L. \& Osborne S.P. (2013): Risk and Innovation. Towards a framework for risk governance in public services; Public Management Review; Vol. 15, No. 2, pp. 186-218.

Cabrero, E. (1997): El modelo de la Nueva Gestión Pública frente a los municipios latinoamericanos: ¿Funcionan las recetas? Management International, Vol. 1, No. 2, 73-80.

Cabrero, E. (2004): Capacidades institucionales en gobiernos sub-nacionales de México ¿Un obstáculo para la descentralización fiscal? Gestión y Política Pública, Vol. 13, No. 3, 753-784.

Cabrero, E. (2005): Between New Public Management and New Public Governance: The Case of Mexican Municipalities. International Public Management Review, Vol. 6, Iss. 1, 76-99.

Cassiman, B, \& Veugelers, R. (2006). In search of complementarity in innovation strategy: Internal R\&D and external knowledge acquisition. Management Science, 52(1): $68-82$.

Chesbrough, H. (2003). Open innovation: The new imperative for creating and profiting from technology. Boston, MA: Harvard Business School Press.

Chesbrough, H. (2011). Open services innovation: Rethinking your business to grow and compete in a new era. San Francisco, CA: Jossey-Bass 
Cohen, W.M., \& Levinthal, D.A. (1990). Absorptive capacity: a new perspective of learning and innovation. Administrative Science Quarterly, 35, 128- 152.

Corrocher, N., Cusmano, L., Morrison, A. (2009) Modes of innovation in knowledge-intensive business services evidence from Lombardy; Journal of Evolutionary Economics; 19:173-196.

Dahlander, L., \& Gann, D.M. (2010). How open is innovation? Research Policy, 39, 699 - 709.

Damanpour, F. \& Schneider, M. (2006) Phases of the adoption of innovation in organizations: Effects of environment, organization and top managers; British Journal of Management; Vol. $17,215-236$

Djellal, F., Francoz, D., Gallouj, C., Gallouj, F., \& Jacquin, Y. (2003). Revising the definition of research and development in the light of the specificities of services. Science and Public Policy, $30(6), 415-429$.

Dosi, G. (1988). Sources, procedures and microeconomic effects of innovation. Journal of Economic Literature, 26(3), 1120 - 1171.

Earl, L. (2002) Innovation and Change in the Public Sector: A Seeming Oxymoron; Working Paper 88F0006XIE No. 01

European Commission (2011) Innobarometer 2010 Analytical Report, Innovation in Public Administration; Flash Eurobarometer No. 305

http://ec.europa.eu/public_opinion/flash/fl_305_en.pdf

Evangelista, R. (2000). Sectoral patterns of technological change in services. Economics of Innovation and New Technology, 9, $183-221$.

Freeman, C. (1995) The 'National System of Innovation' in historical perspective; Cambridge Journal of Economics; 19, 5-24.

Frenz, M., Lambert, R. (2009) Exploring non-technological and mixed modes of innovation across countries; in OECD, Innovation in Firms: A microeconomic perspective; OECD, Paris.

Gallego, J., Rubalcaba, L., \& Suarez, C. (2013). Knowledge for Innovation in Europe: The Role of external knowledge on firms' cooperation strategies. Journal of Business Research, 66(10), 2034 $-2041$.

Gallouj, F. (1998).Innovating in reverse: services and the reverse product cycle. European Journal of Innovation Management, 1(3), 123 - 138.

Gallouj, F. (2002).Innovation in services and the attendant old and new myths. The Journal of Socioeconomics, 31(2), $137-154$.

Gallouj, F., and Djellal, F. (2011) Handbook of service innovation. Edward Elgar.

Gallouj, F., Rubalcaba, L., \& Windrum, P. (2013). Public Private Innovation Networks in Services. Cheltenham: Edward Elgar.

Gallouj, F., \& Weinstein, O. (1997). Innovation in services. Research policy, 26(4), 537 - 556. 
García, G. (2005): Emergence and sustainability of the innovation process of Mexico's local government. Ash Institute for Democratic Government and Innovation.

http://www.innovations.harvard.edu/cache/documents/7933.pdf

Garcia-Goñi, M., Maroto, A.\&Rubalcaba, L. (2007) Workers' motivation in European health services. Health Policy, Vol 84/2-3: 344-358.

Grimpe, C., \& Kaiser, U. (2010). Balancing internal and external knowledge acquisition: The gains and pains from R\&D outsourcing. Journal of Management Studies, 47(8), $1483-1509$.

Gassman, O. (2006). Opening up the innovation process: Towards an agenda. R\&D Management, 36(3), 223-228.

Gassman, O. \& Enkel, E. (2004). Towards a theory of open innovation: Three core process archetypes. https://www.alexandria.unisg.ch/Publikationen/274

Gunday, G., Ulusoy, G., Kilik, K. \& Alpkan, L. (2011) Effects of innovation types on firm performance; International Journal of Production Economics; Vol. 133, Iss. 2, pp. 662-676

Hall, M. \& Holt, R. (2008) New Public Management and cultural change: the case of UK public sector project sponsors as leaders; in Windrum and Koch: Innovation in Public Sector Services: Entrepreneurship, Creativity and Management; Edward Elgar.

Halvorsen, T., Hauknes, J., Miles, I., \&Roste, R. (2005) On the differences between public and private sector innovation; Publin Report D9.

http://unpan1.un.org/intradoc/groups/public/documents/apcity/unpan046809.pdf

Hartley, J. (2005): Innovation in Governance and Public Services: Past and Present, Public Money and Management, January 2005, pp. 27-34.

Hess, M. \& Adams, D. (2007). Innovation in Public Management: The role and function of community knowledge. The Innovation Journal: The Public Sector Innovation Journal, 12(1), Article 2:1-20.

Hipp, C., \& Grupp, H. (2005). Innovation in the service sector: the demand for service-specific innovation measurement concepts and typologies. Research Policy, 34(4), $517-535$.

von Hippel, E. (1988). The sources of innovation. New York: Oxford University Press.

Howells, J. (2000): Services and systems of innovation. In B. Andersen, J. Howells., R. Hull, I.

Hollenstein, H. (2003) Innovation modes in the Swiss service sector: a cluster analysis based on firm level data; Research Policy; 32:845-863.

Hughes, A., Moore, K. \&Kataria, M. (2011) Innovation in Public Sector Organisations, A pilot survey for measuring innovation across the public sector; NESTA, Index Report: March 2011.

Jensen, M.B., Johnson, B., Lorenz, B., Lundval, B.A. (2007) Forms of knowledge and modes of innovation; Research Policy; 36:680-693. 
de Jong, J.P.G.\& Marsili, O. (2006) The fruit flies of innovations: A taxonomy of innovative small firms; Research Policy; 35:213-229.

Koch, P., \& Hauknes, J. (2005). On innovation in the public sector. PUBLIN Report D20. http://survey.nifu.no/step/publin/reports/d20-innovation.pdf

Klein, P.; McGahan, A.; Pitelis, C.; Mahoney, J.T. (2009): Toward a Theory of Public Entrepreneurship. European Management Review. Available at SSRN: http://ssrn.com/abstract=1351494 or http://dx.doi.org/10.2139/ssrn.1351494

Knell, M., \& Srholec, M. (2010) The novelty of innovation and the level of development; paper for the Biannual conference of the European Association for Comparative Economic Studies, August 26-28, Tartu, Estonia.

Langergaard, L., \&Scheuer, D. (2009). Specificities of public sector service innovation. ServPPInReport http://www.servppin.com/uploadFiles/ServPPIN_papers/Files_WP2/Specificities\%20of\%20pub lic\%20sector\%20service\%20innovation.pdf

Laursen K., \& Salter, A. (2006). Open for innovation: the role of openness in explaining innovation performance among UK manufacturing firms. Strategic Management Journal, 27, $131-150$.

Linting, M.(2007) Nonparametric inference in nonlinear principal components analysis: Exploration and beyond; Data Theory Group, Department of Education, Faculty of Social and Behavioural Sciences, Leiden University.

Linting, M., Meulman, J.J., Groenen, P.J.F., \& van der Kooij, A.J. (2007a). Nonlinear principal components analysis: Introduction and application. Psychological Methods, 12(3), $336-358$.

Linting, M., Meulman, J.J., Groenen, P.J.F. \& van der Kooij, A.J. (2007b) Stability of nonlinear principal components analysis: An empirical study using the balanced bootstrap; Psychological Methods; Vol. 12(3), 359-379.

McAdam, R. \& Donaghy, J. (1999) Business process re-engineering in the public sector; Business Process Management Journal; Vol. 5, No. 1, pp. 33-49

Manning, N. (2001): The legacy of the New Public Management in Developing Countries. International Review of Administrative Sciences, Vol. 67, 297-312.

Matthews, M., Lewis, C. \& Cook, G. (2009). Public Sector Innovation: A Review of the Literature. Supplement to the ANAO's Better Practice Guide: Innovation in the Public Sector: Enabling Better Performance, Driving New Directions; Australian National Audit Office.

Maroto, A. (2011). Productivity growth and cyclical behavior in service industries: the Spanish case. Services Industries Journal, 31(5), 725 - 745.

Maroto, A. \& Rubalcaba, L. (2008) Structure, size and reform of the public sector in Europe; in Windrum and Koch: Innovation in Public Sector Services: Entrepreneurship, Creativity and Management; Edward Elgar. 
Maroto, A., \& Rubalcaba, L. (2008). Service Productivity Revisited. The Service Industries Journal, 28(3), $337-353$.

Maroto, A., \& Rubalcaba, L. (2012). The Role of R\&D in Shaping Public Sector Typologies: An European Perspective. Modern Economy, 3(7), 873 - 883.

di Meglio, G., Maroto, A., Stare, M., \& Rubalcaba, L. (2013). Public services in the enlarged EU: An assessment of performance and efficiency. Environment and Planning $C$. (forthcoming).

Metcalfe, J.S. (1994). The economics of evolution and the economics of technology policy. Economic Journal, 104, 931 - 944.

Meulman, J. J., Heiser,W. J., \& SPSS. (1999). SPSS Categories 10.0. Chicago: SPSS.

Meulman, J.J., Van der Kooij, A. J. \&Heiser, W. J. (2004) Principal components analysis with nonlinear optimal scaling transformations for ordinal and nominal data; in D. Kaplan: Handbook of quantitativemethodology for the social sciences; London: Sage Publications.

Miles, I. (2007): Research and Development (R\&D) beyond manufacturing: The strange case of services R\&D. R\&D Management, 37(3), $249-268$.

Miles \& J. Roberts (Eds.), Knowledge and innovation in the new service economy (pp. 215 228), Cheltenham: Edward Elgar.

Miles, I., \& Tether, B. (2003). Innovation in the Service Economy. IPTS Report No 71, pp. 45 - 51.

Miozzo, M, \& Soete, L. (2001): Internationalization of services: A technological perspective. Technological Forecasting and Social Change, 67(4), 159 - 185.

Nelson, R.R., \& Winter, S. (1982). An Evolutionary Theory of Economic Change. Cambridge, MA: Harvard University Press.

Nelson, R.R. (1993) National Innovation Systems: a comparative analysis; New York, NY: Oxford University Press

OECD (Organisation for Economic Co-operation and Development) (2005), Oslo Manual: Guidelines for Collecting and Interpreting Innovation Data. OECD, Paris.

Recascino, L. (2002) Public management reform: competing drivers of change; Public Administration Review; Vol. 62, No. 5, pp. 555-567.

Roste, R. (2005) Studies of Innovation in the Public Sector, a Theoretical Framework; PUBLIN Report D16.

Rubalcaba, L., Michel, S., Sundbo, J., Brown, S.W. \&Reynoso, J. (2012) Shaping, organizing, and rethinking service innovation: a multidimensional framework, Journal of Service Management, Vol. 23 Iss: 5, pp.696 - 715.

Rubalcaba, L., Windrum, P., Gallouj, F., di Meglio, G., Pyka, A., Sundbo, J. \&Webber, M. (2011) The contribution of public and private services to European growth and welfare, and the role of public-private innovation networks. ServPPIN Final Report. ServPPIN Working Papers. 
Saviotti, P.P. \& Metcalfe, J.S. (1984) a theoretical approach to the construction of technological output indicators. Research policy; 13, 141 -151-

Sellenthin, M.O. \& Hommen, L. (2002) How innovative is Swedish industry? A factor and cluster analysis of CIS 2. International Review of Applied Economics; 16: 319-331

Sirilli, G. \& Evangelista, R. (1998) Technological innovation in services and manufacturing: results from Italian surveys; Research Policy; Vol. 27, Iss: 9, pp. 881-899

Vigoda-Gadot, E., Shoham, A., Schwabsky, N. \& Ruvio, A. (2005) Public sector innovation for the managerial and the post-managerial era: Promises and realities in a globalizing public administration; International Public Management Journal; Vol. 8, No.1, pp. 57-81.

Windrum, P. (2008) Innovation and entrepreneurship in public service; in Windrum and Koch: Innovation in Public Sector Services: Entrepreneurship, Creativity and Management; Edward Elgar.

Windrum, P. and Koch, P. (2008) Innovation in Public Sector Services: Entrepreneurship, creativity and management. Edited by, Edward Elgar

Osborne, S.P., \& Brown, L. (2011). Innovation, Public Policy and Public Services Delivery in the UK: The Word that Would Be King? Public Administration, 89:4 pp 1335-50.

Osborne, S.P., \& Brown, L. (2013). Innovation in public services. In S.P. Osborne \& L. Brown (Eds.), Handbook of innovation in public services (pp. 1-14), Cheltenham: Edward Elgar.

Pisano, G. (1990). The R\&D boundaries of the firm: An empirical analysis. Administrative Science Quarterly, 35, 153-176.

Potts, J. (2009). The innovation deficit in public services: The curious problem of too much efficiency and not enough waste and failure. Innovation: Management, Policy \& Practice, 11(1), $34-43$.

Porter, M.E., \& Stern, S. (2001). Innovation: Location matters. Sloan Management Review, $42(4), 28-36$.

Recascino, L. (2002). Public management reform: competing drivers of change. Public Administration Review, 62(5), 555 - 567.

Rigby, D., \& Zook, C. (2002). Open-market innovation. Harvard Business Review, 80(10), 80 89.

Rosenbusch, N., Brinckmann, J. \& Bausch, A. (2011) Is innovation always beneficial? A metaanalysis of the relationship between innovation and performance in SMEs; Journal of Business Venturing; Vol. 26, Iss. 4, pp. 441-457

Roste, R. (2005). Studies of Innovation in the Public Sector, a Theoretical Framework. PUBLIN Report D16. http://survey.nifu.no/step/publin/reports/d16litteraturesurvey.pdf 
Rubalcaba, L. (2006). Which policy for innovation in services? Science and Public Policy, 33(10), $745-756$.

Rubalcaba, L. (2007). The New Service Economy: Challenges and Policy implications for Europe. Cheltenham: Edward Elgar.

Rubalcaba, L., Michel, L., Sundbo, J., Brown, S.W., \& Reynoso, J. (2012). Shaping, organizing, and rethinking service innovation: a multidimensional framework. Journal of Service Management,23(5), $696-715$.

Sakkab, N.Y. (2002). Connect and develop complements research and develop at P\&G. Research-Technology Management, 45(2), 38- 45.

Samaratunge, R; Bennington, L. (2002): New Public Management: Challenge for Sri Lanka. Asian Journal of Public Administration, Vol. 24, No. 1, 87-109.

Santamaria, L., Nieto, M.J., \& Barge-Gil, A. (2009). Beyond formal R\&D: Taking advantage of other sources of innovation in low - and medium - technology industries. Research policy, $38(3), 507-518$.

Sofka, W., \& Grimpe, C. (2010). Specialized search and innovation performance - evidence across Europe. R\&D Management, 40(3), $310-323$.

Tether, B. S. (2005). Do services innovate (differently)? Insights from the European Innobarometer Survey. Industry\& Innovation, 12(2), 153 - 184.

Veugelers, R. (1997). Internal R\&D expenditures and external technology sourcing. Research Policy, 26(3), $303-316$.

Vigoda-Gadot, E., Shoham, A., Schwabsky, N., \& Ruvio, A. (2005). Public sector innovation for the managerial and the post-managerial era: Promises and realities in a globalizing public administration. International Public Management Journal, 8(1), 57 - 81.

Vigoda-Gadot, E., Shoham, A., Schwabsky, N., \& Ruvio, A. (2008). Public sector innovation for Europe: A multinational eight country exploration of citizens' perspectives. Public Administration, 86(2), $307-329$.

West, M. A. \& Farr, J. L. (1990). Innovation and Creativity at Work: Psychological and Organisational Strategies. Chichester: Wiley.

Windrum, P. (2008). Innovation and entrepreneurship in public service. In P. Windrum \& P. Koch (Eds.), Innovation in Public Sector Services: Entrepreneurship, Creativity and Management (pp. 3-20), Cheltenham: Edward Elgar.

Windrum, P., Battisti, G., Gallego, J., \& Rubalcaba, L. (2013). Paradigm Shift? Open Innovation and the Innovative Performance of EU Firms. In Academy of Management Proceedings (Vol. 2013, No. 1, p. 15296). Academy of Management.

Windrum, P., \& Koch, P. (2008). Innovation in Public Sector Services: Entrepreneurship, creativity and management. Cheltenham: Edward Elgar. 
Windrum, P. \& García-Goñi, M. (2008). A neo-Schumpeterian model of health services innovation. Research Policy, 37, 649-672.

Ziccardi, A. (2004): Globalización, pobreza y democracia participativa. Revista Mexicana de Sociología, Vol. 66, Número especial (Oct. 2004), 181-196. 